\title{
The application of the vulnerable populations conceptual framework to determine factors predictive of overweight and obesity in Appalachian children and adolescents
}

\author{
Melanie M. Whelan
}

West Virginia University

Follow this and additional works at: https://researchrepository.wvu.edu/etd

\section{Recommended Citation}

Whelan, Melanie M., "The application of the vulnerable populations conceptual framework to determine factors predictive of overweight and obesity in Appalachian children and adolescents" (2010). Graduate Theses, Dissertations, and Problem Reports. 3094.

https://researchrepository.wvu.edu/etd/3094

This Dissertation is protected by copyright and/or related rights. It has been brought to you by the The Research Repository @ WVU with permission from the rights-holder(s). You are free to use this Dissertation in any way that is permitted by the copyright and related rights legislation that applies to your use. For other uses you must obtain permission from the rights-holder(s) directly, unless additional rights are indicated by a Creative Commons license in the record and/ or on the work itself. This Dissertation has been accepted for inclusion in WVU Graduate Theses, Dissertations, and Problem Reports collection by an authorized administrator of The Research Repository @ WVU.

For more information, please contact researchrepository@mail.wvu.edu. 
The Application of the Vulnerable Populations Conceptual Framework to Determine Factors Predictive of Overweight and Obesity in Appalachian Children and Adolescents

\author{
Melanie M. Whelan
}

Dissertation submitted to the School of Nursing at West Virginia University in partial fulfillment of the requirements for the degree of

Doctor of Philosophy

In

Nursing

\author{
Rose Ann DiMaria-Ghalili, Ph.D., RN, chair \\ Susan McCrone, Ph.D., PMHCNS-BC \\ Irene Tessaro, MA, MSN, Dr.P.H. \\ Daniel W. McNeil, Ph.D. \\ Stacey Culp, Ph.D.
}

\author{
Morgantown, West Virginia \\ 2010
}

Keywords: obesity, overweight, children, adolescents, COHRA

Copyright 2010 Melanie M. Whelan 


\begin{abstract}
The Application of the Vulnerable Populations Conceptual Framework to Determine Factors Predictive of Overweight and Obesity in Appalachian Children and Adolescents
\end{abstract}

Melanie M. Whelan

STATEMENT OF PROBLEM: Appalachian children and adolescents are considered a vulnerable population with a high prevalence of obesity. This study was the first study to apply a vulnerable populations conceptual framework to examine factors associated with overweight and obesity in Appalachian children and adolescents. The purpose of this study was to describe the extent to which resource availability (family income, insurance, family characteristics, parents' education, and transportation) and risk factors (utilization of health care/preventive care, family medical history, and participant medical history) impact overweight and obesity in a vulnerable population. The study also described the frequency of overweight and obesity in a sample of Appalachian children and adolescents.

METHODS: The sample for this secondary data analysis was obtained from the Center for Oral Health Research in Appalachia (COHRA). Data analysis was performed using data from WV children and adolescents ages 7 to 17 years of age at the time of first enrollment in the COHRA study $(\mathrm{n}=509)$. The extent to which factors associated with a vulnerable population model, resource availability and risk factors, contribute to overweight and obesity in Appalachian children and adolescents were investigated using a descriptive predictive, cross-sectional design. Data were analyzed for relationships among the dependent variable: overweight and obesity and the independent variables: risk factors and resource availability. The analyses included parametric and nonparametric statistics.

RESULTS: The demographic results of this study revealed that this sample is a vulnerable population. A high prevalence of obesity was found in this sample of Appalachian children and adolescents. In the 7 to 10 year old group, $13.5 \%$ of the participants were overweight and 26\% were obese. The highest prevalence of obesity was found in the 11 to 13 year old group, 16.7\% of the participants were overweight and 34\% were obese. In the 14 to 17 year old group, 16.9\% of the participants were overweight and $26.6 \%$ were obese. Frequency of visiting a dentist was the only independent variable that had a significant association with BMI. This study revealed that children (7 to 10 years old) who visited a dentist less frequently were almost three times more likely to report being overweight compared to those children (7 to 10 years old) who visited a dentist more frequently.

CONCLUSIONS: Childhood and adolescent obesity continues to be an epidemic that is apparent in the US and Appalachia. Because of the increased prevalence of obesity and the risk of obesity associated chronic diseases, nurses need to be prepared to implement interventions to prevent and identify overweight and obesity in children and adolescents. In order for nurses to design and implement effective interventions and prevention strategies that will improve the health status of Appalachian children and adolescents, further research needs to occur to examine factors associated with overweight and obesity in this vulnerable population. 


\section{DEDICATION}

I dedicate this work to my wonderful husband Ben. Thank you for taking this journey with me. I could not have accomplished this goal without all of your endless support, words of encouragement, and love. 


\section{ACKNOWLEDGEMENTS}

During my doctoral studies I have received tremendous support from faculty, colleagues, and family. I would like to thank my chair and mentor, Dr. Rose Ann DiMaria-Ghalili. Throughout this process you have been a remarkable coach, cheerleader, mentor, colleague, and friend. Without your support and guidance, I would not have completed this process. Thank you to my dissertation committee: Dr. Susan McCrone, Dr. Irene Tessaro, Dr. Daniel McNeil, and Dr. Stacey Culp for taking time to provide me with feedback and assistance throughout this research study. I would especially like to thank Dr. Stacey Culp for all the time and guidance she provided me with my statistical analysis. Thank you to Dr. Mary Jane Smith for always taking time to review my progress and provide encouragement.

Thank you to my department chair at WVU Tech, Dr. Evelyn Klocke. Without your support and willingness to be flexible with my work demands, I never would have been able to complete this process. Thank you to my colleague and friend, Barbara Douglas for your assistance with covering our Community Nursing courses. I would like to also thank all of my doctoral classmates for their continued encouragement throughout this program.

Lastly, I would like to thank my family. To my mother, Sue Smith, for always pushing me to be the best at whatever I chose to do. To my late father, Bill Smith, who always believed I could do anything and was always so proud of me. Thank you both for all of the love and support you have given me over the years. 
TABLE OF CONTENTS

$\begin{array}{lll}\text { ABSTRACT } & \text { ii }\end{array}$

$\begin{array}{ll}\text { DEDICATION } & \text { iii }\end{array}$

ACKNOWLEDGEMENTS iv

LIST OF TABLES viii

LIST OF FIGURES Iv

$\begin{array}{ll}\text { CHAPTER I: INTRODUCTION } & 1\end{array}$

BACKGROUND 1

PROBLEM STATEMENT $\quad 3$

LIMITATIONS AND DELIMITATIONS

DEFINITIONS OF TERMS $\quad 4$

SIGNIFICANCE FOR THE STUDY $\quad 6$

$\begin{array}{ll}\text { THEORETICAL FRAMEWORK } & 8\end{array}$

$\begin{array}{ll}\text { Overview } & 8\end{array}$

Resource Availability $\quad 9$

Relative Risk 10

Health Status 10

CHAPTER II: REVIEW OF THE LITERATURE 14

OBESITY 14

Obesity as a Disease $\quad 14$

Defining Obesity 15

Measurement of Obesity 16

Obesity and Appalachia 17

RESOURCE AVAILABILITY 17

Family Income 17

$\begin{array}{ll}\text { Insurance } & 18\end{array}$

$\begin{array}{ll}\text { Transportation } & 18\end{array}$

Parent's Education Level and Family Characteristics 19

RISK FACTORS 19

Utilization of Health Care/Preventative Care 19

Family Medical History 20

Participant Medical History 20

APPALACHIAN CULTURE $\quad 22$

RURAL RESIDENCY 23

VULNERABLE POPULATIONS CONCEPTUAL MODEL 24

Synthesis of Vulnerable Populations Conceptual Model Literature 30

Gaps in the Vulnerable Populations Conceptual Model Literature 30

CENTER FOR ORAL HEALTH RESEARCH IN APPLALACHIA 31

CONCLUSION 
RESEARCH DESIGN

DATA SOURCE: CENTER FOR ORAL RESEARCH IN APPALACHIA 34 Sample Design of the COHRA Study for the WV Subset 34 Mode of COHRA Data Collection 35 Access to COHRA Data Files

HUMAN SUBJECTS $\quad 36$

PROPOSED COHRA SAMPLE FOR THIS STUDY 36

RESEARCH QUESTIONS AND STATISTICAL ANALYSIS 36

VARIABLES $\quad 39$

Resource Availability 39

Risk Factors $\quad 45$

Overweight and Obesity $\quad 49$

Demographic Variables 50

CHAPTER IV: RESULTS

OBTAINING THE STUDY SAMPLE

SAMPLE DESCRIPTION

$\begin{array}{ll}\text { AIM I } & 58\end{array}$

$\begin{array}{ll}\text { AIM II } & 60\end{array}$

$\begin{array}{ll}\text { AIM III } & 73\end{array}$

CHAPTER V: SUMMARY, DISCUSSION, AND IMPLICATIONS 76

$\begin{array}{ll}\text { INTRODUCTION } & 76\end{array}$

STATEMENT OF THE PROBLEM $\quad 76$

REVIEW OF THE METHODOLOGY

STUDY LIMITATIONS $\quad 77$

MAJOR FINDINGS $\quad 78$

Vulnerable Population $\quad 78$

Prevalence of Obesity $\quad 78$

Resource Availability and Risk Factors $\quad 79$

Predictive Factors of Obesity-Related Health Status $\quad 82$

Unanticipated Findings $\quad 83$

DISCUSSION

STUDY FINDINGS AND THE VULNERABLE POPULATIONS CONCEPTUAL MODEL 86

CLINICAL PRACTICE AND RESEARCH IMPLICATIONS 87 Implications for Nursing Practice $\quad 87$

Recommendations for Further Research $\quad 87$

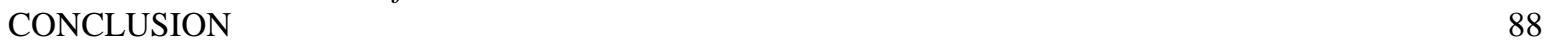

$\begin{array}{lr}\text { APPENDIX A: TABLE } 13 & 90\end{array}$

$\begin{array}{lr}\text { APPENDIX B: TABLE } 14 & 95\end{array}$

$\begin{array}{lr}\text { APPENDIX C: TABLE } 15 & 96\end{array}$

$\begin{array}{lr}\text { APPENDIX D: TABLE } 16 & 97\end{array}$ 
$\begin{array}{lr}\text { REFERENCES } & 99\end{array}$

$\begin{array}{ll}\text { CURRICULUM VITAE } & 112\end{array}$ 


\section{LIST OF TABLES}

Table 1: Sociodemographic Characteristics of the 7 to 10 Year Old Sample................54

Table 2: Sociodemographic Characteristics of the 11 to 13 Year Old Sample..............55

Table 3: Sociodemographic Characteristics of the 14 to 17 Year Old Sample..............56

Table 4: Sociodemographic Characteristics of the Adult Sample........................57

Table 5: Prevalence of Overweight and Obesity among Appalachian Children and

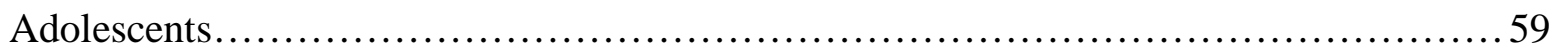

Table 6: Chi-Square Results for Resource Variables in the 7 to 10 Year Old Group........62

Table 7: Chi-Square Results for Risk Factor Variables in the 7 to 10 Year Old Group.....64

Table 8: Chi-Square Results for Resource Variables in the 11 to 13 Year Old Group......65

Table 9: Chi-Square Results for Risk Factor Variables in the 11 to 13 Year Old Group....67

Table 10: Chi-Square Results for Resource Variables in the 14 to 17 Year Old Group.....69

Table 11: Chi-Square Results for Risk Factor Variables in the 14 to 17 Year Old Group...71

Table 12: Logistic Regression Results in the 7 to 10 Year Old Group......................74

Table 13: Variable Codes for COHRA Data Set...................................90

Table 14: Chi-Square Results for Additional Transportation Variables in the 7 to 10 Year

Old Group................................................................95

Table 15: Chi-Square Results for Additional Transportation Variables in the 11 to 13 Year

Old Group.................................................................96

Table 16: Chi-Square Results for Additional Transportation Variables in the 14 to 17 Year

Old Group................................................................97 


\section{LIST OF FIGURES}

Figure 1: The Vulnerable Populations Conceptual Model.............................. 12

Figure 2: Proposed theoretical relationships for this study $\ldots \ldots \ldots \ldots \ldots \ldots \ldots \ldots \ldots \ldots \ldots \ldots$ 


\section{CHAPTER 1}

\section{INTRODUCTION}

\section{Background}

Overweight and obesity in children and adolescents continues to be a public health concern in the United States (US). The 2005-2006 National Health and Nutrition Examination Survey (NHANES) revealed that $10.9 \%$ of children and adolescents aged 2 through 19 years were at or above the $97^{\text {th }}$ percentile of the 2000 body mass index (BMI) for age growth charts; $15.5 \%$ were at or above the $95^{\text {th }}$ percentile and $30.1 \%$ were at or above the $85^{\text {th }}$ percentile of BMI for age (Ogden, Carroll, \& Flegal, 2008). Between NHANES 2003-2004 and NHANES 20052006, BMI for age remained elevated, although there were no significant increases found (Ogden et al., 2008). Furthermore in the US $15.8 \%$ of adolescents nationwide are overweight, while $13.0 \%$ of adolescents nationwide are obese according to the 2007 Youth Risk Behavior Survey (YRBS) (Centers for Disease Control and Prevention, 2008a). Key reasons accounting for childhood and adolescent obesity include alterations in the balance between dietary intake and physical activity levels of children and adolescents and a sedentary life style that includes television, computers, and video games (Dietz \& Gortmaker, 2001; U.S.Department of Health and Human Services, 2001).

Overweight and obesity in childhood and adolescence leads to increases in obesity associated chronic diseases throughout childhood and adulthood including: hyperlipidemia, hypertension (HTN), diabetes (DM), sleep apnea, polycystic ovary disease, hepatic steatosis, cholelithiasis, arthritis, and poor health status (Dietz, 2002; Estrada, 2004; Mokdad et al., 2003; U.S.Department of Health and Human Services, 2001). While overweight and obesity is important in childhood and adolescence it can extend into adulthood (Fowler-Brown \& Kahwati, 
2004; Srinivasan, Weihang, Wattigney, \& Berenson, 1996). Overweight adolescents have a $70 \%$ chance of becoming overweight adults, and this chance increases to $80 \%$ if one or more parent is overweight (U.S.Department of Health and Human Services, 2001). Overweight children and adolescents experience adverse psychosocial consequences which can extend into adulthood (Estrada, 2004; Gortmaker, Must, Perrin, Sobol, \& Dietz, 1993).

Obesity prevalence rates vary throughout the US. Halverson and colleagues (Halverson, Ma, Harner, Hanham, \& Braham, 2004b) discuss geographic areas among Appalachian states with a notably high prevalence of obesity and overweight including: north-central Pennsylvania, southern WV, eastern Kentucky, western Virginia, and northeastern Mississippi. The obesity prevalence in Appalachia is consistently higher when compared with other regions (Halverson et al., 2004b). Appalachia is mainly a rural region with few major metropolitan areas (Halverson et al., 2004b). The majority of counties located in Central Appalachia, consisting of eastern Kentucky (KY), southern WV, and western Virginia (VA), are characterized by higher unemployment rates and levels of poverty, lower incomes, and lower levels of educational attainment compared to the non-Appalachian US (Halverson et al., 2004b).

A current trend is an increasing proportion of rural residents who are overweight or obese (Gamm, Hutchinson, Dabney, \& Dorsey, 2003). Rural residents are more likely to be obese compared to their urban counterparts (Jackson, Doescher, Jerant, \& Hart, 2005; Lutfiyya, Lipsky, Wisdom-Behounek, \& Inpanbutr-Martinkus, 2007; McMurray, Harrell, Bangdiwala, \& Deng, 1999; Ramsey \& Glenn, 2002). In addition, rural residents also have a lower socioeconomic status (Lutfiyya et al., 2007; McMurray et al., 1999; Sobal \& Stunkard, 1989; Veugelers \& Fitzgerald, 2005), less education (Jackson et al., 2005; McMurray et al., 1999), and lower levels 
of physical activity (Lutfiyya et al., 2007; Patterson, Moore, Probst, \& Shingole, 2004) compared to urban residents.

Appalachia is primarily a rural area making this population, specifically children and adolescents, vulnerable to adverse health outcomes. Vulnerable populations are social groups who have an increased risk or susceptibility to adverse health outcomes (Flaskerud \& Winslow, 1998; Leight, 2003). Individuals living in Appalachia are a vulnerable population due to disparities related to health, economic, education, and social disadvantages (Appalachian Regional Commission, 2008; Polk et al., 2008). Therefore, it is important to consider the risk factors and resources that contribute to overweight and obesity in Appalachian children and adolescents.

\section{Problem Statement}

Appalachian children and adolescents are a vulnerable population with a high prevalence of overweight and obesity (Demerath et al., 2003; Muratova et al., 2002; Singh, Kogan, \& Van Dyck, 2008). This research study described the extent to which resource availability (family income, insurance, family characteristics, parents’ education, and transportation) and risk factors (utilization of health care/preventive care, family medical history, and participant medical history) impact overweight and obesity in a vulnerable population. The study also described the frequency of overweight and obesity in a sample of Appalachian children and adolescents.

\section{Limitations and Delimitations}

This study is a secondary analysis of the Center for Oral Health Research in Appalachia (COHRA) study. Therefore, a limitation of this study is that it is a secondary data analysis. Data used in secondary analyses are analyzed for purposes different from those from the primary analyses (McArt \& McDougal, 1985). A researcher performing a secondary data analysis needs 
to always remember that he or she has no control over the data collection process and this could result in problems with data accuracy (Nicoll \& Beyea, 1999). Errors can occur during the process of survey development, question formation, data collection, or data entry that can result in problems with data accuracy.

\section{Definition of Terms}

Adolescence -Adolescence can be divided into early (10 to 14 years), middle (15 to 17 years), and late (18 to mid 20’s) (Elliot \& Feldman, 1990). Adolescents 11-17 years of age were included in this study.

Appalachia-Appalachia is defined as a large geographic expanse that is associated with the Appalachian Mountains, that extends from Southern New York to Northern Mississippi (Appalachian Regional Commission, 2008; Huttlinger \& Purnell, 2008). Appalachia includes all of West Virginia and parts of Alabama, Georgia, Kentucky, Maryland, Mississippi, New York, North Carolina, Ohio, Pennsylvania, South Carolina, Tennessee, and Virginia (Appalachian Regional Commission, 2008; Huttlinger \& Purnell, 2008). Forty-two percent of the population in Appalachia live in rural areas and WV is the most rural of the 13 Appalachian states (Appalachian Regional Commission, 2008; Muratova, Islam, Demerath, Minor, \& Neal, 2001). Participants in the Center for Oral Health Research in Appalachia study were recruited from Nicholas and Webster counties in central WV, which is primarily a rural area. Children-Childhood can be divided into early childhood (1year to 4 years) and middle childhood (5 years to 10 years) (American Academy of Pediatrics, 2008). Children ages $7-10$ years of age were included in this study.

Overweight and Obesity- The terms “obesity” and “overweight” are used almost interchangeably in the literature, but the two concepts are not identical (Field, Barnoya, \& Colditz, 2002). 
"Overweight refers to weighing more than a standard level for height and age; obesity refers to excessive body fat” (Field et al., 2002, p. 3). BMI is commonly used to measure obesity and it is defined as weight (in kilograms) divided by height (in meters) squared $\left(\mathrm{kg} / \mathrm{m}^{2}\right)$ (Field et al., 2002). In this study, BMI for children and adolescents was plotted on the CDC BMI-for-age growth chart (gender specific) to obtain a percentile ranking which take into account normal differences in body fat among age and gender (Centers for Disease Control and Prevention, 2008b). The weight status categories for children and adolescents in this study is in accordance with the CDC as follows: underweight (less than the $5^{\text {th }}$ percentile), healthy weight ( $5^{\text {th }}$ percentile to less than the $85^{\text {th }}$ percentile), overweight $\left(85^{\text {th }}\right.$ percentile to less than the $95^{\text {th }}$ percentile), and obese (equal to or greater than the $95^{\text {th }}$ percentile)(Centers for Disease Control and Prevention, 2008b).

Resource Availability-Resource availability is defined as the availability of socioeconomic and environmental resources (Flaskerud \& Winslow, 1998; Leight, 2003). Resource availability was operationalized in this study as: family income, presence of insurance, available transportation, parents' education level, and family characteristics such as which parents live in the home. Risk Factors-Risk factors can be defined as "anything that increases a person's chance of developing a disease” (Merril \& Timmreck, 2006, p. 236). Risk factors were operationalized in this study as risk factors including: utilization of health care/preventative care, rural residency, family medical history, and medical history of participants.

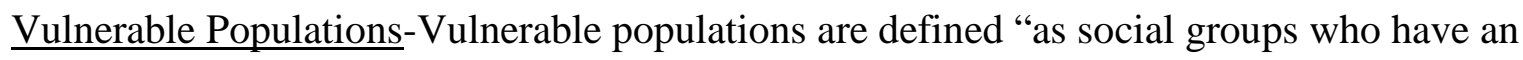
increased relative risk or susceptibility to adverse health outcomes” (Flaskerud \& Winslow, 1998, p. 69). Vulnerable populations can include women and children, ethnic people of color, gay men and lesbians, homeless individuals, individuals living with the human 
immunodeficiency virus and acquired immune deficiency syndrome, individuals who are chronically ill or disabled, individuals with substance abuse problems, individuals with mental illness, individuals who are homicide or suicide prone, abusive families, immigrants and refugees, and the elderly (Aday, 2001; Flaskerud \& Winslow, 1998; Leight, 2003; Sebastian, 2008). Children and adolescents were the vulnerable population in this secondary data analysis.

Significance for the Study

In 2000, obesity was the $2^{\text {nd }}$ leading cause of preventable death in the US, accounting for 400,000 deaths (Mokdad, Marks, Stroup, \& Gerberding, 2004). Childhood and adolescent obesity are important health issues in the US, since overweight children and adolescents are more likely to become obese adults. Furthermore obese children and adolescents, can develop obesity associated chronic diseases and may experience adverse psychosocial consequences as adults (Estrada, 2004).

Of particular note are differences in obesity prevalence rates according to geographic region. When compared to the population in other areas of the US, there is a higher prevalence of obesity and physical inactivity in the Appalachian region with a higher rate of prevalence occurring in the central portion of the region-Eastern Kentucky, Southeastern Ohio, Southern and Central WV, Western VA (Halverson, Harner, \& Ma, 2004a). People in Appalachia suffer the highest percentage of mortality from heart disease (Halverson et al., 2004a). Currently heart disease is the leading cause of death in WV and in the US, and obesity is a major risk factor for heart disease (Halverson et al., 2004a). Ramsey and Glenn (1998) found that men and women from a rural, Appalachian population are at significant risk for heart disease. Major modifiable risk factors that were identified include: tobacco use; lack of exercise; high-fat, low-fiber diets; abnormal serum lipid levels; and obesity (Ramsey \& Glenn, 1998). 
A high prevalence of obesity exists among Appalachian children and adolescents (Demerath et al., 2003; Muratova et al., 2002; Singh et al., 2008). Children may have one or more risk factors for coronary artery disease (CAD) which can include: obesity, hypertension, and dyslipidemia (Muratova et al., 2001). The Coronary Artery Risk Detection in Appalachian Communities (CARDIAC) project identified that the risk of having dyslipidemia and hypertension was much higher in obese Appalachian children than in non-overweight Appalachian children (Muratova et al., 2002).

Appalachian children and adolescents are considered a vulnerable population. Children and adolescents living in Appalachia are even more vulnerable due to living in a region that is characterized by low income, low levels of urbanization, educational deficits, and a lower standard of living than the rest of the US (Appalachian Leadership Initiative on Cancer (ALIC), 1994; Huttlinger \& Purnell, 2008; Muratova et al., 2001). Appalachia has a high prevalence of cardiovascular disease, diabetes, obesity, and cancer (Halverson et al., 2004a).

Further research is needed to continue to examine overweight and obesity in Appalachian children and adolescents. This study is the first study to apply a vulnerable populations conceptual framework to examine factors associated with overweight and obesity in Appalachian children and adolescents. In order to design and implement effective interventions and prevention strategies that will improve the health status of Appalachian children and adolescents, the nature of the relationship between overweight and obesity and a vulnerable population needs to be elucidated. 


\section{Theoretical Framework}

Overview

The Vulnerable Populations Conceptual Framework proposes that the concepts of resource availability, relative risk, and health status are related (Flaskerud \& Winslow, 1998) (see Figure 1). Resource availability is viewed as "the availability of socioeconomic and environmental resources” (Flaskerud \& Winslow, 1998, p. 69). Relative risk is considered to be the ratio of the risk of poor health among groups who are lacking resources and are exposed to risk factors compared with those groups who do have resources and are not exposed to risk factors (Flaskerud \& Winslow, 1998). Health status is viewed as “age-and gender-specific morbidity and mortality” (Flaskerud \& Winslow, 1998, p. 73).

The Vulnerable Populations Conceptual Framework discusses three fundamental relationships among the concepts in the model (Flaskerud \& Winslow, 1998). The first relationship in the model exists between resource availability and relative risk (Flaskerud \& Winslow, 1998). A lack of resources can increase relative risk (Flaskerud \& Winslow, 1998). The next relationship in the model is between relative risk and health status (Flaskerud \& Winslow, 1998). Increased exposure to risk factors causes an increased morbidity and mortality in a population group (Flaskerud \& Winslow, 1998). Increased morbidity and mortality may also exacerbate further exposure to risk factors (Flaskerud \& Winslow, 1998). The final relationship is between health status and resource availability (Flaskerud \& Winslow, 1998). Morbidity and mortality that is present in a community may feed back into resource availability and further deplete any available resources (Flaskerud \& Winslow, 1998). Nursing research, practice, and ethical and policy analysis are presented in the model because of the potential to affect resource availability, relative risk, and health status (Flaskerud \& Winslow, 1998). 


\section{Resource Availability}

Resource availability is "conceptualized as the availability of socioeconomic and environmental resources” (Flaskerud \& Winslow, 1998, p. 70). Socioeconomic resources can include human capital, social connectedness or integration, and social status (Flaskerud \& Winslow, 1998). Human capital is “operationalized as income, jobs, education, and housing” (Flaskerud \& Winslow, 1998, p. 70). In 2006, 36.5 million people were living in poverty in the US (DeNavas-Walt, Proctor, \& Smith, 2007). Persons living in poverty have higher rates of chronic illness, higher infant morbidity and mortality, shorter life expectancy, more complex health problems, and more complications and physical limitations from chronic disease (Bolla, 2008). Employment is another empirical indicator of human capital (Flaskerud \& Winslow, 1998; Leight, 2003). Several areas of Central Appalachia have unemployment rates and the number of people living in poverty that have remained consistently above the national average (Huttlinger \& Purnell, 2008). Homelessness is another empirical indicator of human capital. In rural areas, families with children, children who have been abandoned or are runaways, single women and female head of households, the elderly and people who are mentally ill are at the highest risk for becoming homeless (Bushy, 2000; Leight, 2003).

Social connectedness or integration can be operationalized by examining patterns of family and community life (Flaskerud \& Winslow, 1998; Leight, 2003). "Individuals who are marginalized, stigmatized and discriminated against are not socially connected or integrated (Flaskerud \& Winslow, 1998, pg. 71). Rural populations are affected by the loss of jobs by more than just livelihood; they lose the infrastructure that has supported traditional patterns of family and community (Jones, 1995; Leight, 2003). Higher social status groups have power and lower social status groups do not (Flaskerud \& Winslow, 1998). "People with power are those who 
control the political process, decision making, and the distribution of resources” (Flaskerud \& Winslow, 1998, p. 71).

Environmental resources are operationalized as access to health care and quality of care (Flaskerud \& Winslow, 1998; Leight, 2003). Lack of environmental resources can lead to increased morbidity and mortality (Flaskerud \& Winslow, 1998). Barriers for rural residents may include: distance to the nearest health care facility, economic factors forcing the closure of rural clinics, and presence of health insurance (Flaskerud \& Winslow, 1998; Leight, 2003). Relative Risk

Relative risk is referred to as the likelihood of exposure to risk factors (Flaskerud \& Winslow, 1998; Leight, 2003). Lack of socioeconomic and environmental resources are thought to be related to an increase in risk factors among population groups (Flaskerud \& Winslow, 1998). Common risk factors include: lifestyle choices, health promoting behaviors such as screening procedures and immunization programs, and exposure to stressful events such as violence, crime, and abuse (Flaskerud \& Winslow, 1998; Leight, 2003). Individuals from rural areas are less likely to engage in preventive behaviors such as: physical activity, seat belt use, regular blood pressure checks, Pap smears, and complete breast self-examinations (Bushy, 2008; Leight, 2003).

\section{Health Status}

Empirical indicators for health status are morbidity and mortality (Flaskerud \& Winslow, 1998; Leight, 2003). “Exposure and participation in a greater number of risk factors are related to patterns of increased morbidity and premature mortality in various population groups” (Flaskerud \& Winslow, 1998, p. 73). Rural adults, when compared with urban adults have a poorer perception of their overall health and functional status, are more likely to have one of 
more of the following chronic conditions: cardiovascular disease (CVD), chronic obstructive pulmonary disease (COPD), hypertension (HTN), arthritis, diabetes mellitus (DM), and seek medical care less often despite their poorer perception of health and higher incidence of chronic disease (Bushy, 2008).

The Vulnerable Populations Conceptual Model has been recently tested and limitations exist with the utilization of the model. In the Vulnerable Populations Conceptual Model, constructs (resource availability, relative risk, and health status) are population measures, but most people have operationalized the constructs as individual measures (Dr. J. Flaskerud, Personal communication, July 8, 2008). This issue is of particular concern for relative risk. Individuals who have utilized the model have empirically defined relative risk as an individual measure. Because the current study is not theory testing, the model is being modified to guide the present study. In this study relative risk will be conceptualized as individual risk factors.

In this study, resource availability will be measured by analyzing the following family variables: family income, parents’ education level, presence of insurance, family characteristics and availability of transportation to medical/dental visits. Risk factors will be measured by analyzing the following family/individual variables: utilization of health care/preventive care, family medical history, and participant medical history. Health status will be measured by examining the prevalence of overweight and obesity among participants (see Figure 2). 


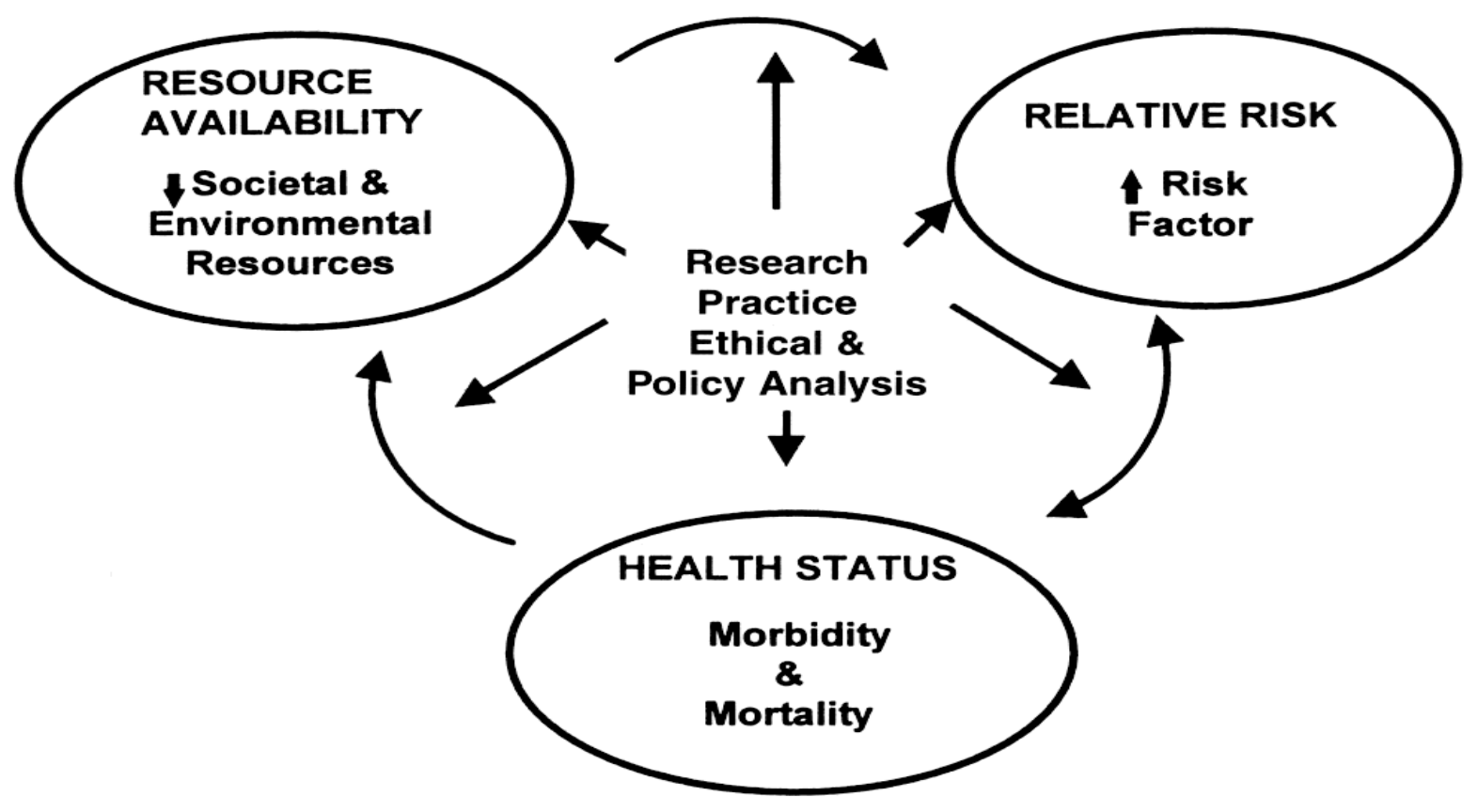

Figure 1: The Vulnerable Populations Conceptual Model (Flaskerud \& Winslow, 1998) 


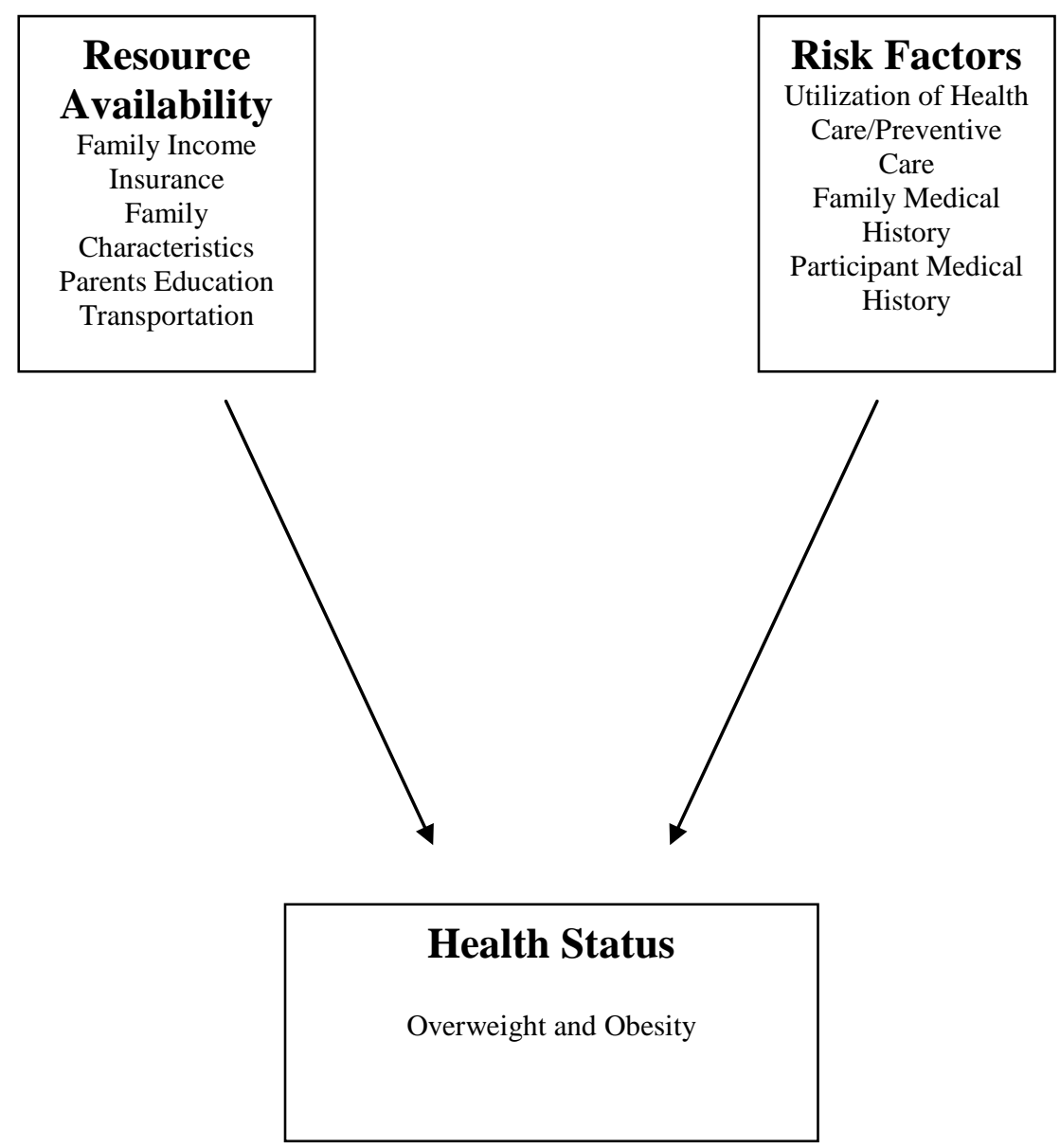

Figure 2: Proposed theoretical relationships for this study 


\section{CHAPTER II}

\section{REVIEW OF THE LITERATURE}

The second chapter presents the literature review for this study. In this study, the relationship among variables that contribute to vulnerability: resource availability, health status, and relative risk were examined. The literature review is organized by discussing each of these three variables, studies that have utilized the Vulnerable Populations Conceptual Model (VPCM) as a framework, and articles discussing the Center for Oral Health Research in Appalachia study.

\section{Obesity}

Obesity is the measure of health status that was utilized in this study. This section of the literature review is organized by discussing obesity as a disease, definitions of obesity, measurement of obesity, and obesity in Appalachia.

\section{Obesity as a Disease}

Obesity has been recognized as a complex condition that has numerous causal factors and contributors including factors that are beyond an individual's control (Allison et al., 2008). Obesity being classified as a disease has been a thoughtful and controversial argument (Allison et al., 2008). Jung (1997) argued that there is a major environmental effect on obesity but genetic susceptibility alone moves obesity from a social stigma to the disease category. The Obesity Society recognized that there is a majority view to call obesity a disease, but most authoritative bodies that have offered statements supporting this view have not published a thorough and rigorous argument or evidential basis in support of this statement (Allison et al., 2008). The Council of the Obesity Society (2008) has stated that: 
We believe if obesity is determined a disease it will: benefit our citizenry by soliciting more resources for prevention and treatment of, and research on, obesity; encourage health-care professionals to view treating obesity as a vocation worthy of effort and respect; and reduce the stigma and discrimination experienced by many persons with obesity (p. 1151).

\section{Defining Obesity}

Currently, there is no universally accepted definition or system for the classification of childhood and adolescent obesity (Chinn, 2006; Cole, Bellizzi, Flegal, \& Dietz, 2000; Neovius, Linne, Barkeling, \& Rossner, 2004; Speiser et al., 2005). As mentioned in Chapter 1, the CDC has established BMI percentile cut-off points based on gender and age (Centers for Disease Control and Prevention, 2008b). The CDC cutoff points cannot be used for a standard international definition because the reference population is the US pediatric population, which is not globally representative (Neovius et al., 2004). Cole and colleagues (2000) recommended an international definition and cut-off points for childhood obesity. Data on BMI for children from six large nationally representative cross sectional surveys on growth from Brazil, Great Britain, Hong Kong, the Netherlands, Singapore, and the US were utilized as the reference population (Cole et al., 2000). Adult BMI cut-off points (BMI of 25-29.9 is overweight and BMI of 30 or greater is obese) were utilized and linked to BMI centiles for children (Cole et al., 2000). Although this method has been cited by numerous articles, it has not been universally accepted as a standard definition for obesity (Chinn, 2006). One limitation with Cole and colleagues' (2000) work is that even though the analysis included large representative samples from six countries, it was still not globally representative (Cole et al., 2000; Neovius et al., 2004). A U.S. expert committee revised recommendations made in 1998 to utilize the same CDC cut-off points, 
but utilize different terminology for the cut-off points (Barlow \& Expert Committee, 2007). Overweight is defined as a BMI at the $85^{\text {th }}$ to $94^{\text {th }}$ percentile (previously defined as at risk for overweight) and obesity is defined as a BMI at the $95^{\text {th }}$ percentile or greater (previously defined as overweight) (Barlow \& Expert Committee, 2007).

Measurement of Obesity

Current methods utilized to measure obesity include: BMI, skinfold thickness, bioelectric impedance assay (BIA), hydrodensitometry, dual-energy x-ray absorptiometry (DEXA), imaging, waist circumference, and waist to hip ratios (Speiser et al., 2005).

Measurement issues related to defining obesity that are identified in the literature include: a lack of a simple, precise, reproducible approach to measure body fat in children and adolescents and the lack of cut-off points to identify children at increased cardiovascular and metabolic risk (Speiser et al., 2005). BMI is an "indirect estimate of total adiposity" (Speiser et al., 2005, p. 1873). However, BMI is still the most acceptable measurement to assess weight status that is utilized due to its simplicity (Hall \& Cole, 2006; McCarthy, Cole, Fry, Jebb, \& Prentice, 2006; Must \& Anderson, 2006). In order for BMI to be meaningful in children and adolescents it must be compared to a reference standard that accounts for child age and gender (Must \& Anderson, 2006). BMI has been referred to as an imperfect tool because it does not distinguish between excess body fat or lean muscle mass, and it does not necessarily predict health risk for children (Must \& Anderson, 2006; Speiser et al., 2005). Skinfold thickness measures can be an inexpensive and simple method to measure body fat, but training is required to ensure accuracy and reproducibility, especially in obese patients (Atkinson, 2004; Cole \& Rolland-Cachera, 2002; Speiser et al., 2005). Waist circumferences and waist-to-hip ratios are simple and cheap measurements, but training is required to produce adequate reproducibility (Cole \& Rolland- 
Cachera, 2002). BIA is a quick, simple and inexpensive measurement but results can be affected by meals, physical activity, and hydration status (Atkinson, 2004; Speiser et al., 2005). Hydrodensitometry, DEXA, and imaging can be used to measure body fat, but require special equipment and are expensive (Speiser et al., 2005). Therefore, even though BMI is an imperfect tool, it is a quick and simple tool utilized to measure obesity.

\section{Obesity and Appalachia}

A high prevalence of childhood and adolescent obesity exists in Appalachia. Data from the 2007 YRBS survey indicates that 17\% of WV adolescents were overweight, while 14.7\% of WV adolescents were obese (Centers for Disease Control and Prevention, 2008a). Data from the CARDIAC project ( $n=5,8875^{\text {th }}$ graders, 1999-2002) revealed a high prevalence of obesity among Appalachian children, 18 \% were overweight and 25.7\% were obese (Muratova et al., 2002). Bolding and colleagues (2005) revealed that 37\% of adolescents in Appalachia were significantly overweight or obese, with BMIs greater than the $85^{\text {th }}$ percentile for gender and age.

\section{Resource Availability}

For the purpose of this study, socioeconomic and environmental factors will be examined. Resource availability was operationalized in this study as: family income, presence of insurance, available transportation, parent’s education level, and family characteristics.

\section{Family Income}

People who are poor are more likely to live in hazardous environments, work in high-risk jobs, have less nutritious diets, and have multiple stressors (Sebastian, 2008). The 2000 census found that Appalachian residents continued to have lower incomes than residents in the rest of the US (Pollard, 2003). In 1999, 17.9\% of WV residents lived in poverty (Pollard, 2003). Individuals living in poverty have higher rates of chronic illness, shorter life expectancies, more 
complex health problems, and more significant complications and physical limitations from chronic disease (Bolla, 2008). Studies have revealed that childhood and adolescent obesity is potentially affected by low socioeconomic status, which is related to overweight and obesity (McMurray et al., 2000; Vieweg, Johnston, Lanier, Fernandez, \& Pandurangi, 2007). Shrewsbury and Wardle (2008) conducted a literature review examining 45 studies from different western developed countries; 19 of the studies revealed that low SES was related to increased adiposity.

Insurance

A lack of access to care may be related to the following: inability to pay for health care, lack of insurance, geographic location, language, unequal distribution of providers, transportation difficulties, inconvenient clinic hours, and negative attitudes of health care providers toward poor clients (Bolla, 2008). In 2006, 8.7 million (11\%) children under the age of 18 in the US were without insurance (DeNavas-Walt et al., 2007). According to the US Census Bureau (2007), 44.6\% of children under 19 years of age live at or below $200 \%$ of the poverty level and $4.8 \%$ of these children are without insurance. The US Census Bureau (2007) based the previous statistics on a three year average: 2004, 2005, and 2006. A survey conducted by Huttlinger and colleagues (2004) in Appalachia found that a significant number (80\%) of individuals living in the same household as the respondent did not have any coverage. Other individuals in the households who were uninsured included working adults between the ages of 18 and 57 (80\%) and children (52\%) (Huttlinger, Schaller-Ayers, \& Lawson, 2004).

\section{Transportation}

A lack of transportation has been shown to decrease healthcare utilization (Arcury, Preisser, Gesler, \& Powers, 2005). In most rural areas of Appalachia, there is limited or no 
access to public transportation (Huttlinger \& Purnell, 2008). Individuals may have modes of transportation, but may have other barriers to receiving care such as distance to nearest healthcare provider or specialist, or rugged terrain (Deskins et al., 2006; Huttlinger et al., 2004). Family Characteristics

Family characteristics can be associated with childhood and adolescent obesity. Hesketh and colleagues (2007) reported that children in single parent homes, homes without siblings and homes with less educated mothers and fathers tend to have higher BMIs and are more likely to be overweight. Overweight in children has been strongly associated with characteristics of parents, such as parents being overweight and having a low education level (Lasserre, Chiolero, Cachat, Paccaoud, \& Bovet, 2007).

\section{Risk Factors}

While there are many risk factors for obesity, this review focuses only on the risk factors available to the researcher because of the questions asked by the survey. Risk factors that were examined in this study included: utilization of health care/preventative care, family medical history, and medical history of participants.

\section{Utilization of Health Care/Preventive Care}

As mentioned in the previous paragraphs Appalachian culture and rural residency are barriers to the utilization of health care and prevention activities. Deskins and colleagues (2006) conducted focus groups in WV and identified the following barriers to participating in preventive care: cost of health care, having no insurance, availability of care, and lack of time. Children revealed that they do not believe adults care about their own health and reported little social pressure from parents or peers to engage in preventive behaviors (Deskins et al., 2006). Appalachian health care providers have identified barriers to participation in preventive cancer 
screening as: fatalism; strong religious beliefs; low educational attainment; lack of cancer knowledge; present, day to day orientation; and screening and health prevention is not considered a priority (Shell \& Tudiver, 2004).

Family Medical History

One of the classic studies to identify risk factors for CHD is the Framingham Study (Dawber \& Kannel, 1966; Kannel, Dawber, Kagan, Revotskie, \& Stokes, 1961; Kannel \& McGee, 1979). Several of the major CHD risk factors identified by the Framingham Study include: high cholesterol levels, hypertension, excess body weight and diabetes (Dawber \& Kannel, 1966; Kannel et al., 1961; Kannel \& McGee, 1979). Appalachia is a region that has a high prevalence of CHD and WV currently ranks $1^{\text {st }}$ in the nation for prevalence of CHD (Centers for Disease Control and Prevention, 2007; Halverson et al., 2004a). Ramsey and Glenn (1998) examined risk factors for heart disease in rural, Appalachian adults and identified the following major modifiable risk factors: tobacco use; lack of exercise; high-fat, low-fiber diets; abnormal serum lipid levels, and obesity.

Participant Medical History

Childhood and adolescent obesity can be associated with risks of hypertension, hyperlipidemia, type II diabetes mellitus, and psychosocial consequences (such as depression and anxiety) (Calderon, Yucha, \& Schaffer, 2005; Estrada, 2004). The Bogalusa Heart Study identified that overweight in children and adolescents can be associated with risk factors for CHD including: elevated blood pressure, increased low-density lipoprotein (LDL), increased total cholesterol (TC), increased triglycerides, decreased high-density lipoprotein (HDL), and increased insulin and glucose levels (Freedman, Dietz, Srinivasan, \& Berenson, 1999; Srinivasan et al., 1996). 
Studies have examined the relationship between overweight children and CHD risk factors in Appalachia. A goal of CARDIAC, a school-based cardiovascular health program, is to estimate the prevalence of obesity and related CHD risk factors (Demerath et al., 2003; Neal et al., 2001). Muratova and colleagues (2002) examined data from the 1999-2002 CARDIAC screenings, which was comprised of $5,8875^{\text {th }}$ graders enrolled in 183 elementary schools across 27 rural WV counties. The prevalence of obesity was high (25.7\%) based on the $95^{\text {th }}$ percentile for age and gender, another $18 \%$ of children were overweight based on the $85^{\text {th }}$ percentile for age and gender (Muratova et al., 2002). The obesity rates varied greatly among counties in WV (15\% to $50 \%$ ), but the study did not indicate a statistically significant difference in the prevalence of obesity in northern counties (25.0\%) vs. southern counties (26.4\%) in WV (Muratova et al., 2002).

In comparing children who are non-overweight, overweight, and obese, this study found that TC, systolic blood pressure (SBP) and diastolic blood pressure (DBP) were significantly higher for obese children compared to non-overweight and overweight children (Muratova et al., 2002). HDL cholesterol was also found to be significantly lower in obese children compared to non-overweight and overweight children (Muratova et al., 2002). Obese children compared to non-overweight children were 2.2 times as likely to have a high TC level, 3.3 times as likely to have a low HDL level, 3.9 times as likely to have a high SBP, and 3.0 times as likely to have a high DBP (Muratova et al., 2002). Hyperinsulinemia among children who tested for fasting insulin (214) was 6.0\% and all children who had hyperinsulinemia were obese (Muratova et al., 2002).

Bolding and colleagues (2005) conducted a descriptive chart analysis of 100 consecutive patients at an adolescent medicine clinic in WV with the following findings: $28 \%$ of adolescents 
had a BMI $>95^{\text {th }}$ percentile for age and gender, while $9 \%$ of adolescents had a BMI $>85^{\text {th }}$ percentile for age and gender. A total of 17\% (17/100) had Acanthosis Nigricans, and 94\% of this cohort $(16 / 17)$ had a BMI $>95^{\text {th }}$ percentile for age and gender (Bolding, Wratchford, Perkins, \& Ogershok, 2005). Fasting insulin levels were obtained in Acanthosis Nigricans positive adolescents and were found to be elevated with a mean of $33.6 \mu \mathrm{IU} / \mathrm{ml}$ (range 14.0 to 77. $0 \mu \mathrm{IU} / \mathrm{ml}$ ) (Bolding et al., 2005).

Psychosocial factors, such as depression and anxiety, are related to obesity in children and adolescents. Erickson and colleagues (2000) reported that BMI was associated with depressive symptoms in $3^{\text {rd }}$ grade females. Young-Hyman and colleagues (2006) found that an increased BMI was associated with depression and anxiety in black children and all female children. Studies also have found that obesity is associated with depression in adolescents (Eremis et al., 2004; Needham \& Crosnoe, 2005). Needham and colleagues (2005) found that obesity was associated with depression in females only; this association was stronger among adolescents in lower grades $\left(7^{\text {th }}\right.$ and $8^{\text {th }}$ grade). Erermis and colleagues (2004) identified an association with depression and anxiety in clinically obese adolescents.

Appalachian Culture

The Appalachian region does contain several large cities, but the region is mostly rural. “The rugged location of many communities in Appalachia results in a population that is often isolated from the mainstream of health-care services” (Huttlinger \& Purnell, 2008, p. 95). Characteristics of Appalachian culture often include: fatalism, personalism, self-reliance, traditionalism, family and religious fundamentalism (Coyne, Demian-Popescu, \& Friend, 2006; Huttlinger \& Purnell, 2008). Self-reliance is a strong cultural trait. Many Appalachians delay seeking health care until they have attempted to rectify or treat health problems on their own 
(Huttlinger et al., 2004; Huttlinger \& Purnell, 2008; Smith \& Tessaro, 2005). Rosswurm and colleagues (1996) found that Appalachians believed they could not prevent illness, they can only cope with its consequences. Individuals in Appalachia view disease and accidents, like other hardships, as a way of life (Coyne et al., 2006). Appalachians rely on religious faith to help them cope with illness and to seek healing, which makes it a very important cultural influence on a person’s health (Coyne et al., 2006; Rosswurm, Dent, Persily, Woodburn, \& Davis, 1996). Appalachian cultural beliefs have been identified as barriers to participation in health screenings (Deskins et al., 2006). Deskins and colleagues (2006) identified the following Appalachian culture beliefs as barriers to participating in prevention activities: a resistance to a preventive approach to health, resistance to new people and ideas, using denial as a coping strategy, and having a fatalistic view toward health.

\section{Rural Residency}

Rural residency can be a risk factor. Rural adults are more likely to have one or more of the following chronic conditions when compared to urban adults: heart disease, chronic obstructive pulmonary disease, hypertension, arthritis and rheumatism, diabetes, cardiovascular disease, and cancer (Bushy, 2008). Living in a rural area can be associated with a greater risk for obesity. Ramsey and Glenn (2002) reported that significantly more southern rural women were the least healthy (coefficient of health status (CoHS) $=.230 \pm .209 ; \mathrm{P}<.05$ ) and had the highest obesity rates $(\mathrm{ht} / \mathrm{wt}$ ratio $=1.19 \pm 0.60 ; \mathrm{P}<.05)$ compared to urban and suburban southern women. Lutfiyya and colleagues (2007) found that children living in rural areas in the U.S. are about 25\% (OR = 1.252; CI, 1.248, 1.256) more likely to be overweight or obese compared to children living in urban areas. Rural residency is not only a risk factor for overweight in 
children, but overweight rural children have additional risk factors of poverty, no health insurance, no preventive care in the past year, and little physical activity (Lutfiyya et al., 2007). Vulnerable Populations Conceptual Model

Flaskerud and Winslow (1998) developed the Vulnerable Populations Conceptual Model (VPCM) which proposes that that concepts of resource availability, relative risk, and health status are related. The VPCM has been utilized as an organizing framework in three literature reviews (Bay, Kreulen, Shavers, \& Currier, 2006; Copeland, 2007; Leight, 2003) and two research studies (Flaskerud \& Lee, 2001; Rodehorst, Wilhelm, \& Stepans, 2006).

Bay and colleagues (2006) utilized the VPCM to organize a literature review applied to traumatic brain injury. Resource availability was operationalized as unemployment or underemployment; decreased social connectedness (socioeconomic factors); potential for decreased access to health care and inadequate living conditions (environmental factors) (Bay et al., 2006). Bay and colleagues (2006) proposed that individuals with traumatic brain injury who lack available resources (environmental and/or socioeconomic) are at increased risk for negative health outcomes.

Relative risk was operationalized by exposures to risk factors such as lifestyle choices (substance use, dietary and exercise behaviors) or injuries (risk taking behavior/impulsivity and use of violence/weapons) (Bay et al., 2006). Bay and colleagues (2006) proposed that poor health status can be the result of increased risk factor exposure and that increased exposure to risk factors can worsen health status after traumatic brain injury. Health status was operationalized as age related differences, altered functional health status, mental illness, substance abuse, and dementia (Bay et al., 2006). Bay and colleagues (2006) discussed that symptoms associated with a brain injury increases vulnerability to adverse health outcomes 
through resource depletion or increased exposure to risk factors associated with the developmental level of the person.

Copeland (2007) utilized the VPCM as an organizing framework for a literature review concerning family violence and mental illness. Resource availability was operationalized as employment, income, education, housing, social connection, stigma, and access/quality of health care (Copeland, 2007). Relative risk was operationalized as risk for violent behavior, risk for violent victimization, and use of preventive services (Copeland, 2007). Health status was operationalized as alterations in physical and emotional health, burden, and coping (Copeland, 2007). Copeland (2007) discussed that an increased risk of victimization in combination with a lack of social connection and available resources can increase a family's vulnerability to further violence and the negative consequences of violence.

Leight (2003) conducted a literature review applying the VPCM to rural health. Resource availability was operationalized as: human capital income, jobs, education, housing, patterns of family and community life, and health care (Leight, 2003). Relative risk was operationalized as: quality of care, lifestyle behaviors and choices, health-promoting behaviors (screening, immunization), and exposure to stressful events (Leight, 2003). Health status was operationalized as: delayed diagnosis, increased illness, and premature death (Leight, 2003). Leight (2003) discussed that the VPCM provides opportunity for thoughtful consideration of clinical practice interventions (primary, secondary, and tertiary levels) with vulnerable rural residents.

Flaskerud and Lee (2001) conducted a descriptive study to test a vulnerable populations model that includes both societal and individual characteristics, and views female caregivers as a vulnerable or at risk group. Another purpose of this study was to compare ethnically and 
socioeconomically diverse female caregivers of persons with human immune deficiency syndrome/acquired immune deficiency syndrome (HIV/AIDS) and age related dementia (ARD) (Flaskerud \& Lee, 2001). Participants in this convenience sample were female caregivers ( $\mathrm{n}=$ 76) of adults with HIV/AIDS $(n=36)$ or with ARD $(n=40)$ recruited from the waiting room of an HIV clinic in a public hospital and from a Veterans Affairs medical hospital (Flaskerud \& Lee, 2001). Resource availability was operationalized by: income, education, religion, social status, marital status, and utilization of a support group (Flaskerud \& Lee, 2001). Relative risk was operationalized by: number of years of caregiving, hour/day caregiving, memory and behavior problems in the care recipient, functional status of the care recipient, and distressing emotions in the caregiver (anxiety, anger and loneliness) (Flaskerud \& Lee, 2001). Health status was operationalized by depressive mood symptoms and perception of physical health (Flaskerud \& Lee, 2001).

Health status of caregivers was measured by perception of health and depressive mood scores (Flaskerud \& Lee, 2001). Caregivers of persons with HIV rated their physical health poorer (58.5\%) than did caregivers of persons with ARD (37.5\%) (Flaskerud \& Lee, 2001). Depressive symptom scores for caregivers of people with HIV were significantly higher ( $\mathrm{p}=$ 0.006) than scores for caregivers of people with ARD (Flaskerud \& Lee, 2001).

Available resources were measured by: income, education, religion, social status, marital status, and use of support groups (Flaskerud \& Lee, 2001). Caregivers of people with ARD had significantly more income $(p=0.002)$, more education $(p=0.001)$, were more often married $(p=$ 0.0001), of nonminority ethnicity $(\mathrm{p}=0.0002)$, and had more involvement in support groups ( $\mathrm{p}=$ 0.0001) than caregivers of people with HIV (Flaskerud \& Lee, 2001). 
Situational risks were measured by: years of caregiving, hours per day of caregiving, memory and behavior problems in the care receiver, and functional status of the care receiver (Flaskerud \& Lee, 2001). The mean number of years caregiving differed significantly ( $\mathrm{p}=$ 0.0001) with caregivers of people with ARD providing care for 5.19 yrs and caregivers of people with HIV for 2.16 yrs (Flaskerud \& Lee, 2001). ARD care receivers had significantly more memory and behavior problems $(p=0.000)$ and more wandering behavior $(p=0.001)$ than HIV care receivers (Flaskerud \& Lee, 2001). Emotional risks were measured by presence of distressing emotions in the caregiver, specifically anxiety, anger, and loneliness (Flaskerud \& Lee, 2001). Caregivers of people with HIV were significantly more anxious $(p=0.01)$ and angrier $(p=0.001)$ than caregivers of people with ARD (Flaskerud \& Lee, 2001). In this study, resource variables contributed the most to the explanation of health status (Flaskerud \& Lee, 2001).

Limitations in this study included a small sample size and use of a convenience sample (Flaskerud \& Lee, 2001). Another limitation that Flaskerud and Lee (2001) discussed is that physical and mental health problems experienced by caregivers may have been related to social and resources variables that were not included in the study. The social and resources variables were the stigma of AIDS and ARD, health insurance, access and availability of care, and quality of care (Flaskerud \& Lee, 2001).

Rodehorst and colleagues (2006) conducted a multi-site exploratory descriptive study to identify risk factors, current health status, and resource availability as it relates to asthma risk among a group of rural school-aged children. The VPCM was used to guide this study. A convenience sample of children, 6 to 18 years of age $(n=770)$, from a rural Midwestern state, was used in this study (Rodehorst et al., 2006). Relative risk was defined as exposures to 
triggers of asthma and signs and symptoms of asthma that a child might have (Rodehorst et al., 2006). Health status was defined as the respiratory status of the child, specifically expiratory lung volumes (Rodehorst et al., 2006). Resource availability was defined as access to school nurses and health care providers for purposes of follow-up care for the child's asthma (Rodehorst et al., 2006).

Relative risk was operationalized by the Life Quality Asthma Questionnaire (3 variations used for different age groups), which served as the written screening to identify children at risk for asthma (Rodehorst et al., 2006). Criteria for referral was one or more than one “yes” answers on the written asthma screening tool (Rodehorst et al., 2006). Eighty-four children (32.6\%) 6-8 years old, 156 of children (37.5\%) 9-14 years old, and 19 of adolescents (19.3\%) ages 15-18 years old had a score of greater than one “yes” on the Life Quality Asthma Questionnaire (Rodehorst et al., 2006).

Health status was operationalized as the respiratory status of the child, specifically expiratory lung volumes (Rodehorst et al., 2006). The values used for referral included: forced expiratory volume in 1 second $(\mathrm{FEV} 1)<$ or $=80 \%$, forced volume capacity $(\mathrm{FVC})<$ or $=80 \%$, peak exploratory flow $(\mathrm{PEF})<$ or $=80 \%$, and the average expiratory flow over the middle half of the FVC $($ FEF 25-75) < or = 65\% (Rodehorst et al., 2006). There were 104 participants ( $n=762)(17.4 \%)$ who met the criteria for referral via spirometry and one or more "yes” answers on the written screening (Rodehorst et al., 2006). Participants $(n=123)$ who had abnormal or inconclusive results or were absent on the $1^{\text {st }}$ screening were re-tested 2 weeks later and 93 (75.6\%) met criteria for referral (Rodehorst et al., 2006). Twelve percent of children were identified by the screening to need health care referral (Rodehorst et al., 2006). 
Resource availability was operationalized by a follow-up call to parents/school nurses of children who were referred to their healthcare provider as a result of their screening (Rodehorst et al., 2006). Ninety-three (12.1\%) children were referred to their healthcare provider as a result of their screening (Rodehorst et al., 2006). Fifteen (16.1\%) of these subjects were seen by a health care provider (as reported by the school nurse) but parents were unable to be contacted so these results were not confirmed (Rodehorst et al., 2006). Forty-eight children (51.6\%) had been seen by a healthcare provider, five children's parents (5.3\%) were not planning a follow-up appointment and 25 subjects referred to a healthcare provider were unable to be contacted for information (Rodehorst et al., 2006). The results for children $(\mathrm{n}=48)$ who had been seen by a healthcare provider included: two (4.2\%) were unable to identify if they had been diagnosed with asthma, 26 (54.2\%) of the children were diagnosed with asthma, and nine (18.8\%) were not diagnosed with asthma (Rodehorst et al., 2006).

Limitations were identified in this study. An asthma educational component was not included as part of the operationalizing of resource availability (Rodehorst et al., 2006). Rodehorst and colleagues (2006) discussed that a more individualized education may have increased parents understanding of asthma and perhaps would have gotten children seen by a primary care provider sooner. Case finding results of the study may have been different if spirometric measures had been conducted at regular intervals during the year (Rodehorst et al., 2006). Rodehorst and colleagues (2006) discuss that this study was conducted in a rural Midwestern state where agriculture is widely known and results from the spirometric measures may have differed depending on the season. Several parents did not complete a Life Quality Questionnaire prior to spirometry (Rodehorst et al., 2006). The investigator utilized student responses which may have resulted in answers different from those parents may have given 
(Rodehorst et al., 2006). A number of children (26.9\%) had incomplete follow-up information (Rodehorst et al., 2006).

Synthesis of the Vulnerable Populations Conceptual Model Literature

Vulnerable populations used in this literature review include: individuals with traumatic brain injury (Bay et al., 2006), families with violence and mental illness (Copeland, 2007), rural individuals (Leight, 2003), caregivers of persons with HIV/AIDS and ARD (Flaskerud \& Lee, 2001), and children with asthma (Rodehorst et al., 2006). Resource availability was operationalized as employment, income, education, housing, social connectedness, stigma, access to care/quality of care, religion, marital status, and utilization of a support group. Relative risk was operationalized as: exposure to risk factors, lifestyle behaviors/choices, risk taking behavior, risk for violent behavior, risk for violent victimization, use of preventative services, quality of care, health promoting behaviors, exposure to stressful events, number of years caregiving, hours per day caregiving, memory and behavior problems in the care recipient, functional status of the care recipient, distressing emotions in the caregiver, and the Life Quality Asthma Questionnaire. Health status was operationalized as: age related differences; altered functional health status; mental illness; substance abuse; dementia; alterations in physical and emotional health, burden, and coping; delayed diagnosis; increased illness; premature death; depressive mood symptoms; perception of physical health; and respiratory status, specifically expiratory lung volumes.

Gaps in the Vulnerable Populations Conceptual Model Literature

As previously discussed in Chapter 1, the VPCM defines the concepts (resource availability, relative risk, and health status) as population measures. Each of the studies (Bay et al., 2006; Copeland, 2007; Flaskerud \& Lee, 2001; Leight, 2003; Rodehorst et al., 2006) in this 
review operationalized the concepts (resource availability, relative risk, and health status) as individual measures, which is a limitation with the utilization of the VPCM. None of the studies (Bay et al., 2006; Copeland, 2007; Flaskerud \& Lee, 2001; Leight, 2003; Rodehorst et al., 2006) included in this review have utilized the VPCM with Appalachian children and adolescents to determine factors that are associated with overweight and obesity. The proposed study would fill this gap in the reviewed literature.

\section{Center for Oral Health Research in Appalachia}

COHRA was established in 2000 at the University of Pittsburgh in partnership with West Virginia University (Polk et al., 2008). An initial aim of the COHRA study was to determine the contributions of individual, family, and community factors to oral disease in Appalachian children and adolescents (Polk et al., 2008). The COHRA study hypothesized that many of the risk factors associated with poor oral health across the lifespan may have originated in childhood or adolescence (Polk et al., 2008). A cross-sectional etiology study design was utilized for the COHRA study (Polk et al., 2008). A recently published study (Martin et al., 2008) used the data collected from this larger study.

Martin and colleagues (2008) conducted a descriptive study using pilot data for the CORHA study. The purpose of this study was to provide information about the need and demand for orthodontic treatment in an Appalachian population (Martin et al., 2008). The study sample included 58 adolescents and one or both of each adolescents biological parents $(\mathrm{N}=78)$ that were residents of Nicholas and Webster counties in WV (Martin et al., 2008). All of the participants in this study were white and the child, the parent, or both were patients at a primary medical center in WV (Martin et al., 2008). 
An equal proportion of adolescents in this study (17 [29.3\%] of 58) had received (or currently were receiving) orthodontic treatment compared with the NHANES III sample of white adolescents (27.4\%) in the same age range (Martin et al., 2008). A significantly lower proportion of parents in comparison with adults from the NHANES III sample had ever received orthodontic treatment (Martin et al., 2008). Appalachian children had more often received orthodontic treatment compared to their parents (Martin et al., 2008). More parents than adolescents declined to undergo the orthodontic examination (Martin et al., 2008). Treatment needs of Appalachian adolescents were similar to white adolescents in the NHANES III sample (Martin et al., 2008). When compared to an international sample in which $31.5 \%$ of adults demonstrated orthodontic need, Appalachian parents had more unmet treatment needs (Martin et al., 2008). Significantly fewer Appalachian adolescents needed orthodontic treatment relative to their parents (Martin et al., 2008). Appalachian adolescents expressed lower demand overall for orthodontic treatment. Proportionally more Appalachian parents, compared to an international sample in which $19.2 \%$ of adults indicated a desire for treatment, recognized their need for treatment (Martin et al., 2008). Significantly more parents had an unrecognized need for treatment compared to their children (Martin et al., 2008).

Several limitations were identified in this study. Sampling bias may have been present due to participants being connected to a primary health care center (Martin et al., 2008). Martin and colleagues (2008) discussed that it cannot be assumed that the participants represented all of Appalachia because there is diversity within Appalachia. Participants beliefs were assessed about their need for orthodontic treatment, but no other perspectives on treatment need were included (Martin et al., 2008). Lastly, a limitation of this study is the small sample size (Martin et al., 2008). 


\section{Conclusion}

In conclusion, literature related to overweight and obesity, resource availability, risk factors, VPCM, Appalachian culture, rural residency, and COHRA was discussed in this chapter. Studies have demonstrated that overweight and obesity in this age group is linked to morbidity and later mortality (Calderon et al., 2005; Estrada, 2004; Freedman et al., 1999; Srinivasan et al., 1996). While the following populations: individuals with traumatic brain injury (Bay et al., 2006), families with violence and mental illness (Copeland, 2007), rural individuals (Leight, 2003), caregivers of persons with HIV/AIDS and ARD (Flaskerud \& Lee, 2001), and children with asthma (Rodehorst et al., 2006) have been utilized with the VPCM, no studies utilizing the VPCM have been conducted with rural Appalachian children and adolescents. The literature has not yet recognized that Appalachian children and adolescents are a vulnerable population and inherent to this population are increased risk factors and decreased resource availability. The research does suggest that risk factors and issues with resource availability put children and adolescents at risk for overweight and obesity. This study is the first study to apply a vulnerable populations framework to examine factors associated with overweight and obesity in Appalachian children and adolescents. 


\section{CHAPTER III}

\section{METHODOLOGY}

\section{Research Design}

The extent to which factors associated with a vulnerable population model, resource availability and risk factors, contribute to overweight and obesity in Appalachian children and adolescents were investigated using a descriptive predictive, cross-sectional design. Data were analyzed for relationships among the dependent variable: overweight and obesity and the independent variables: risk factors and resource availability. The analyses included parametric and nonparametric statistics.

Data Source: Center for Oral Research in Appalachia

The COHRA study was a longitudinal study that is examining 500 families three times over 7 years. "The overarching goal of COHRA is to delineate the covariation among genetic, behavioral, family, and community factors associated with orodental disease and tooth loss in rural and African American urban Appalachian families” (Marazita, Weyant, Resick, Crout, \& McNeil, 2006, p. 1) was formed in 2002 with funding from the National Institutes of Health (NIH/NIDCR RO1-DE014899) and is administered by the University of Pittsburgh School of Dental Medicine in partnership with the West Virginia University School of Dentistry. The COHRA study grant was from June 1, 2003 to May 31, 2009 with a 6 month extension until the end of November 2009. The data set that was utilized for analysis in this study included 1, 822 participants from WV.

Sample Design of the COHRA Study for the WV Subset

A representative sample of 500 families that reflect both socioeconomic and domicile distribution of Appalachia were being recruited from 2 contiguous counties in WV (Nicholas and 
Webster) and 2 western Pennsylvania counties (Washington and McKean) from a total population of about 13, 000 households based on census data (Marazita et al., 2006; Polk et al., 2008). The study sample is not intended to be representative of all of Appalachia, but it is an appropriate sample to understand the relation of health and environment variables in a population in $\mathrm{WV}$, which is the only state entirely located within Appalachia. The unit of recruitment for the COHRA study is the family, which is defined by "at least one adult primary caregiver and at least one biological offspring between 1-18 years of age in the same dwelling” (Marazita et al., 2006, p. 13). Children under 1 year of age were deferred from the COHRA study and all nonbiologically related children and adults in the same dwelling were asked to participate (Marazita et al., 2006). The nuclear family was interviewed every 2 years following baseline evaluations (Marazita et al., 2006).

Mode of COHRA Data Collection

The COHRA study design included protocols for recruiting participants and collecting data. Individuals who expressed interest in the COHRA study were initially screened through a telephone interview (Marazita et al., 2006). Once participants were deemed eligible, they were given an appointment at the assigned field site (Marazita et al., 2006). Each adult and participant was evaluated on a broad range of oral health variables utilizing age appropriate physical examination along with parent and self-report history and current status (Marazita et al., 2006). At the initial visit, all required consents were explained and signed, self-report questionnaires were completed, samples were collected, dental screening were performed and medical interviews and physical exams were completed (Marazita et al., 2006). 
Access to COHRA Data Files

A COHRA plan of analysis was completed and submitted to Dr. Daniel McNeil, Professor, Psychology, Eberly Professor of Public Service, Clinical Professor, Department of Dental Practice and Rural Health at WVU and a co-investigator on the COHRA study. The plan of analysis was reviewed by the study co-investigators and approved after revisions were made. A request for data was made by Dr. McNeil. De-indentified data files were delivered by email and CD-Rom.

\section{Human Subjects}

This study is a secondary data analysis and is covered by the COHRA study Institutional Review Board (IRB) approval from the West Virginia University, Office for Protection of Research Subjects. The COHRA subjects' names are not retained on questionnaires and identities are coded and kept confidential (Marazita et al., 2006). The COHRA data file was not obtained through intervention or interaction with participants in the COHRA study.

Proposed COHRA Sample for this Study

From the COHRA data file, children and adolescents ages 7-17 years of age at the time of first enrollment in the study were included in the secondary data analysis. The sample for this study needed to consist of a minimum of 150 or a maximum of 350 children and adolescents to obtain a power of .80 and a medium effect size for logistic regression at a .05 level of significance with multiple predictors (Hsieh, Bloch, \& Larsen, 1998).

Research Questions and Statistical Analysis

This study addressed three specific aims. The corresponding research questions, hypothesis and statistical analysis plan for each aim are presented below. Statistical analysis was 
conducted using SPSS. The 0.05 alpha level was set as the criterion for statistical significance for all analyses.

Aim I: To explore the prevalence of overweight and obesity in Appalachian children and adolescents.

Research Question I: What is the prevalence of overweight and obesity in this study population?

Statistical Analysis: Frequency distribution was utilized to examine the prevalence of overweight and obesity.

Aim II: To explore resources and risk factors associated with overweight and obesity across age groups (7-10, 11-13 and 14-17 year olds) in Appalachian children and adolescents.

Research Question II A: To what extent are resources associated with overweight and obesity across age groups?

Hypothesis II A.1: The distribution of each resource variable (family income, health insurance, family characteristics, parents’ education level and transportation) will be dependent on BMI categorization (underweight, normal weight, overweight and obese) across age groups. Specifically, each negative response for a resource variable will have a higher frequency in the overweight and obese BMI categories.

Hypothesis II A-2: There will be a relationship between each resource variable (family income, health insurance, family characteristics, parents’ education level and transportation) and overweight and obese BMI categories in each age group. Research Question II B: To what extent are risk factors associated with overweight and obesity across age groups? 
Hypothesis II B-1: The distribution of each risk factor variable (utilization of healthcare/preventive care, family medical history, and personal medical history) will be dependent on BMI categorization (underweight, normal weight, overweight and obese) across age groups. Specifically, each negative response for a risk factor variable will have a higher frequency in the overweight and obese BMI categories.

Hypothesis II B-2: There will be a relationship between each risk factor variable (utilization of healthcare/preventive care, family medical history, and personal medical history) and overweight and obese BMI categories in each age group.

Statistical Analysis: Since the outcome variables, overweight and obesity and independent variables are at the nominal level of measurement, a Pearson's chi square test was performed to analyze the hypotheses.

Aim III: To examine the extent to which resources and risk factors predict obesity-related health status in Appalachian children and adolescents.

Research Question III A: To what extent do resources best explain BMI in Appalachia across age groups?

Hypothesis IIIA: Family income, health insurance, family characteristics, parents’ education level and transportation will predict overweight and obese categories in each age group.

Research Question III-B: To what extent do risk factors best explain BMI in Appalachia across age groups?

Hypothesis III-B: Utilization of healthcare/preventive care, family medical history, and personal medical history will predict overweight and obese categories in each age group. 
Statistical Analysis: Since the outcome variables, overweight and obesity are at the nominal level of measurement, logistic regression was used to answer both hypotheses. Overweight and obesity were recoded into a dichotomous variable in order to perform binary logistic regression. The independent variables were checked for multicollinearity. A univariate analysis was conducted for each hypothesis to fit a logistic regression model for the predictors separately. A multivariate analysis was also used to examine the predictors. The predictors that are significant in the univariate analysis were entered into the multivariate analysis all at once.

\section{Variables}

Operational definitions for resource availability, risk factors, health status and demographic variables are discussed in this section. The variable codes are presented in the Appendix A, Table 13.

\section{Resource Availability}

1. Annual Income: Annual parental/family income is a categorical variable with 11 categories to choose from. The categories include: less than 10, 000 (1), 10, $000-14$, 999 (2), 15, 000 - 24, 999 (3), 25, 000 - 34, 999 (4), 35, 000 - 49, 999 (5), 50, 000 - 74, 999 (6), 75, 000 - 99, 999 (7), 100, 000 - 149, 999 (8), 150, 000 - 199, 999 (9), 200, 000 or more (10), or don't know (88). Annual income was recoded in each of the three age groups for analysis. The don't know responses were recoded as missing values. In the 710 year old group, the categories of annual income were collapsed to three categories that included: (1), <25, 000, (2), 25, 000-49, 999, and (3), $\geq 50,000$. In the 11-13 year old and 14-17 year old groups, the categories of annual income were collapsed to two 
categories so the assumptions for chi-square could be met. The two categories included: (1), < 25, 000 and (2), $>25,000$.

2. Insurance Type: Type of insurance is a categorical variable with seven categories to choose from. The response for each yes (1), no (0), or don't know (88). Each category of insurance type was recoded to two responses yes (1) or no (0). The don’t know responses were recoded as missing values. The categories are:

a. None

b. Private/through my employer. If respondent answers yes to this option, then they are asked to specify.

c. Medicare

d. Medical Assistance

e. Medicaid

f. CHIP- This option was not listed for 14-17 y/o respondents.

g. Vision Coverage- If respondent answers yes to this option, then they are asked to specify.

h. Other- If respondent answers yes to this option, then they are asked to specify. The insurance variables were only used if they met the assumptions of chi-square. Medicare, medical assistance, and none were not used in the analysis for all three age groups, because they didn’t meet the assumptions of chi-square.

3. Insurance Length of Time: Length of time having insurance is a categorical variable that has four categories. The categories are: for the last month (1); for more than 1 month, but less than 1 year (2); for more than 1 year (3); and don’t know (88). The categories included in this variable were collapsed in all 3 age groups for analysis. In the 7-10 year 
old group, this variable was recoded to include: for the last month (1); for more than 1 month, but less than 1 year (2); and for more than 1 year (3). In the 11-13 and 14-17 year old groups, this variable was recoded to two categories in order to meet the assumptions for chi-square. The two categories included: less than 1 year (1) and more than 1 year (2). The don’t responses were recoded as missing values.

4. Family Relationship: Family relationship was asked differently to each age group.

a. 7-10 y/o: two questions are used to assess family relationship.

i. Do both parents of your children live in the same household? Yes (1), No (2), and Don’t know (0). This family relationship variable was recoded to have two categories: yes (1) or no (2). The don't know responses were recoded as missing values.

ii. If you answered no to the above question, which parent is in the household? Mother (1) or Father (0)

iii. How are your children related to you? There are five categories for this variable: my biological child (1); my step child (2); my adopted child (3); other (4)-if yes then specify (relatoth); and don’t know (88).

b. 11-13 y/o: one question is used to assess family relationship.

i. Which older adults do you live with? There are seven categories with this variable: I live with both of my biological parents (1); I live with one parent, who is my biological parent (2), mother (1) or father (2); I live with two parents, and one is my step parent (3), mother (1) or father (2); I live with one parent, who is my step parent (4), mother (1) or father (2); I am adopted and live with my adoptive family (5); other (6), specify; and 
don’t know (88). The family relationship variable in the 11-13 year old group was collapsed from seven categories to two categories: I live with one or both biological parents (1) or I live with one or both step parents/I live with an adopted family/other (2). The don’t know responses were recoded as missing values.

c. 14-17 y/o: four questions are used to assess family relationship.

i. Do your parents or older adults live with you? Yes (1) if yes please specify; No (2); or Don’t Know (88).

ii. If you live with at least one parent, do you live with both of your parents in the same house? Yes (1), if yes, which parent do you normally live with: mother (1) or father (2); No (0); and Don’t Know (88). This family relationship variable was recoded to have two categories: yes (1) or no (2). The don't know responses were recoded as missing values.

iii. If you live with at least one parent, how are you related to them? This variable has seven categories that include: I live with both of my biological parents (1); I live with one parent, which is my biological parent (2); I live with both parents, and one is my step parent (3) -Who? Mother (1) or Father (2); I live with one parent who is my step parent (4); I am adopted (5); other (6), specify; and don’t know (88). This family relationship variable in the 14-17 year old group was collapsed from seven categories to two categories: I live with one or both biological parents (1) or I live with two parents, and one is my step parent/I live with one parent, 
who is my step parent/I am adopted/other (2). The don't know responses were recoded as missing values.

iv. If you do not live with your parents or other older adults, which other people your age do you live with? This variable has six categories that include: I live with one or more roommates (1); I live with my boy/girl friend (2); I live with my spouse (3); I do not live with any other adults (4); other (5), specify; and don’t know (88).

Family relationship variables were only used in the analysis if they met the assumptions of chi-square.

5. Transportation: Transportation was assessed with three questions in adults and in adolescents 14-17 y/o only?

a. How many vehicles do you own or lease? This variable is self-reported as a numerical value. Respondents are asked to enter 88 if they don't know. This variable was not used in the analysis.

b. What modes of transportation do you use? This variable is a categorical variable with nine responses. The respondent can answer yes (1), no (0), or don’t know (88) to each of the nine responses. The three answers for each of the nine responses for this transportation variable were recoded to two answers: yes (1) or no (0). The don’t know responses were recoded as missing values. The nine responses are: I drive myself in my own car/truck/vehicle; I drive myself in a family’s member’s car/truck/vehicle; I drive myself in a non family member’s car/truck/vehicle; a family member drives; a friend drives; a social service agency drives; I walk or bike; I use public transportation/bus/van; and other, specify. 
c. How do you travel to medical and dental appointments? This variable is a categorical variable with 10 responses. The respondent can answer yes (1), no (0), or don't know (88) to each of the 10 responses. The three answers for each of the 10 responses for this transportation variable were recoded to two answers: yes (1) or no (0). The don't know responses were recoded as missing values. The 10 responses are: I drive myself in my own car/truck/vehicle; I drive myself in a family member’s car/truck/vehicle; I drive myself in a non-family member’s car/truck/vehicle; a family member drives; a friend drives; a social service agency drives; I walk or bike; I use public transportation/bus/van; other, specify; and I have never gone to appointments.

Transportation variables were only used in this study if they met the assumptions of chi-square.

6. Education: Three questions were used to assess education level in adults.

a. How many years of education have you had altogether (12 yrs = High School Graduate)? Total years of education are reported as a numeric value. This variable was not used in the analysis.

b. What is the highest grade level you have completed? (K-12) This variable was not used in the analysis.

c. What is your highest educational degree or certificate? This variable is a categorical variable with seven responses. The seven responses are: none (1); high school diploma (2); technical school/associate degree (3); some college, no degree (4); undergraduate degree (5); graduate degree (6); or don’t know (88). Highest educational degree or certificate was recoded in each of the three age 
groups for analysis. In the 7-10 and 11-13 year old groups, the categories of highest educational degree or certificate were collapsed to four categories that included: none (1); high school diploma (2); completed college (3); and some college, no degree (4). In the 14-17 year old group, the categories of highest educational degree or certificate were collapsed to four categories that included: none (1); high school diploma (2); some college, no degree (3); and obtained a college degree (4). The don’t know responses were recoded as missing values. This was the only education variable utilized in the analysis.

\section{Risk Factors}

1. Frequency of Seeing a Health Care Provider: Frequency of seeing a health care provider is a categorical variable with eight responses. Responses for this variable include: more than once a month (1); about once a month (2); about twice a year (3); about once a year (4); less than once a year (5); as needed or whenever needed-no regular schedule (6); never (7); or don’t know (88). Frequency of seeing a health care provider was recoded in each of the three age groups for analysis. In the 7-10 year old group, the categories of frequency of seeing a health care provider were collapsed to four categories that included: more than once a month/about once a month (1); about twice a year (2); about once a year (3); and less than once a year/as needed (4). In the 11-13 year old group, the categories were collapsed to four categories that included: more than once a month/about once a month (1); about twice a year (2); about once a year (3); and whenever needed, no regular schedule (4). In the 14-17 year old group, the categories were collapsed to four categories that included: at least once a month (1); about twice a year (2); about once a year (3); and less than once a year/whenever needed, no regular 
schedule (4). All don't know responses for the three age groups were recoded as missing values.

2. Vaccine Status: Vaccine is a categorical variable with three responses: yes (1), no (0), or don't know (88). The vaccine variable was recoded to have two responses in all three age groups: yes (1) or no (0). The don’t know responses were recoded as missing values.

3. Oral Health Care Utilization: Oral health care utilization was asked differently to each age group

a. 7-10 y/o: How long has it been since your child last saw a dentist? Responses include: < 6 months (1); 6 months $<1$ year (2); 1 year $<2$ years (3); 2 years $<3$ years (4); > 3 years (5); never (6); or don’t know (88). The oral health care utilization variable categories were collapsed to three categories that included: $<6$ months (1); 6 months $<1$ year (2); and $\geq 1$ year (3).

b. 11-13 y/o: About how long has it been since you last visited a dentist or hygienist? Responses include: 6 months or less (1); more than 6 months, but not more than 1 year (2); more than 1 year, but not more than 2 years ago (3); more than 2 years, but not more than 3 years ago (4); more than 3 years, but not more than 5 years ago (5); more than 5 years ago (6); never (7); or don’t know (88). The oral health care utilization variable categories were collapsed to three categories that included: 6 months or less (1); > 6 months but not more than 1 year (2); and > 1 year (3).

c. 14-17 y/o: About how long has it been since you last visited a dentist? Include all types of dentist, such as orthodontists, oral surgeons, all other dental 
specialists, as well as dental hygienists. Responses include: 6 months or less (1); more than 6 months, but not more than 1 year (2); more than 1 year, but not more than 2 years ago (3); more than 2 years, but not more than 3 years ago (4); more than 3 years, but not more than 5 years ago (5); more than 5 years ago (6); never (7); or don’t know (88). The oral health care utilization variable categories were collapsed to three categories that included: 6 months or less (1); > 6 months but not more than 1 year (2); and > 1 year or never (3).

The don't know responses in all three age groups were recoded as missing values.

4. Medical History-Adult: Have you ever been diagnosed with any of the following? The three diagnoses that were analyzed in this study are high blood pressure, diabetes, and heart disease.

a. High blood pressure responses include: yes (1), if yes the respondent reports onset in years; no (0); or don’t know (88).

b. Diabetes responses include: yes (1), if yes the respondent reports onset in years; no (0); or don’t know (88).

c. Heart disease responses include: yes (1), if yes the respondent reports onset in years; no (0); or don't know (88).

High blood pressure, diabetes, and heart disease were combined to form one variable named CVD risk factors. If an adult respondent had a yes response to one or more of the three medical history variables, the CVD risk factor response was yes (1). If an adult respondent has a no response to all three medical history variables, the CVD risk factor response was no (0). The don’t know responses were recoded as missing values. 
5. Medical History-11-13y/o and 14-17 y/o: Have you ever been diagnosed with any of the following? The three diagnoses that were analyzed in this study are high blood pressure, diabetes, and heart disease.

a. High blood pressure responses include: yes (1), if yes the respondent reports onset in years; no (0); or don’t know (88).

b. Diabetes responses include: yes (1), if yes the respondent reports onset in years; no (0); or don’t know (88).

c. Heart disease responses include: yes (1), if yes the respondent reports onset in years; no (0); or don’t know (88).

All three of these variables were recoded to include two responses: yes (1) or no (2). The don't know responses were recoded as missing values. These variables did not meet the assumptions for chi-square.

6. Medical History-7-10 y/o: Have you ever been diagnosed with any of the following? Only diabetes and heart disease were assessed for this age group.

a. Diabetes responses include: yes (1), if yes the respondent reports onset in years and onset is reported as months (1) or years (2); no (0); or don't know (88).

b. Heart disease responses include: yes (1), if yes the respondent reports onset in years and onset is reported as months (1) or years (2); no (0); or don’t know (88).

These two variables were recoded to include two responses: yes (1) or no (2). The don't know responses were recoded as missing values. These variables did not meet the assumptions for chi-square.

7. Mental Health-11-13 y/o and 14-17 y/o: Have you ever experienced the following? The two experiences that were analyzed in this study are anxiety and depression. 
a. Anxiety responses include: yes (1), if yes the respondent reports if this was a diagnosis [yes (1) or no (0)]; no (0); or don’t know (88). The anxiety variable was recoded to include two responses: yes (1) or no (0). The don't know responses were recoded as missing values. This variable did not meet the assumptions of chi-square in the 11-13 y/o age group.

b. Depression responses include: yes (1), if yes the respondent reports if this was a diagnosis [yes (1) or no (0)]; no (0); or don’t know (88). The depression variable was recoded to include two responses: yes (1) or no (0). The don't know responses were recoded as missing values.

8. Mental Health-7-10 y/o: Have any of your children ever experienced anxiety or a phobia? Depression was not assessed in this age group.

a. Anxiety responses include: yes (1), if yes the respondent need to specify which one; no (0); or don't know (88). The anxiety variable was recoded to include two responses: yes (1) or no (0). There were not any don’t know responses to recode as missing values.

\section{Overweight and Obesity}

Height and weight were measured for all 3 age groups (7-10 y/o, 11-13 y/o, and 14-17 y/o) in the COHRA study. BMI was calculated by using the standard formula, weight (in kilograms) divided by height (in meters) squared $\left(\mathrm{kg} / \mathrm{m}^{2}\right)$, and a BMI percentile for gender and age was determined. Categories including underweight (less than the $5^{\text {th }}$ percentile), normal weight ( $5^{\text {th }}$ percentile to less than the $85^{\text {th }}$ percentile), overweight ( $85^{\text {th }}$ percentile to less than the $95^{\text {th }}$ percentile), and obese (equal to or greater than the $95^{\text {th }}$ percentile) were developed. The researcher utilized the CDC BMI for age percentiles chart for gender and age to determine BMI 
ranges for each weight category for each age and gender. The BMI category variables for each age and gender were combined to form an overall BMI category variable for each of the 3 age groups. In order to meet the assumptions of chi-square, the BMI category variable was collapsed to make a dichotomous variable for analysis: not overweight (1) and overweight (2). Demographic Variables

1. Age: Age was calculated by using the birth date and reported as chronological age in years.

2. Gender: Gender was a self-reported variable and is expressed as a categorical variable of girl (0) and boy (1) in 7-10 y/o and male (1) and female (2) in 11-13 y/o and 14-17 y/o.

3. Race/Ethnicity: Race/Ethnicity was a self-reported variable and is expressed as a categorical variable with eight possible responses. The categories include: White (1), African American (2), Hawaiian/Pacific Islander (3), Hispanic (4), Native American (5), Asian (6), Other (7), and don’t know (88). 


\section{CHAPTER IV}

\section{RESULTS}

This study described the extent to which resource availability (family income, insurance, family characteristics, parents' education, and transportation) and risk factors (utilization of health care/preventive care, family medical history, and participant medical history) impact overweight and obesity in a vulnerable population. This study also described the frequency of overweight and obesity in a sample of Appalachian children and adolescents. Results of this secondary data analysis are herein presented. Descriptive results are presented first, followed by findings related to the study aims.

\section{Obtaining the Study Sample}

The sample for this secondary data analysis was obtained from the COHRA study. The entire COHRA sample included 1, 822 participants, ages 1-93 years old, from WV. The sample used for this secondary data analysis included WV children and adolescents ages 7-17 years of age at the time of first enrollment in the study $(n=509)$.

\section{Sample Description}

Sociodemographic descriptors of the sample are presented in Tables 1, 2, 3, and 4. In the 7 to 10 year old group $(n=223), 48.4 \%$ were female and $51.6 \%$ were male. Gender was almost equally distributed. The mean age of this group was 8.5 years $(S D=1.15)$ and $27.4 \%$ were 7 year olds, $22 \%$ were 8 year olds, $24.2 \%$ were 9 year olds, and 26.5\% were 10 year olds.

In the 11 to 13 year old group $(n=162), 56.8 \%$ were female and $43.2 \%$ were male. The mean age of this group was 12.03 years $(S D=0.83)$ and $32.7 \%$ were 11 year olds, $31.5 \%$ were 12 year olds, and 35.8\% were 13 year olds. Age and gender were not statistically significant. 
In the 14 to 17 year old group $(n=124), 51.6 \%$ were female and $48.4 \%$ were male. The distribution of gender is almost equal in this age group. The mean age of this group was 15.13 years $(S D=1.04)$ and $33.1 \%$ were 14 year olds, 34.7\% were 15 year olds, $16.9 \%$ were 16 year olds, and $14.5 \%$ were 17 year olds. Age was statistically significant, $X^{2}(4, \mathrm{n}=124)=16.78, p<$ 0.01, and was not equally distributed in this group.

In all age groups race was statistically significant, with the majority of respondents being Caucasian. In the 7 to 10 year old group, the distribution of race was: $96.4 \%$ white, $2.2 \%$ African Americans and 0.4\% Hispanics, $X^{2}(3, \mathrm{n}=222)=611.37, p<0.01$. In the 11 to 13 year old group, the distribution of race was: 96.3\% white, 1.2\% African Americans, and 1.2\% Hispanics, $X^{2}(3, \mathrm{n}=161)=443.85, p<0.01$. Lastly, in the 14 to 17 year old group, the distribution of race was: $98.4 \%$ white and $0.8 \%$ Hispanic, $X^{2}(1, \mathrm{n}=123)=119.03, p<0.01$.

The adult demographics included in this chapter are for WV adults who were designated as the proband in the COHRA study. The proband was the individual completing the screening interview (Polk et al., 2008). The adult sample $(n=464)$ consisted of $94.6 \%$ females and 5.4\% males. Respondents ranged in age from 18 to 66 years with a mean age of 32.79 years $(\mathrm{SD}=7.92)$. The majority of the adult sample was married $(61.6 \%)$. Approximately $7 \%$ of the adult respondents lived with a domestic partner, 5.8\% were separated, $12.9 \%$ were divorced, 1.5\% was widowed, and 9.1\% have never been married. When examining highest level of education achieved, $15.1 \%$ had not received a diploma or degree, $47 \%$ were high school graduates, just over 10\% had received a Technical school or Associate degree, $13.1 \%$ had attended college but received no degree, $8.8 \%$ had received an undergraduate degree, and 3\% received a graduate degree. Approximately 26\% of the adult respondents were employed fulltime and $13.1 \%$ were employed part-time compared to $40.1 \%$ who were unemployed. 
Approximately $9 \%$ of adult participants were disabled, $0.2 \%$ was retired, and less than $1 \%$ had never been employed. 
Table 1

Sociodemographic Characteristics of the 7 to 10 Year Old Sample

\begin{tabular}{|c|c|c|c|}
\hline Variable & Category & $\mathrm{n}(\%)$ & $\begin{array}{c}\text { Chi-square, } \\
\text { p value }\end{array}$ \\
\hline Age & 7 & $61(27.4)$ & \\
\hline Mean age 8.5 years & 8 & $49(22.0)$ & \\
\hline \multirow[t]{2}{*}{$(\mathrm{SD}=1.15)$} & 9 & $54(24.2)$ & \\
\hline & 10 & $59(26.5)$ & $1.56, p=0.67$ \\
\hline \multirow[t]{2}{*}{ Gender } & Female & $108(48.4)$ & \\
\hline & Male & $115(51.6)$ & $0.22, p=0.64$ \\
\hline \multirow[t]{4}{*}{ Race } & White & 215 (96.4) & \\
\hline & African American & $5(2.2)$ & \\
\hline & Hispanic & $1(0.4)$ & \\
\hline & Other & $1(0.4)$ & 611.37, $\mathrm{p}<0.01$ \\
\hline
\end{tabular}

Note. $\mathrm{N}=223$ 
Table 2

Sociodemographic Characteristics of the 11 to 13 Year Old Sample

\begin{tabular}{|c|c|c|c|}
\hline Variable & Category & n (\%) & $\begin{array}{c}\text { Chi-square, } \\
\text { p value }\end{array}$ \\
\hline$\overline{\text { Age }}$ & 11 & $53(32.7)$ & \\
\hline Mean age 12.03 years & 12 & $51(31.5)$ & \\
\hline$(\mathrm{SD}=0.83)$ & 13 & $58(35.8)$ & $0.48, p=0.79$ \\
\hline \multirow[t]{2}{*}{ Gender } & Female & 92 (56.8) & \\
\hline & Male & $70(43.2)$ & $2.99, p=0.08$ \\
\hline \multirow[t]{4}{*}{ Race } & White & $156(96.3)$ & \\
\hline & African American & $2(1.2)$ & \\
\hline & Hispanic & $2(1.2)$ & \\
\hline & Other & $1(0.6)$ & 443.85, $\mathrm{p}<0.01$ \\
\hline
\end{tabular}

Note. $\mathrm{N}=162$ 
Table 3

Sociodemographic Characteristics of the 14 to 17 Year Old Sample

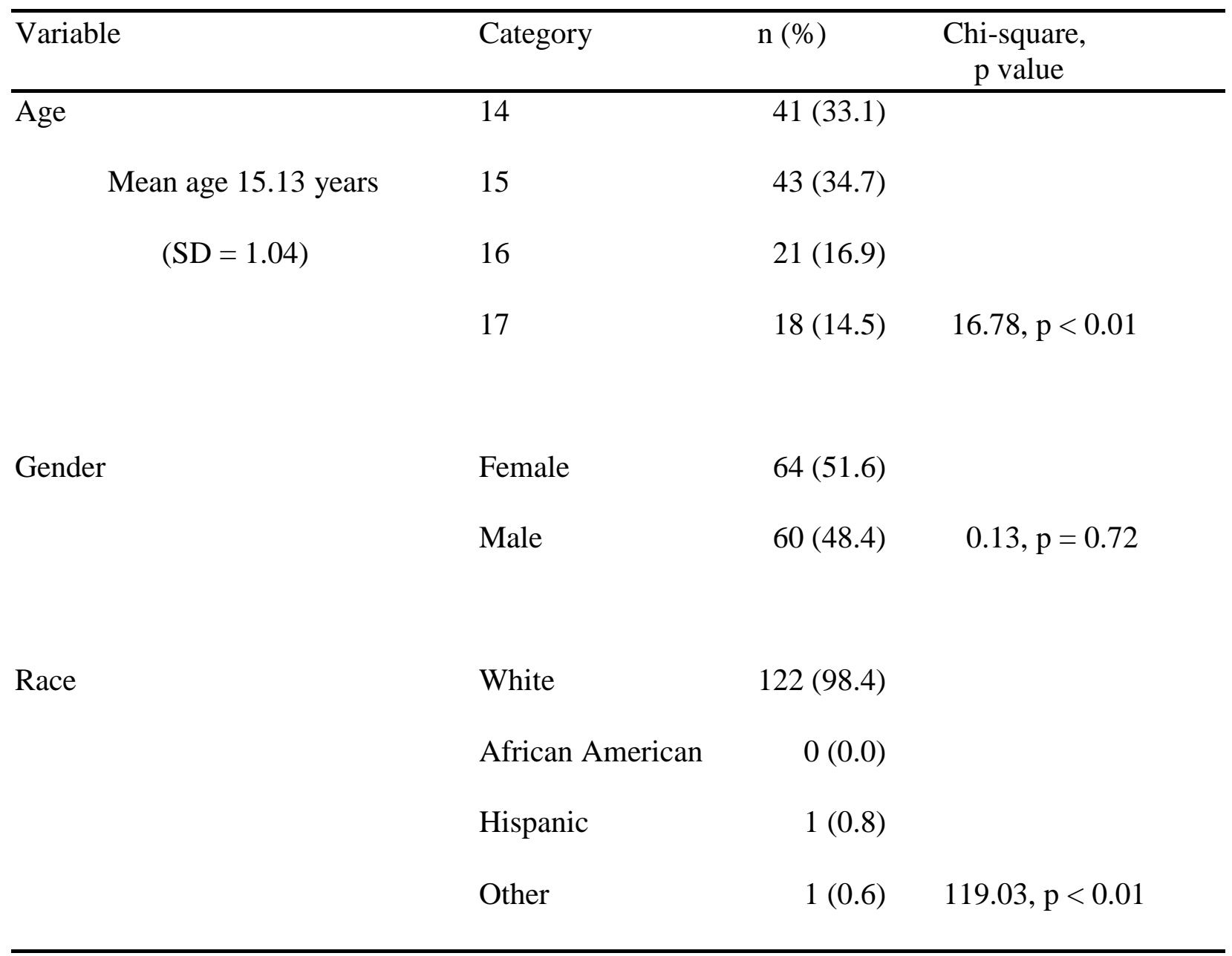

Note. $\mathrm{N}=124$ 
Table 4

Sociodemographic Characteristics of the Adult Sample

\begin{tabular}{|c|c|c|}
\hline Variable & Category & n (\%) \\
\hline \multirow[t]{2}{*}{ Gender } & Female & 439 (94.6) \\
\hline & Male & $25(5.4)$ \\
\hline \multirow[t]{3}{*}{ Race } & White & 458 (98.7) \\
\hline & African American & $1(0.2)$ \\
\hline & Hispanic & $1(0.2)$ \\
\hline \multirow[t]{6}{*}{ Marital Status } & Never married & $42(9.1)$ \\
\hline & Domestic partner & $34(7.3)$ \\
\hline & Married & $286(61.6)$ \\
\hline & Separated & $27(5.8)$ \\
\hline & Divorced & 60 (12.9) \\
\hline & Widowed & $7(1.5)$ \\
\hline \multirow[t]{7}{*}{ Education } & None & $70(15.1)$ \\
\hline & High school diploma & $218(47.0)$ \\
\hline & Technical school/ & \\
\hline & Associate degree & $48(10.3)$ \\
\hline & Some college, no degree & $61(13.1)$ \\
\hline & Undergraduate degree & $41(8.8)$ \\
\hline & Graduate degree & $14(3.0)$ \\
\hline \multirow[t]{7}{*}{ Employment } & Full time employment & 120 (25.9) \\
\hline & Part time employment & $61(13.1)$ \\
\hline & Disabled & $42(9.1)$ \\
\hline & Unemployed & $186(40.1)$ \\
\hline & Never employed & $3(0.6)$ \\
\hline & Other & $36(7.8)$ \\
\hline & Retired & $1(0.2)$ \\
\hline
\end{tabular}

Note. $\mathrm{N}=464$ 


\begin{abstract}
Aim I
Aim one of this study was to explore the prevalence of overweight and obesity in Appalachian children and adolescents. A frequency distribution was utilized to answer the following research question, what is the prevalence of overweight and obesity in this study population? In all three age groups BMI category was statistically significant and was not equally distributed. Prevalence of overweight and obesity in Appalachian children and adolescents is presented in Table 5. In the 7 to 10 year old group $(n=223), 13.5 \%$ were overweight and $26 \%$ were obese. In the 11 to 13 year old group $(n=162), 16.7 \%$ were overweight and 34\% were obese. Lastly, in the 14 to 17 year old group $(n=124), 16.9 \%$ were overweight and $26.6 \%$ were obese. In table 5 , there are low frequency counts in some of the BMI categories among the three age groups. The levels of the BMI category variable were collapsed to two categories, not overweight and overweight, for analysis in aim two and aim three.
\end{abstract}


Table 5

Prevalence of Overweight and Obesity among Appalachian Children and Adolescents

\begin{tabular}{|c|c|c|c|}
\hline Age Group & BMI Category & n (\%) & $\begin{array}{c}\text { Chi-square, } \\
\text { p value }\end{array}$ \\
\hline \multirow[t]{4}{*}{7 to 10 year olds } & Underweight & $4(1.8)$ & \\
\hline & Normal weight & 117 (52.5) & \\
\hline & Overweight & 30 (13.5) & \\
\hline & Obese & $58(26.0)$ & $134.90, \mathrm{p}<0.01$ \\
\hline \multirow[t]{4}{*}{11 to 13 year olds } & Underweight & $21(13.0)$ & \\
\hline & Normal weight & 49 (30.2) & \\
\hline & Overweight & 27 (16.7) & \\
\hline & Obese & $55(34.0)$ & 21.58, $\mathrm{p}<0.01$ \\
\hline \multirow[t]{4}{*}{14 to 17 year olds } & Underweight & $3(2.4)$ & \\
\hline & Normal weight & $57(46.0)$ & \\
\hline & Overweight & 21 (16.9) & \\
\hline & Obesity & $33(26.6)$ & $54.00, \mathrm{p}<0.01$ \\
\hline
\end{tabular}

Note. $\mathrm{N}=509$ 


\section{Aim II}

Aim two of this study was to explore resources and risk factors associated with overweight and obesity across age groups (7-10, 11-13 and 14-17 year olds) in Appalachian children and adolescents. A Chi-square test for independence was performed to analyze the research questions and hypotheses for aim two.

The relationship between resource variables (family income, health insurance, family characteristics, parents’ education level and transportation) and BMI categories was investigated using a Chi-square test for independence in each of the three age groups (7-10, 11-13 and 14-17 year olds). Results for each of the three age groups are presented in tables 6, 8, and 10. Results for additional transportation variables for each of the three age groups are presented in Appendix B, C, and D. No significant associations were found between resource variables and overweight and BMI category.

In each of the three age groups, just over half of the sample had a family income of less than \$25, 000. According to the U.S. Department of Health and Human Services (USDHHS), the 2009 Poverty Guidelines for a family of four was \$22,050 (U.S.Department of Health and Human Services, 2010). At least half or more of the sample in the 7-10 year old (68.3\%) and 11-13 year old (50\%) age groups had public insurance (Medicaid or CHIP). In the 14-17 year old group, $42.1 \%$ of the respondents reported having Medicaid as their insurance. Looking at parents' education level, a high percentage of parents in each of the 3 age groups had completed high school or above including: $81.3 \%$ in the $7-10$ year old group, $88.2 \%$ in the $11-13$ year old group, and $84.7 \%$ in the $14-17$ year old group. Over $80 \%$ of families in each of the three age groups drove themselves in their own vehicles to medical and dental appointments. In the 7-10 year old age group, approximately $63 \%$ of the sample lived with both parents in the same 
household. The majority of the respondents in the 11-13 year old (84.4\%) and 14-17 year old (71.3\%) reported living with one or both biological parents.

The relationship between risk variables (utilization of healthcare/preventive care, family medical history, and personal medical history) and BMI categories was also investigated using a Chi-square test for independence in each of the three age groups (7-10, 11-13 and 14-17 year olds). Results for each of the three age groups are presented in tables 7, 9, and 11. There was a significant association between frequency of visiting a dentist and BMI categories, $X^{2}(2, \mathrm{n}=$ $205)=8.46, p=0.02$, with a higher frequency of visiting the dentist associated with not being overweight when compared to children who visited the dentist less frequently. No significant relationships were found among the other risk variables and BMI category.

The majority of respondents in all three age groups went to the doctor whenever needed including: $39.6 \%$ of $7-10$ year olds, $47.8 \%$ of $11-13$ year olds, and $49.1 \%$ of $14-17$ year olds. Over half of the respondents in the 11-13 (66.9\%) and 14-17 (63.4\%) year old age groups visited the dentist every 6 months. A very high percentage, over 85\%, of respondents in all three age groups reported having their vaccines up to date. A very small percentage $(<4.5 \%)$ of respondents in all age groups reported having a positive personal medical history of diabetes, heart disease, and hypertension. A slightly higher percentage of respondents in all groups reported having a positive personal medical history of depression and anxiety, with the highest prevalence of anxiety being reported in the 7 to 10 year old group (15\%) and the highest prevalence of depression being reported in the 14 to 17 year old group (20\%). Approximately $20-25 \%$ of family respondents in all three age groups reported having a CVD risk factor (diabetes, heart disease, and/or hypertension). 
Table 6

Chi-square Results for Resource Variables in the 7 to 10 Year Old Group






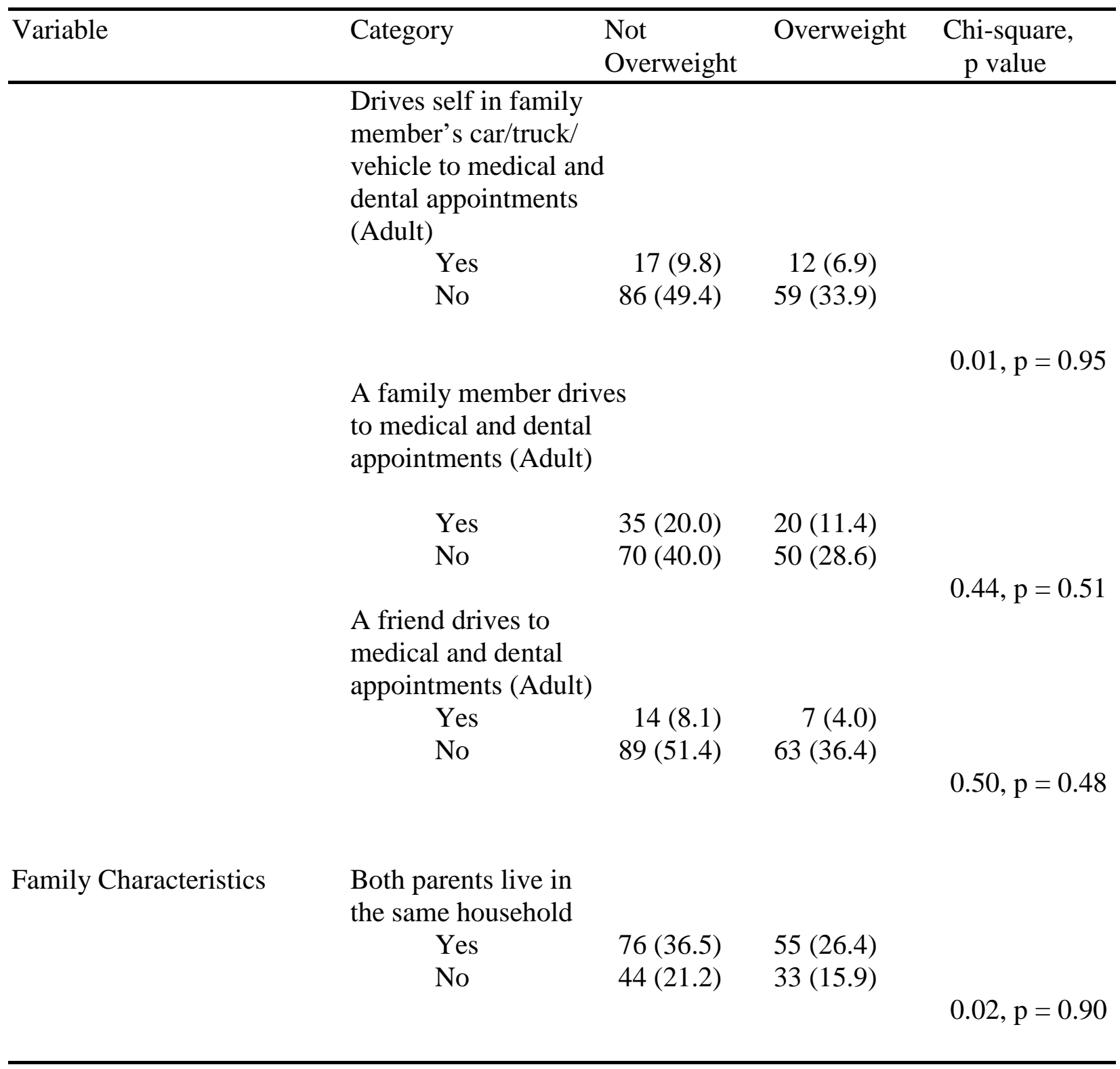

Note. n (\%) 
Table 7

Chi-square Results for Risk Variables in the 7 to 10 Year Old Group

\begin{tabular}{|c|c|c|c|c|}
\hline Variable & Category & $\begin{array}{l}\text { Not } \\
\text { Overweight }\end{array}$ & Overweight & $\begin{array}{l}\text { Chi-square, } \\
\text { p value }\end{array}$ \\
\hline \multicolumn{5}{|l|}{$\begin{array}{l}\text { Utilization of Health Care/ } \\
\text { Preventive Care }\end{array}$} \\
\hline $\begin{array}{l}\text { Frequency of } \\
\text { Visiting a Doctor }\end{array}$ & $\begin{array}{l}\text { More than once a } \\
\text { month/about once a } \\
\text { month } \\
\text { About twice a year } \\
\text { About once a year } \\
\text { Less than once a } \\
\text { year/as needed }\end{array}$ & $\begin{array}{r}18(8.7) \\
27(13.0) \\
31(15.0) \\
43(20.8)\end{array}$ & $\begin{array}{r}12(5.8) \\
14(6.8) \\
23(11.1) \\
39(18.8)\end{array}$ & \\
\hline $\begin{array}{l}\text { Frequency of } \\
\text { Visiting a Dentist }\end{array}$ & $\begin{array}{l}<6 \text { months } \\
6 \text { months }<1 \text { year } \\
=\text { or }>1 \text { year }\end{array}$ & $\begin{array}{r}87(42.4) \\
20(9.8) \\
14(6.8)\end{array}$ & $\begin{array}{r}46(22.4) \\
16(7.8) \\
22(10.7)\end{array}$ & $2.11, p=0.55$ \\
\hline Current Vaccines & $\begin{array}{l}\text { Yes } \\
\text { No }\end{array}$ & $\begin{array}{r}107(51.7) \\
12(5.8)\end{array}$ & $\begin{array}{r}73(35.3) \\
15(7.2)\end{array}$ & $\begin{array}{l}8.46, p=0.02 \\
2.16, p=0.14\end{array}$ \\
\hline \multicolumn{5}{|l|}{ Personal Medical History } \\
\hline Diabetes & $\begin{array}{l}\text { Yes } \\
\text { No }\end{array}$ & $\begin{array}{r}0(0.0) \\
121(57.9)\end{array}$ & $\begin{array}{r}1(0.5) \\
87(41.6)\end{array}$ & \\
\hline Heart Disease & $\begin{array}{l}\text { Yes } \\
\text { No }\end{array}$ & $\begin{array}{r}3(1.4) \\
118(56.5)\end{array}$ & $\begin{array}{r}2(1.0) \\
86(41.1)\end{array}$ & \\
\hline Anxiety & $\begin{array}{l}\text { Yes } \\
\text { No }\end{array}$ & $\begin{array}{r}14(6.7) \\
107(51.2)\end{array}$ & $\begin{array}{r}11(5.3) \\
77(36.8)\end{array}$ & $0.04, p=0.84$ \\
\hline
\end{tabular}

Family Medical History

$\begin{array}{llcc}\text { CVD Risk Factors } & \text { Yes } & 31(15.6) & 18(9.0) \\ & \text { No } & 85(42.7) & 65(32.7)\end{array}$

$0.66, p=0.42$

Note. n (\%) 
Table 8

Chi-square Results for Resource Variables in the 11 to 13 Year Old Group

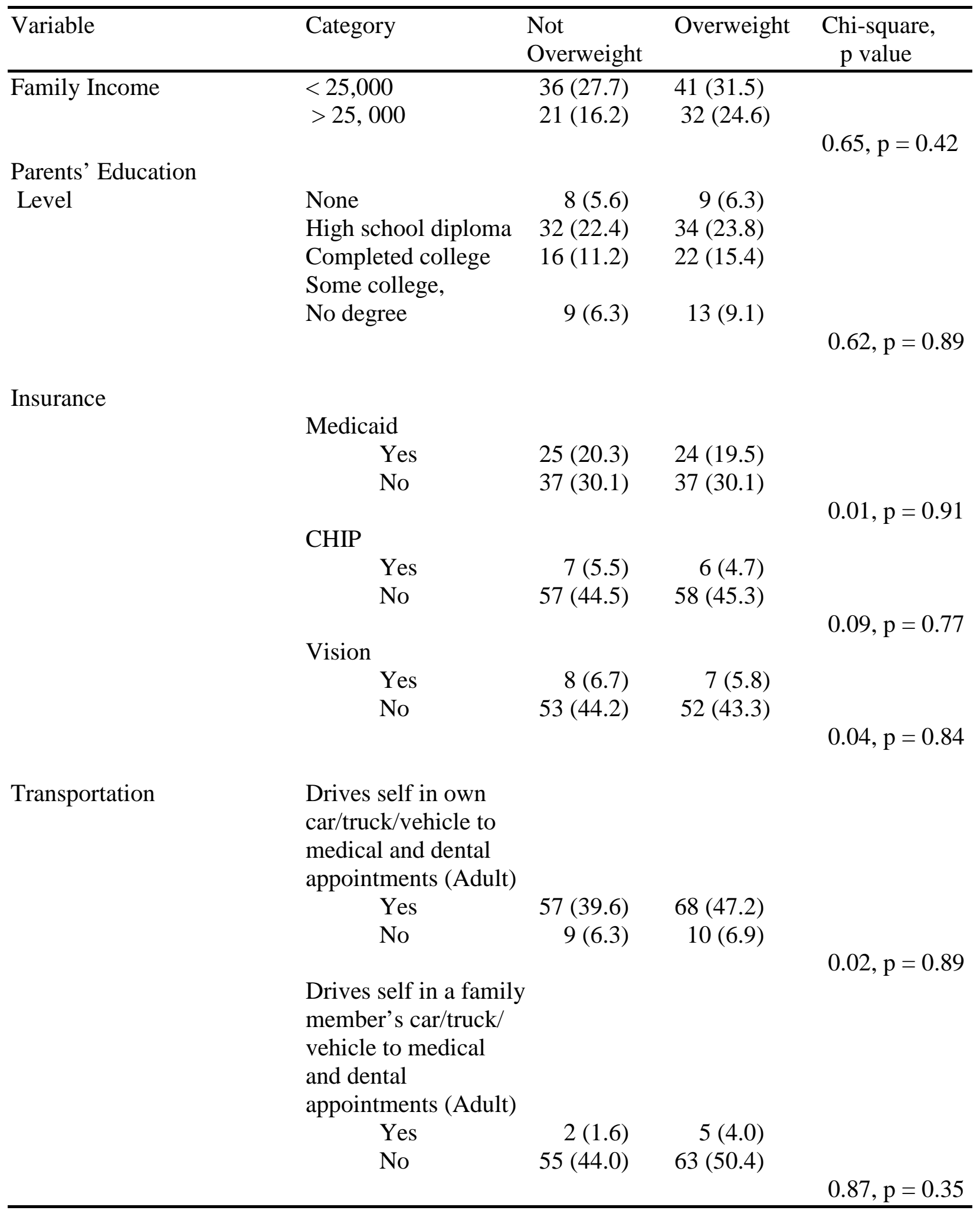




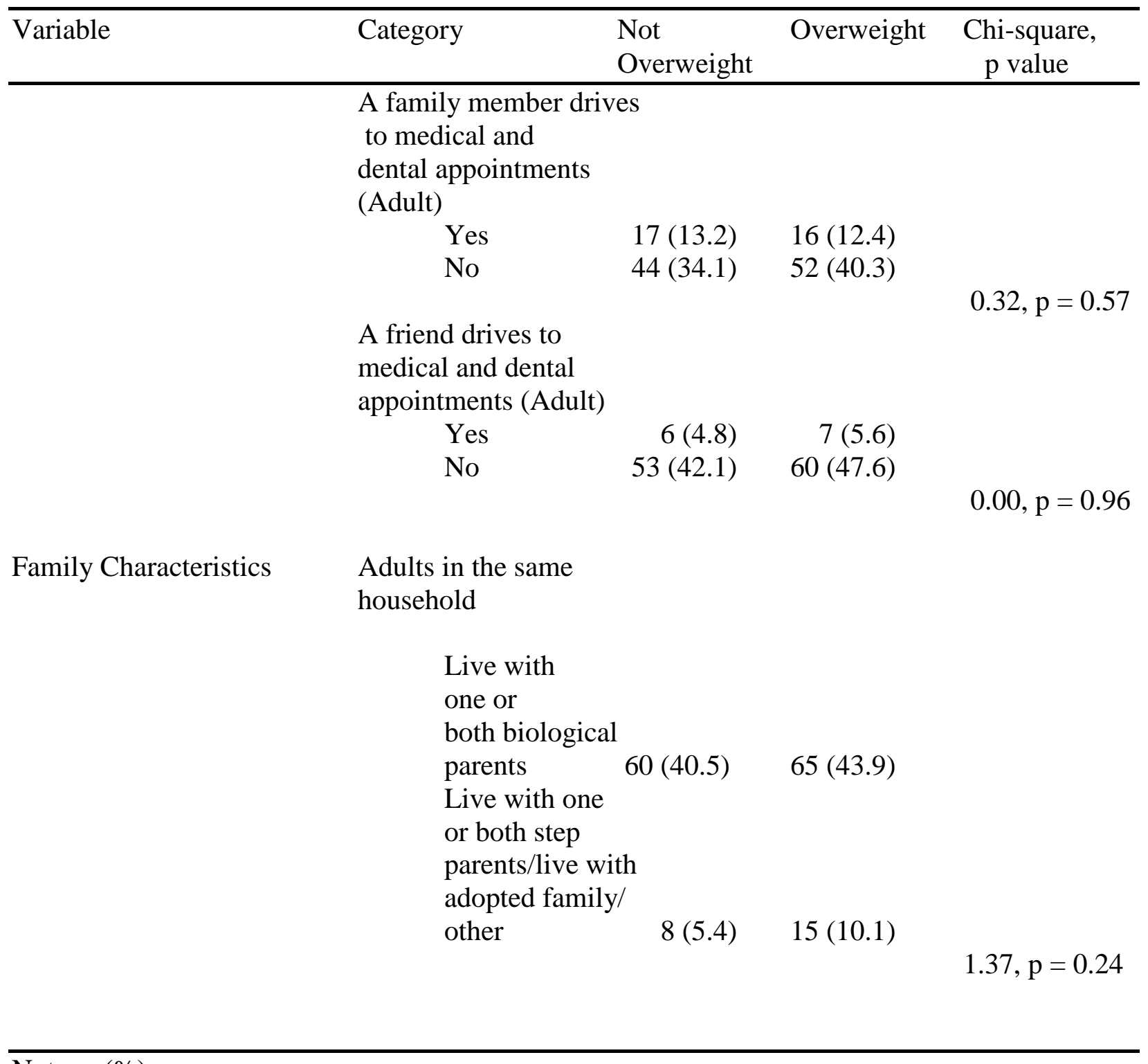

Note. n (\%) 
Table 9

Chi-square Results for Risk Variables in the 11 to 13 Year Old Group

\begin{tabular}{|c|c|c|c|c|}
\hline Variable & Category & $\begin{array}{l}\text { Not } \\
\text { Overweight }\end{array}$ & Overweight & $\begin{array}{c}\text { Chi-square, } \\
\text { p value }\end{array}$ \\
\hline \multicolumn{5}{|l|}{$\begin{array}{l}\text { Utilization of Health Care/ } \\
\text { Preventive Care }\end{array}$} \\
\hline $\begin{array}{l}\text { Frequency of } \\
\text { Visiting a Dentist }\end{array}$ & $\begin{array}{l}\text { More than once a } \\
\text { month/about once a } \\
\text { month } \\
\text { About twice a year } \\
\text { About once a year } \\
\text { Whenever needed, } \\
\text { no regular schedule } \\
6 \text { months or less } \\
>6 \text { months but not } \\
\text { more than } 1 \text { year } \\
>1 \text { year }\end{array}$ & $\begin{array}{r}13(9.6) \\
6(4.4) \\
10(7.4) \\
36(26.5) \\
43(30.3) \\
15(10.6) \\
8(5.6)\end{array}$ & $\begin{array}{r}21(15.4) \\
12(8.8) \\
9(6.6) \\
29(21.3) \\
52(36.6) \\
17(12.0) \\
7(4.9)\end{array}$ & 4.43, $p=0.22$ \\
\hline Current Vaccines & $\begin{array}{l}\text { Yes } \\
\text { No }\end{array}$ & $\begin{array}{r}59(48.4) \\
1(0.8)\end{array}$ & $\begin{array}{r}57(46.7) \\
5(4.1)\end{array}$ & \\
\hline \multicolumn{5}{|l|}{ Personal Medical History } \\
\hline Diabetes & $\begin{array}{l}\text { Yes } \\
\text { No }\end{array}$ & $\begin{array}{r}1(0.7) \\
64(43.8)\end{array}$ & $\begin{array}{r}0(0.0) \\
81(55.5)\end{array}$ & \\
\hline Heart Disease & $\begin{array}{l}\text { Yes } \\
\text { No }\end{array}$ & $\begin{array}{r}0(0.0) \\
67(45.3)\end{array}$ & $\begin{array}{r}0(0.0) \\
81(54.7)\end{array}$ & \\
\hline High Blood Pressure & $\begin{array}{l}\text { Yes } \\
\text { No }\end{array}$ & $\begin{array}{r}1(0.7) \\
64(43.5)\end{array}$ & $\begin{array}{r}1(0.7) \\
81(55.1)\end{array}$ & \\
\hline Depression & $\begin{array}{l}\text { Yes } \\
\text { No }\end{array}$ & $\begin{array}{r}5(3.3) \\
64(42.7)\end{array}$ & $\begin{array}{r}8(5.3) \\
73(48.7)\end{array}$ & \\
\hline Anxiety & $\begin{array}{l}\text { Yes } \\
\text { No }\end{array}$ & $\begin{array}{r}5(3.4) \\
64(43.2)\end{array}$ & $\begin{array}{r}4(2.7) \\
75(50.7)\end{array}$ & $0.33, p=0.57$ \\
\hline
\end{tabular}




\begin{tabular}{lllll}
\hline Variable & Category & $\begin{array}{l}\text { Not } \\
\text { Overweight }\end{array}$ & Overweight & $\begin{array}{c}\text { Chi-square, } \\
\text { p value }\end{array}$ \\
\hline Family Medical History & & & & \\
CVD Risk Factors & Yes & & & \\
& No & $48(33.3)$ & $63(43.8)$ & $0.70, \mathrm{p}=0.40$ \\
& & & & \\
\hline
\end{tabular}

Note. n (\%) 
Table 10

Chi-square Results for Resource Variables in the 14 to17 Year Old Group

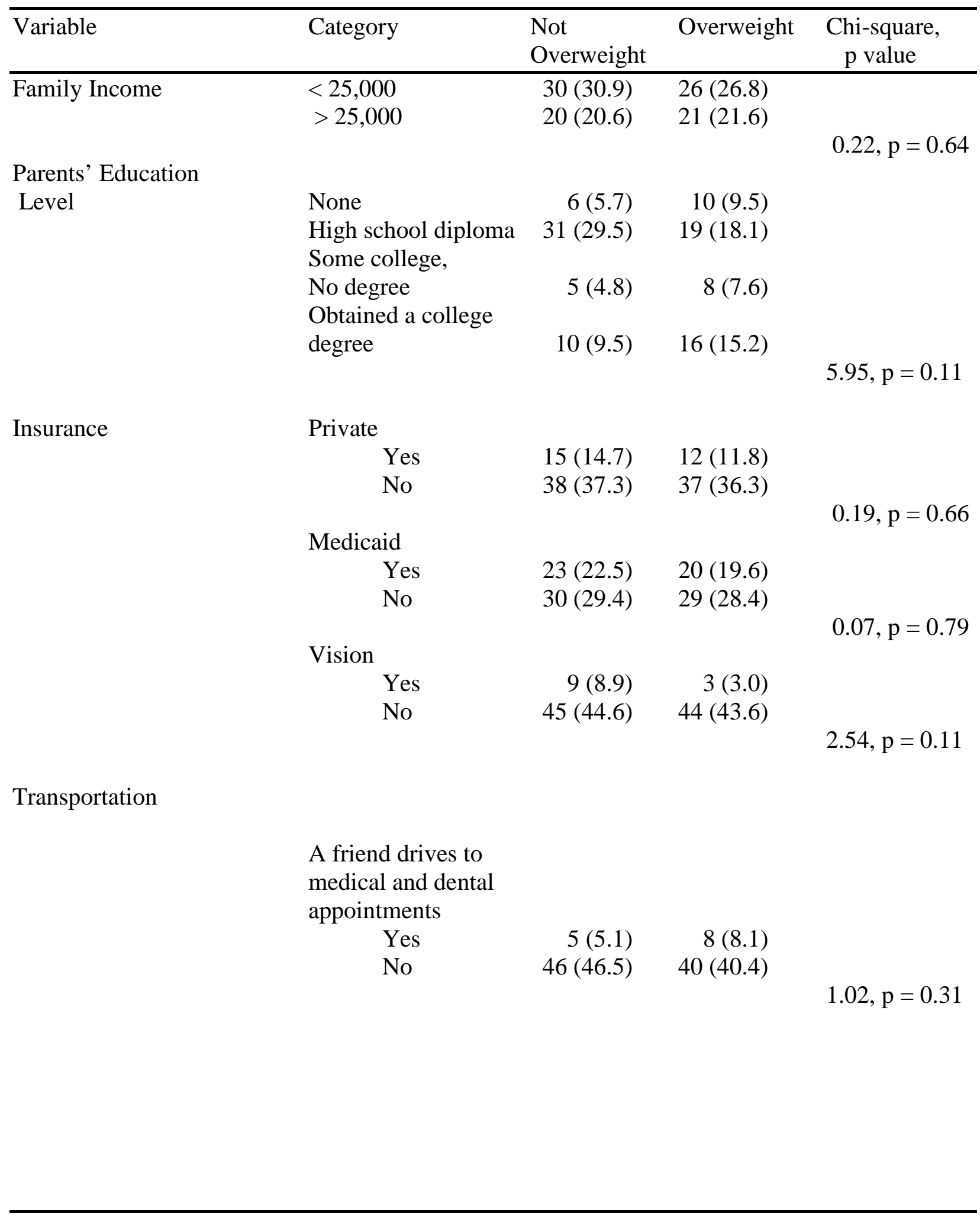




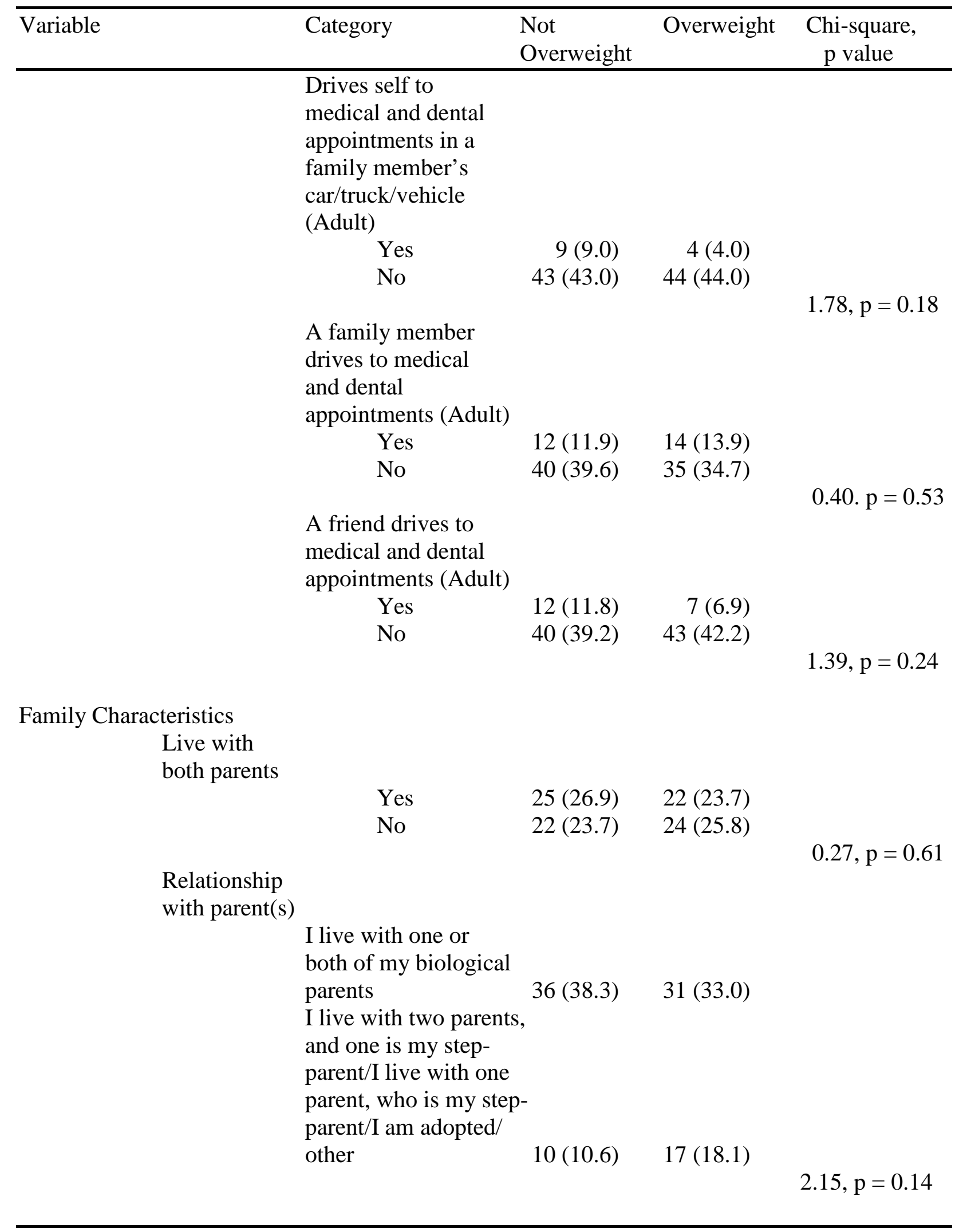

Note. n (\%) 
Table 11

Chi-square Results for Risk Variables in the 14 to 17 Year Old Group

\begin{tabular}{|c|c|c|c|c|}
\hline Variable & Category & $\begin{array}{l}\text { Not } \\
\text { Overweight }\end{array}$ & Overweight & $\begin{array}{l}\text { Chi-square, } \\
\text { p value }\end{array}$ \\
\hline \multicolumn{5}{|l|}{$\begin{array}{l}\text { Utilization of Health Care/ } \\
\text { Preventive Care }\end{array}$} \\
\hline $\begin{array}{l}\text { Frequency of } \\
\text { Visiting a Dentist }\end{array}$ & $\begin{array}{l}\text { At least once a } \\
\text { month } \\
\text { About twice a year } \\
\text { About once a year } \\
\text { Less than once a year/ } \\
\text { Whenever needed, } \\
\text { no regular schedule } \\
6 \text { months or less } \\
>6 \text { months but not } \\
\text { more than } 1 \text { year } \\
>1 \text { year or never }\end{array}$ & $\begin{array}{r}17(15.5) \\
7(6.4) \\
4(3.6) \\
\\
\\
\\
\\
37(25.5) \\
\\
11(93.0) \\
11(9.8)\end{array}$ & $\begin{array}{r}9(8.2) \\
10(9.1) \\
9(8.2) \\
\\
26(23.6) \\
34(30.4) \\
11(9.8) \\
8(7.1)\end{array}$ & $\begin{array}{l}4.95, p=0.18 \\
0.28, p=0.87\end{array}$ \\
\hline Current Vaccines & $\begin{array}{l}\text { Yes } \\
\text { No }\end{array}$ & $\begin{array}{r}54(51.4) \\
3(2.9)\end{array}$ & $\begin{array}{r}48(45.7) \\
0(0.0)\end{array}$ & \\
\hline \multicolumn{5}{|l|}{ Personal Medical History } \\
\hline Diabetes & $\begin{array}{l}\text { Yes } \\
\text { No }\end{array}$ & $\begin{array}{r}0(0.0) \\
59(52.2)\end{array}$ & $\begin{array}{r}1(0.9) \\
53(46.9)\end{array}$ & \\
\hline Heart Disease & $\begin{array}{l}\text { Yes } \\
\text { No }\end{array}$ & $\begin{array}{r}0(0.0) \\
59(52.2)\end{array}$ & $\begin{array}{r}2(1.8) \\
52(46.0)\end{array}$ & \\
\hline High Blood Pressure & $\begin{array}{l}\text { Yes } \\
\text { No }\end{array}$ & $\begin{array}{r}0(0.0) \\
59(52.2)\end{array}$ & $\begin{array}{r}5(4.4) \\
49(43.4)\end{array}$ & \\
\hline Depression & $\begin{array}{l}\text { Yes } \\
\text { No }\end{array}$ & $\begin{array}{l}11(10.0) \\
46(41.8)\end{array}$ & $\begin{array}{l}11(10.0) \\
42(38.2)\end{array}$ & \\
\hline Anxiety & $\begin{array}{l}\text { Yes } \\
\text { No }\end{array}$ & $\begin{array}{r}5(4.4) \\
55(48.2)\end{array}$ & $\begin{array}{r}7(6.1) \\
47(41.2)\end{array}$ & $\begin{array}{l}0.04, p=0.85 \\
0.65, p=0.42\end{array}$ \\
\hline
\end{tabular}




\begin{tabular}{|c|c|c|c|c|}
\hline Variable & Category & $\begin{array}{l}\text { Not } \\
\text { Overweight }\end{array}$ & Overweight & $\begin{array}{c}\text { Chi-square, } \\
\text { p value }\end{array}$ \\
\hline \multicolumn{5}{|l|}{ Family Medical History } \\
\hline \multirow[t]{2}{*}{ CVD Risk Factors } & $\begin{array}{l}\text { Yes } \\
\text { No }\end{array}$ & $\begin{array}{l}13(12.0) \\
42(38.9)\end{array}$ & $\begin{array}{r}9(8.3) \\
44(40.7)\end{array}$ & \\
\hline & & & & $0.74, p=0.39$ \\
\hline
\end{tabular}

Note. n (\%) 


\section{Aim III}

Aim three of this study was to examine the extent to which resources and risk factors predict obesity-related health status in Appalachian children and adolescents. Binary logistic regression was used to analyze the research questions and hypotheses for aim three.

Binary logistic regression was performed to assess the extent to which the frequency of visiting a dentist best explains BMI in Appalachia. In the 7 to 10 year old group, frequency of visiting a dentist was the only independent variable entered into the logistic regression analysis, because it was the only variable that had a significant association with BMI category. The model contained one dependent variable (BMI category). Since binary logistic regression was used, the BMI category variable had two categories: not overweight and overweight. The full model was statistically significant, $X^{2}(2, \mathrm{n}=205)=8.37, p=0.02$, indicating that the model was able to distinguish between respondents who were not overweight or overweight. The model as a whole explained between 4\% (Cox and Snell R square) and 5.4\% (Nagelkerke R square) of the variance in BMI category, and correctly classified $62.9 \%$ of cases. As shown in Table 13 , the strongest predictor for being overweight was visiting a dentist equal to or greater than a year in frequency, recording an odds ratio of 2.97. This indicated that respondents who visited a dentist less frequently were almost 3 times more likely to report being overweight compared to respondents who visited a dentist at least once every 6 months. 
Table 12

Logistic Regression Results in the 7 to 10 Year Old Group

\begin{tabular}{|c|c|c|c|c|c|c|c|c|}
\hline \multirow[t]{2}{*}{ Variable } & \multirow[t]{2}{*}{$B$} & \multirow[t]{2}{*}{ S.E. } & \multirow[t]{2}{*}{ Wald } & \multirow[t]{2}{*}{$d f$} & \multirow[t]{2}{*}{$p$} & \multirow[t]{2}{*}{$\begin{array}{l}\text { Odds } \\
\text { Ratio }\end{array}$} & \multicolumn{2}{|c|}{$\begin{array}{c}\text { 95\% C.I. } \\
\text { for Odds Ratio }\end{array}$} \\
\hline & & & & & & & Lower & Upper \\
\hline \multicolumn{9}{|l|}{$\begin{array}{l}\text { Frequency of } \\
\text { Visiting a } \\
\text { Dentist }\end{array}$} \\
\hline$<6$ months & & & 8.12 & 2 & 0.02 & & & \\
\hline $\begin{array}{l}6 \text { months }< \\
1 \text { year }\end{array}$ & 0.41 & 0.38 & 1.18 & 1 & 0.29 & 1.51 & 0.72 & 3.20 \\
\hline$\geq 1$ year & 1.09 & 0.39 & 7.90 & 1 & 0.01 & 2.97 & 1.39 & 6.35 \\
\hline Constant & -0.64 & 0.18 & 12.22 & 1 & 0.00 & 0.53 & & \\
\hline
\end{tabular}

Note. $n=205$ 
There were a total of 6 hypotheses in this study, four hypotheses were associated with aim two and two hypotheses were associated with aim three. The first four hypotheses associated with aim two were not supported since each resource and risk variable did not have a significant association with BMI category. The last two hypotheses associated with aim three were not supported since each resource and risk variable did not predict overweight and obese categories. However, an important finding was revealed in this study, the frequency of visiting a dentist is significantly associated with BMI category in the 7 to 10 year old group. Furthermore, children in the 7 to 10 year old group who visited a dentist less frequently were more likely to report being overweight compared to children who visited a dentist every 6 months or less. 


\section{CHAPTER V \\ SUMMARY, DISCUSSION, AND IMPLICATIONS \\ Introduction}

This study describes a cross-sectional analysis of data from the COHRA study. The main focus of this research was to utilize a vulnerable populations conceptual framework to examine factors associated with overweight and obesity in Appalachian children and adolescents. The sample from the COHRA study included 1, 822 participants from WV. The sample utilized for this secondary data analysis included WV children and adolescents ages 7-17 years of age at the time of first enrollment in the study $(n=509)$. A summary and discussion of the results of the analyses are presented in this chapter as well as implications for practice and recommendations for future research.

\section{Statement of the Problem}

The literature has recognized that Appalachian children and adolescents are a vulnerable population with a high prevalence of overweight and obesity (Demerath et al., 2003; Muratova et al., 2002; Singh et al., 2008). However, the researcher discovered a gap in the literature; the VPCM has not been utilized with Appalachian children and adolescents to determine factors that are associated with overweight and obesity. This secondary data analysis described the extent to which resource availability (family income, insurance, family characteristics, parents' education, and transportation) and risk factors (utilization of health care/preventive care, family medical history, and participant medical history) impact overweight and obesity in a vulnerable population. The study also described the frequency of overweight and obesity in a sample of Appalachian children and adolescents. 


\section{Review of the Methodology}

The statistical analysis methods performed in this study included parametric and nonparametric statistics. Data were analyzed for relationships among the dependent variable: overweight and obesity and the independent variables: risk factors and resource availability. Frequency distributions were utilized to examine the prevalence of overweight and obesity in this sample. Chi-square test for independence was used to evaluate associations between the independent variable and dependent variables. Finally, binary logistic regression was performed to examine the extent to which resources and risk factors predicted overweight and obesity in this sample.

\section{Study Limitations}

This study has several limitations. First, the major limitation of this study is that the variables in the secondary data analysis were self-reported through interviews with the COHRA staff. The next limitation of this study is the homogenous sample that was utilized for analysis. The WV sample for the COHRA study was only recruited from 2 contiguous, rural counties in WV, which limits the generalizability of the findings. Another limitation of this study is the method of recruitment that was utilized in the COHRA study. Participants of the COHRA study were recruited by radio and newspaper announcements, flyers distributed at churches, retail sites, schools, medical facilities, daycare centers, and head start sites (Polk et al., 2008). The sample from the COHRA study was not a random sample. Finally the last limitation of this study is that it is a secondary data analysis. Again, the researcher performing a secondary data analysis needs to remember that the data used for analysis are analyzed for purposes different from those of the primary analysis (McArt \& McDougal, 1985). Nicoll and Beyea (1999) discussed an advantage of primary data collection is that data collection techniques can be specifically adapted to answer 
a research question. When secondary data is utilized, the researcher has no control over how the variables were measure in the primary data collection.

$$
\text { Major Findings }
$$

\section{Vulnerable Population}

The demographic results of this study revealed that this sample is a vulnerable population. Again, the literature has recognized children and adolescents as a vulnerable population (Aday, 2001; Flaskerud \& Winslow, 1998). The sample utilized in this study is comprised of children and adolescents from WV, which is part of Appalachia. In each of the age groups (7-10, 11-13, and 14-17 year olds), a little more than half of the participants lived in poverty. Income levels were less than $\$ 25,000$ for $55.1 \%$ of the $7-10$ year old group, $59.2 \%$ of the $11-13$ year old group, and $57.7 \%$ of the $14-17$ year old group. Again, according to the USDHHS, the 2009 Poverty Guidelines for a family of four was \$22, 050 (U.S.Department of Health and Human Services, 2010). Children and adolescents living in Appalachia are considered even more vulnerable as a result of living in a region that is characterized by poverty and educational deficits (Appalachian Leadership Initiative on Cancer (ALIC), 1994; Huttlinger \& Purnell, 2008; Muratova et al., 2001). The education level of parents in each of the three age groups revealed that $18.6 \%$ in the $7-10$ year old group, $11.9 \%$ in the $11-13$ year old group, and $15.2 \%$ in the $14-17$ year old group had reported having less than a high school diploma as their highest obtained degree or certificate. Appalachian children and adolescents were a vulnerable population in this study and this finding is supported in the literature.

\section{Prevalence of Obesity}

The prevalence of obesity found in this study is similar to other Appalachian regions. This study revealed a high prevalence of obesity across age groups. In the 7 to 10 year old 
group, $13.5 \%$ of the participants were overweight and $26 \%$ were obese. The highest prevalence of obesity was found in the 11 to 13 year old group, $16.7 \%$ of the participants were overweight and $34 \%$ were obese. In the 14 to 17 year old group, $16.9 \%$ of the participants were overweight and 26.6\% were obese. Other studies conducted in Appalachia and more specifically WV have reported similar obesity prevalence rates among children and adolescents. Muratova and colleagues (2002) reported $18 \%$ of $5^{\text {th }}$ grade participants $(n=5,887)$ were overweight and $25.7 \%$ were obese. Demerath and colleagues (2003) reported comparable results among $5^{\text {th }}$ grade participants in WV $(n=1,338), 17.5 \%$ of participants were overweight and $27 \%$ were obese. The $5^{\text {th }}$ grade subjects included in the previous two studies most closely correlate with the 7-10 year old group in this study. Adolescent obesity prevalence rates have been reported in a study conducted in WV $(\mathrm{n}=100)$ which revealed that $9 \%$ of adolescent participants were overweight and 28\% were obese (Bolding et al., 2005). Montgomery-Reagan and colleagues (2009) conducted a school-based BMI screening with 6-11 year old children in southeastern Ohio, which is a part of Appalachia. Results from this study revealed that $17 \%$ of the children were overweight and 20.9\% were obese (Montgomery-Reagan, Bianco, Heh, Rettos, \& Huston, 2009). In summary, a high prevalence of obesity was revealed in this study which is consistent with findings from other studies.

\section{Resource Availability and Risk Factors}

In this study it was hypothesized that resource availability would be different for overweight and not overweight, and in this sample it was not. The trends across age groups included: a majority of the sample lived in poverty, a large percentage of the 7-10 year old group (68.3\%) had public insurance (Medicaid or CHIP), a high percentage of parents completed at least a high school education, and the majority of families had transportation to medical and 
dental visits. In regards to health insurance, $68.3 \%$ of the $7-10$ year old group, $50 \%$ of the $11-13$ year old group, and $42.1 \%$ of the 14-17 year old group had WV Medicaid or CHIP. Huttlinger and colleagues (2004) reported that an initial analysis of their survey data revealed that 90\% of respondents had public insurance coverage (Medicare or Medicaid). However, further analysis showed that a large number (80\%) of other individuals living in the household of the respondent did not have any health insurance coverage including working adults between 18 and 57 years of age (80\%) and children (52\%) (Huttlinger et al., 2004). The sample for Huttlinger and colleagues (2004) study included 922 households that represented 2, 188 people with an average age of 54 years. Other sample characteristics included more males responded than females, average income reported was $\$ 25,000-\$ 29,999$, and 28\% of participants were over the age of 65 years. Because the sample in this study appeared to be primarily homogeneous with little difference in health insurance coverage between overweight and not overweight respondents this points to another factor that may contribute to the development of obesity, such as the parent's BMI. Lasserre and colleagues (2007) reported that overweight in children has been strongly associated with the characteristics of parents, such as parents being overweight. Parent's BMI was not included as a risk factor variable in this study.

In this study it was also hypothesized that risk factors would be different for overweight and not overweight, and again in this sample, it was not, except for frequency of visiting a dentist in the 7-10 year old group. The trends across age groups included the majority of respondents went to the doctor as needed, visited the dentist every 6 months, and had their vaccinations up to date. Close to $20-25 \%$ of family respondents in all three age groups reported having a CVD risk factor (diabetes, heart disease, or hypertension). Several of the major CHD risk factors identified by the Framingham Study include: high cholesterol levels, hypertension, excess body weight 
and diabetes (Dawber \& Kannel, 1966; Kannel et al., 1961; Kannel \& McGee, 1979).

Appalachia is a region that has a high prevalence of CHD and WV currently ranks $1^{\text {st }}$ in the nation for prevalence of CHD (Centers for Disease Control and Prevention, 2007; Halverson et al., 2004a). A very small percentage in all groups reported having a positive personal medical history of diabetes, heart disease, or hypertension.

The percentage of respondents in all age groups having a positive personal medical history of depression or anxiety was slightly higher, with the highest prevalence of anxiety (15\%) being reported in the 7-10 year old group and the highest prevalence of depression found in the 14-17 year old group (20\%). In the literature depression and anxiety have been shown to be associated with an increased BMI in children. Although in this study, there was not a significant relationship found. Young-Hyman and colleagues (2006) reported than an increased BMI was associated with depression and anxiety in black children and all female children (black and white). Children included in the Young-Hyman and colleagues (2006) study had a mean age of 11.9 years. Eremis and colleagues (2004) identified an association with depression and anxiety in clinically obese adolescents ages 12 to 16 . In a longitudinal study conducted by Rofey and colleagues (2009), both childhood depression and anxiety were associated with increased BMI percentiles when compared with health controls. Children in the Rofey and colleagues study (2009) ranged from 8 to 18 years in age and the majority of respondents were Caucasian. Depression and anxiety were self-report measures in this study and were not measured by a standard tool. Because depression and anxiety were self-report measures, this could possibly explain why no significant relationship was found in this study. In a future study, if the relationship between depression and obesity in children and adolescents is examined, an age appropriate validated tool would be utilized. 


\section{Predictive Factors of Obesity-Related Health Status}

As stated previously, frequency of visiting a dentist was the only independent variable utilized in the logistic regression analysis, because it was the only variable that had a significant association with BMI category. This study revealed that respondents in the 7 to 10 year old group who visited a dentist less frequently were almost 3 times more likely to report being overweight than those who visited a dentist more frequently. Thus, possibly visiting a dentist every 6 months was a preventive factor when examining obesity. Deskin and colleagues (2006) reported that children in WV revealed that they experienced little social pressure from parents or peers to engage in preventive behaviors. Parents' attitudes and knowledge about preventive behaviors were not measured in this study. A possibility for this finding could be that parents in this study had knowledge concerning the importance of preventive behaviors. The sample for the COHRA study was a volunteer sample that was recruited at multiple sites (Polk et al., 2008). Adult participants in the Deskin and colleagues (2006) study identified cost as a barrier to participating in screenings, which are a part of preventive care. As reported earlier, about half of the sample in this study lived in poverty, but $68.3 \%$ of the $7-10$ year old group had medical and dental coverage. The dental coverage in the 7-10 year old group was provided through WV Medicaid and the WV Children's Health Insurance Program (CHIP) (WV Department of Health and Human Services, 2009; WV Children's Health Insurance Program, 2009). The 7-10 year old group had the highest percentage of participants with Medicaid or CHIP among the age groups studied. It is possible that cost was not a barrier to participating in preventive care for this sample. Another possible explanation for this significant finding in the 7 to 10 year old group is the fact that this age group is less subjected to peer pressure and more subjected to parental control. 


\section{Unanticipated Findings}

This study did not find any significant associations between resource availability variables and BMI and only revealed one significant association between the risk factor variable of frequency visiting a dentist and BMI. This is in contrast to a study by Montgomery-Regan and colleagues who collected primary data. Montgomery-Reagan and colleagues (2009) conducted a school-based BMI screening program in a rural Appalachian county in southeastern Ohio. A Health Information Survey (HIS) was developed to identify demographic and behavioral risk factors associated with BMI (Montgomery-Reagan et al., 2009). Demographic information included income, health insurance status, and household composition and other information included in the survey was nutritional choices and habits, recreational activities, and health information (Montgomery-Reagan et al., 2009). Approximately 2, 000 children aged 6-11 years were included in the study yielding a total of 5, 306 height and weight measurements from three different data collections (Montgomery-Reagan et al., 2009). Some of the major findings from this study included a high prevalence of childhood obesity in the Appalachian sample, demographic and behavioral risk factor correlates (low SES, parental smoking, eating meals at school and television viewing) of BMI, and factors (higher SES, having more than one caregiver in the home, and participation in gymnastics) inversely related to a high BMI (MontgomeryReagan et al., 2009).

Montgomery-Reagan and colleagues utilized several similar variables to those collected in this study, but the researchers collected their own data. As previously stated an advantage of primary data collection is that collection approaches can be specifically adapted to answer a research question (Nicoll \& Beyea, 1999). Again, in a secondary data analysis the research has no control over how the variables were measured. Subjects were recruited from one rural county 
in southeastern Ohio while this secondary data analysis included a sample recruited from two contiguous rural counties in WV, but the sample size in Montgomery-Regan and colleagues study was higher. The lack of significant associations between resource availability and risk factor variables and BMI could possibly be explained because of the smaller sample size utilized in this study and the fact that this study is a secondary data analysis. As stated previously, the sample for this study needed to have a minimum of 150 or a maximum of 350 children and adolescents to obtain power (Hsieh et al., 1998). The 7-10 year old group had 223 individuals in the sample and the 11-13 year old group had 162 individuals in the sample. The 14-17 year old group had the smallest sample size $(n=124)$ and it was less than the minimum of 150 participants. The 14 to 17 year old group may have not been adequately powered to detect a difference. Another possible explanation for the lack of significant associations in this study is participant burden. The participants in the COHRA study may have experienced some participant burden due to the large number of questions asked during the interviews.

\section{Discussion}

In Appalachian children living in WV, a high prevalence of obesity was found. This study did not reveal any significant associations between resource variables and BMI. However in the 7 to 10 year old group, the study did find that frequency of visiting a dentist is significantly associated with BMI, and participants who visited a dentist more frequently were less likely to be overweight.

It is evident from this study that a high prevalence of obesity exists. Numerous studies have reported similar findings with Appalachian children and adolescents (Bolding et al., 2005; Demerath et al., 2003; Montgomery-Reagan et al., 2009). The prevalence of obesity that existed in this sample is higher than the national obesity prevalence in this age group. In the 11-13 year 
old group $16.7 \%$ were overweight and 34\% were obese, while $16.9 \%$ were overweight and $34 \%$ were obese in the 14-17 year old group. In the US, 15.8\% of adolescents nationwide are overweight, while $13.0 \%$ of adolescents nationwide are obese according to the 2007 YRBS (Centers for Disease Control and Prevention, 2008a).

Another important finding evident in this study is the significant association between the frequency of visiting a dentist and BMI. Overweight rural children have the additional risk factors of poverty and no health insurance (Lutfiyya et al., 2007), which can lead to a decreased access to care. In this sample, the majority of the 7-10 year old group had dental coverage through Medicaid and CHIP, which provided this group with more access to care. As discussed earlier, Deskin and colleagues (2006) discussed that children in WV communicated that they experienced little social pressure from parents or peers to engage in preventive behaviors. A limitation to this study is that it did not examine parents' knowledge and attitudes concerning preventive behavior. The study sample for the COHRA study was a volunteer sample (Polk et al., 2008). Participants of the COHRA study were recruited by radio and newspaper announcements, flyers distributed at churches, retail sites, schools, medical facilities, daycare centers, and head start sites (Polk et al., 2008). Polk and colleagues (2008) also reported that additional information was distributed at health fairs. It is possible that some participants recruited for the COHRA study had a prior knowledge of the importance of preventive behavior since some recruitment took place at medical facilities and health fairs. Another important point to consider is that the COHRA study was a dental study. Participants that volunteered to participate in the study could have been looking for dental care or were aware of dental issues which motivated them to participate in the COHRA study. 
Study Findings and the Vulnerable Populations Conceptual Model

Findings from this study provided limited support for the Vulnerable Populations Conceptual Model. Other studies (Flaskerud \& Lee, 2001; Rodehorst et al., 2006) have researched individual resource availability and risk factors and the effect on health status. In this study, resource availability was measured by analyzing the following family variables: family income, parents' education level, presence of insurance, family characteristics and availability of transportation to medical/dental visits. Risk factors were measured by analyzing the following family/individual variables: utilization of health care/preventive care, family medical history, and participant medical history. Health status was measured by examining the prevalence of overweight and obesity among participants. However, other research studies have supported the use of the model with other samples. For example, the relationship proposed in the Flaskerud and Lee (2001) study was that female caregivers are vulnerable because of limited resources and increased exposure to risks that contribute to poor health. This proposed relationship is similar to the proposed relationship utilized in this study. Rodehorst and colleagues (2006) also used the VPCM as a guide for their study. The study sample consisted of 771 children and adolescents that were categorized into the following age groups: 6-8 years old, 9-14 years old, and 15-18 years old (Rodehorst et al., 2006). The sample size and categorized age groups in the Rodehorst and colleagues (2006) study is similar to this study. The main difference between this study and the two studies discussed is primary data collection. As previously mentioned, the lack of significant associations between resource availability and risk factor variables and BMI could possibly be explained by the fact that this study is a secondary data analysis. The researcher in this study did not have control over how the variables utilized in this study were measured. Further research is needed utilizing the Vulnerable Populations Conceptual Model with 
Appalachian children to determine if resource availability and risk factor variables are associated with overweight and obesity.

\section{Clinical Practice and Research Implications}

Implications for Nursing Practice

Childhood and adolescent obesity continues to be an epidemic that is apparent in the US and Appalachia. Overweight and obesity in childhood and adolescents leads to increases in obesity associated chronic diseases throughout childhood and adulthood including: hyperlipidemia, HTN, DM, sleep apnea, polycystic ovary disease, hepatic steatosis, cholelithiasis, arthritis, and poor health status (Dietz, 2002; Estrada, 2004; Mokdad et al., 2003; U.S.Department of Health and Human Services, 2001). While overweight and obesity are important in childhood and adolescence, it can extend into adulthood (Fowler-Brown \& Kahwati, 2004; Srinivasan et al., 1996). Because of the increased prevalence of obesity and the risk of obesity associated chronic diseases, nurses need to be prepared to implement interventions to prevent and identify overweight and obesity in children and adolescents. Education needs to be provided to Appalachian families in WV about the available public health insurance plans they may qualify for if they meet poverty guidelines. In WV, families who meet poverty guidelines are eligible for Medicaid and CHIP to provide medical and dental coverage, which increases access to care.

Recommendations for Further Research

It is clearly evident that further research needs to occur to examine factors associated with overweight and obesity in Appalachian children and adolescents. In order for nurses to design and implement effective interventions and prevention strategies that will improve the health status of Appalachian children and adolescents, the nature of the relationship between 
overweight and obesity and a vulnerable population needs to be examined. A future research study could use data collected from WV children and adolescents in a school-based setting, like the school-based BMI screening Montgomery-Reagan and colleagues (2009) conducted. An informational survey could be developed for parents or caregivers to collect data on resource availability and risk factor variables. Height and weight measurements would need to be obtained from a parent so the parent's BMI could be included in the study as a risk factor variable. Additional risk factors that were examined by Montgomery-Reagan and colleagues (2009) were nutritional habits and presence of sedentary behaviors, such as watching TV. These additional risk factors could be included in a future study. Approximately 2, 000 students participated in the Montgomery-Reagan and colleagues (2009) study. A comparable sample size would need to be recruited in a future research study to ensure the assumptions of power are met in all age groups.

\section{Conclusion}

Appalachian children and adolescents are identified as a vulnerable population where a high prevalence of obesity exists. This study was the first study to apply a vulnerable populations framework to examine factors associated with overweight and obesity in Appalachian children and adolescents. A high prevalence of obesity in Appalachia, specifically WV children and adolescents was evident in this study. This study also revealed that children, ages 7 to 10 years old, who visited a dentist less frequently were more likely to report being overweight than those who visited a dentist more frequently. Further research is needed with a larger sample to examine the relationship between resource availability and risk factor variables, and overweight and obesity in this vulnerable population. A future research study would need to 
use primary data collected from WV children and adolescents, as well as the parents or caregivers. 
Appendix A

Table 13

Variable Codes for COHRA Data Set

\begin{tabular}{|c|c|c|c|c|}
\hline Variable & $\begin{array}{c}\text { 7-10 years } \\
\text { old }\end{array}$ & 11-13 years old & $\begin{array}{l}14-17 \text { years } \\
\text { old }\end{array}$ & Adult \\
\hline Age & AGE & D102 & D102 & \\
\hline Gender & SEX & D107 & D107 & \\
\hline Race/Ethnicity & RACE & D108 & D108 & \\
\hline Annual Income & & & D120 & D120 \\
\hline $\begin{array}{l}\text { Insurance Type } \\
\text { None }\end{array}$ & InsNo & DI11 & DI16a1 & \\
\hline $\begin{array}{l}\text { Insurance Type } \\
\text { Private/through my } \\
\text { employer }\end{array}$ & InsPrv & DI11PrivEmp & DI16a2 & \\
\hline If yes, specify & InsPrvSp & DI11PrivEmpTx & DI16a2TX & \\
\hline $\begin{array}{l}\text { Insurance Type } \\
\text { Medicare }\end{array}$ & InsMCAR & DI11Mcare & DI16a3 & \\
\hline $\begin{array}{l}\text { Insurance Type } \\
\text { Medical Assistance }\end{array}$ & InsMA & DI11Masst & DI16a4 & \\
\hline $\begin{array}{l}\text { Insurance Type } \\
\text { Medicaid }\end{array}$ & InsMCAD & DI11Mcaid & DI1116a5 & \\
\hline $\begin{array}{l}\text { Insurance Type } \\
\text { CHIP }\end{array}$ & InsCHP & DI11CHIP & & \\
\hline $\begin{array}{l}\text { Insurance Type } \\
\text { Vision Coverage } \\
\text { If yes, specify }\end{array}$ & InsVis & DI11VisTx & DI116a6Tx & \\
\hline $\begin{array}{l}\text { Insurance Type } \\
\text { Other } \\
\text { If yes, specify }\end{array}$ & $\begin{array}{l}\text { InsOther } \\
\text { InsOtherSp }\end{array}$ & $\begin{array}{l}\text { DI11O } \\
\text { DI11OTx }\end{array}$ & $\begin{array}{l}\text { DI16a7 } \\
\text { DI16a7Tx }\end{array}$ & \\
\hline $\begin{array}{l}\text { Insurance Length of } \\
\text { Time }\end{array}$ & InsD & DI11a & DI16a & \\
\hline Family Relationship & $\begin{array}{l}\text { Parliv } \\
\text { Relat- } \\
\text { children } \\
\text { related }\end{array}$ & $\begin{array}{l}\text { DI03-who do } \\
\text { you live with? } \\
\text { DI03MF1-live } \\
\text { with one parent- } \\
\text { mother or father } \\
\text { DI03MF2-live }\end{array}$ & $\begin{array}{l}\text { DI03-Do you } \\
\text { live with } \\
\text { parents or } \\
\text { older adults? } \\
\text { DI03Tx-if } \\
\text { yes, specify }\end{array}$ & \\
\hline
\end{tabular}




\begin{tabular}{|c|c|c|c|c|}
\hline Variable & $\begin{array}{l}\text { 7-10 years } \\
\text { old }\end{array}$ & 11-13 years old & $\begin{array}{c}14-17 \text { years } \\
\text { old }\end{array}$ & Adult \\
\hline If other, specify & Relatoth & $\begin{array}{l}\text { with } 2 \text { parents- } \\
\text { one is a step- } \\
\text { parent } \\
\text { DI03MF3-live } \\
\text { with } 1 \text { parent } \\
\text { who is my } \\
\text { stepparent- } \\
\text { mother or father } \\
\end{array}$ & $\begin{array}{l}\text { DI03a-live } \\
\text { with at least } \\
\text { one parent, } \\
\text { do you live } \\
\text { with both } \\
\text { parents } \\
\text { DI03aMF-if } \\
\text { yes, which } \\
\text { parent do } \\
\text { you normally } \\
\text { live with- } \\
\text { mother or } \\
\text { father? } \\
\text { DI03b-how } \\
\text { are you } \\
\text { related to } \\
\text { parent? } \\
\text { DI03bMF- } \\
\text { live with } \\
\text { both parents } \\
\text { and one is a } \\
\text { step parent- } \\
\text { mother or } \\
\text { father } \\
\text { DI03bO } \\
\text { DI03c-if not } \\
\text { parents or } \\
\text { other older } \\
\text { adults-who } \\
\text { do you live } \\
\text { with? } \\
\text { DI03cO-if } \\
\text { other, } \\
\text { specify }\end{array}$ & \\
\hline $\begin{array}{l}\text { Transportation } \\
\text { Number of Vehicles } \\
\text { Own or Lease }\end{array}$ & & & DI14a & DI14a \\
\hline Transportation & & & DI14b1 & DI14b1 \\
\hline
\end{tabular}




\begin{tabular}{|c|c|c|c|c|}
\hline Variable & $\begin{array}{l}\text { 7-10 years } \\
\text { old }\end{array}$ & $11-13$ years old & $\begin{array}{c}14-17 \text { years } \\
\text { old }\end{array}$ & Adult \\
\hline \multicolumn{5}{|l|}{$\begin{array}{l}\text { Modes-Own } \\
\text { Car/Truck/Vehicle }\end{array}$} \\
\hline $\begin{array}{l}\text { Transportation Modes- } \\
\text { Family Member's } \\
\text { Car/Truck/Vehicle }\end{array}$ & & & DI14b2 & DI14b2 \\
\hline $\begin{array}{l}\text { Transportation Modes- } \\
\text { Non Family Member's } \\
\text { Car/Truck/Vehicle }\end{array}$ & & & DI14b3 & DI14b3 \\
\hline $\begin{array}{l}\text { Transportation Mode-A } \\
\text { Family Member Drives }\end{array}$ & & & DI14b4 & DI14b4 \\
\hline $\begin{array}{l}\text { Transportation Mode-A } \\
\text { Friend Drives }\end{array}$ & & & DI14b5 & DI14b5 \\
\hline $\begin{array}{l}\text { Transportation Mode-A } \\
\text { Social Service Agency } \\
\text { Drives }\end{array}$ & & & DI14b6 & DI14b6 \\
\hline $\begin{array}{l}\text { Transportation Mode-I } \\
\text { walk or bike }\end{array}$ & & & DI14b7 & DI14b7 \\
\hline $\begin{array}{l}\text { Transportation Mode- } \\
\text { Use Public } \\
\text { Transportation/Bus/Van }\end{array}$ & & & DI14b8 & DI14b8 \\
\hline $\begin{array}{l}\text { Transportation Mode- } \\
\text { Other }\end{array}$ & & & DI14b9 & D114b9 \\
\hline If yes, specify & & & DI14b9TX & DI14b9TX \\
\hline $\begin{array}{l}\text { Transportation } \\
\text { Modes to Medical and } \\
\text { Dental Appointments- } \\
\text { Own } \\
\text { Car/Truck/Vehicle }\end{array}$ & & & DI14c1 & DI14c1 \\
\hline $\begin{array}{l}\text { Transportation Modes } \\
\text { to Medical and Dental } \\
\text { Appointments- } \\
\text { Family Member's } \\
\text { Car/Truck/Vehicle }\end{array}$ & & & DI14c2 & DI14c2 \\
\hline $\begin{array}{l}\text { Transportation Modes } \\
\text { to Medical and Dental } \\
\text { Appointments-Non } \\
\text { Family Member's } \\
\text { Car/Truck/Vehicle }\end{array}$ & & & DI14c3 & DI14c3 \\
\hline $\begin{array}{l}\text { Transportation Mode to } \\
\text { Medical and Dental } \\
\text { Appointments-A }\end{array}$ & & & DI14c4 & DI14c4 \\
\hline
\end{tabular}




\begin{tabular}{|c|c|c|c|c|}
\hline Variable & $\begin{array}{l}7-10 \text { years } \\
\text { old }\end{array}$ & 11-13 years old & $\begin{array}{l}14-17 \text { years } \\
\text { old }\end{array}$ & Adult \\
\hline Family Member Drives & & & & \\
\hline $\begin{array}{l}\text { Transportation Mode to } \\
\text { Medical and Dental } \\
\text { Appointments-A Friend } \\
\text { Drives }\end{array}$ & & & DI14c5 & DI14c5 \\
\hline $\begin{array}{l}\text { Transportation Mode to } \\
\text { Medical and Dental } \\
\text { Appointments-A Social } \\
\text { Service Agency Drives }\end{array}$ & & & DI14c6 & DI14c6 \\
\hline $\begin{array}{l}\text { Transportation Mode to } \\
\text { Medical and Dental } \\
\text { Appointments-I walk or } \\
\text { bike }\end{array}$ & & & DI14c7 & DI14c7 \\
\hline $\begin{array}{l}\text { Transportation Mode to } \\
\text { Medical and Dental } \\
\text { Appointments-Use } \\
\text { Public } \\
\text { Transportation/Bus/Van }\end{array}$ & & & DI14c8 & DI14c8 \\
\hline $\begin{array}{l}\text { Transportation Mode to } \\
\text { Medical and Dental } \\
\text { Appointments-Other }\end{array}$ & & & DI14c9 & DI14c9 \\
\hline If yes, specify & & & DI14c9TX & DI14c9TX \\
\hline $\begin{array}{l}\text { Transportation Mode to } \\
\text { Medical and Dental } \\
\text { Appointments-I have } \\
\text { never gone }\end{array}$ & & & DI14c10 & DI14c10 \\
\hline $\begin{array}{l}\text { Education-Years of } \\
\text { Education }\end{array}$ & & & & DI17a \\
\hline $\begin{array}{l}\text { Education-Highest } \\
\text { Grade Level Completed }\end{array}$ & & & & DI17b \\
\hline $\begin{array}{l}\text { Education-Highest } \\
\text { Degree or Certificate }\end{array}$ & & & & DI17c \\
\hline $\begin{array}{l}\text { Frequency of Seeing a } \\
\text { Health Care Provider }\end{array}$ & Drfreq & DI10 & DI15 & \\
\hline Vaccine Status & Vacc & & & \\
\hline $\begin{array}{l}\text { Oral Health Care } \\
\text { Utilization }\end{array}$ & Dentfreq & OI15a & OI17 & \\
\hline $\begin{array}{l}\text { Medical History- } \\
\text { High Blood Pressure }\end{array}$ & & $\begin{array}{l}\text { HBp } \\
\text { If yes, } \\
\text { report onset } \\
\text { in years } \\
\text { (HBpOn) }\end{array}$ & $\begin{array}{l}\text { HBp } \\
\text { If yes, } \\
\text { report onset } \\
\text { in years } \\
\text { (HBpOn) }\end{array}$ & $\begin{array}{l}\text { HBp } \\
\text { If yes, } \\
\text { report onset } \\
\text { in years } \\
\text { (HBpOn) }\end{array}$ \\
\hline
\end{tabular}




\begin{tabular}{|c|c|c|c|c|}
\hline Variable & $\begin{array}{c}\text { 7-10 years } \\
\text { old }\end{array}$ & 11-13 years old & $\begin{array}{c}\text { 14-17 years } \\
\text { old }\end{array}$ & Adult \\
\hline \multirow{2}{*}{$\begin{array}{l}\text { Medical History- } \\
\text { Diabetes }\end{array}$} & Diabetes & $\mathrm{D}$ & $\mathrm{D}$ & $\mathrm{D}$ \\
\hline & $\begin{array}{l}\text { If yes, report } \\
\text { onset in } \\
\text { years } \\
\text { (dbon)- } \\
\text { months or } \\
\text { years } \\
\text { (dbmory) }\end{array}$ & $\begin{array}{l}\text { If yes, report } \\
\text { onset in years } \\
\text { (DOn) }\end{array}$ & $\begin{array}{l}\text { If yes, report } \\
\text { onset in } \\
\text { years (DOn) }\end{array}$ & $\begin{array}{l}\text { If yes, report } \\
\text { onset in } \\
\text { years (DOn) }\end{array}$ \\
\hline \multirow{2}{*}{$\begin{array}{l}\text { Medical History- } \\
\text { Heart Disease }\end{array}$} & Heartd & HD & HD & HD \\
\hline & $\begin{array}{l}\text { If yes, report } \\
\text { onset in } \\
\text { years } \\
\text { (hdon)- } \\
\text { months or } \\
\text { years } \\
\text { (hdmory) }\end{array}$ & $\begin{array}{l}\text { If yes, report } \\
\text { onset in years } \\
\text { (HDOn) }\end{array}$ & $\begin{array}{l}\text { If yes, report } \\
\text { onset in } \\
\text { years } \\
\text { (HDOn) }\end{array}$ & $\begin{array}{l}\text { If yes, report } \\
\text { onset in } \\
\text { years } \\
\text { (HDOn) }\end{array}$ \\
\hline \multirow[t]{2}{*}{$\begin{array}{l}\text { Mental Health- } \\
\text { Anxiety }\end{array}$} & & & & \\
\hline & $\begin{array}{l}\text { If yes, the } \\
\text { respondent } \\
\text { needs to } \\
\text { specify } \\
\text { (phobsp) }\end{array}$ & $\begin{array}{l}\text { If yes, was } \\
\text { this a } \\
\text { diagnosis } \\
\text { (BPb5bdia) }\end{array}$ & $\begin{array}{l}\text { If yes, was } \\
\text { this a } \\
\text { diagnosis } \\
\text { (BPb5bdia }\end{array}$ & \\
\hline \multirow[t]{2}{*}{$\begin{array}{l}\text { Mental Health- } \\
\text { Depression }\end{array}$} & & BPb5d & BPb5d & \\
\hline & & $\begin{array}{l}\text { If yes, was } \\
\text { this a } \\
\text { diagnosis } \\
\text { (BPb5ddia) }\end{array}$ & $\begin{array}{l}\text { If yes, was } \\
\text { this a } \\
\text { diagnosis } \\
\text { (BPb5ddia) }\end{array}$ & \\
\hline Height & $\begin{array}{l}\mathrm{Hft} \\
\mathrm{Hin}\end{array}$ & $\begin{array}{l}\text { Hft } \\
\text { Hin }\end{array}$ & $\begin{array}{l}\mathrm{Hft} \\
\mathrm{Hin}\end{array}$ & \\
\hline Weight & WT & WT & WT & \\
\hline
\end{tabular}




\section{Appendix B}

Table 14

Chi-square Results for Additional Transportation Variables in the 7 to 10 Year Old Group

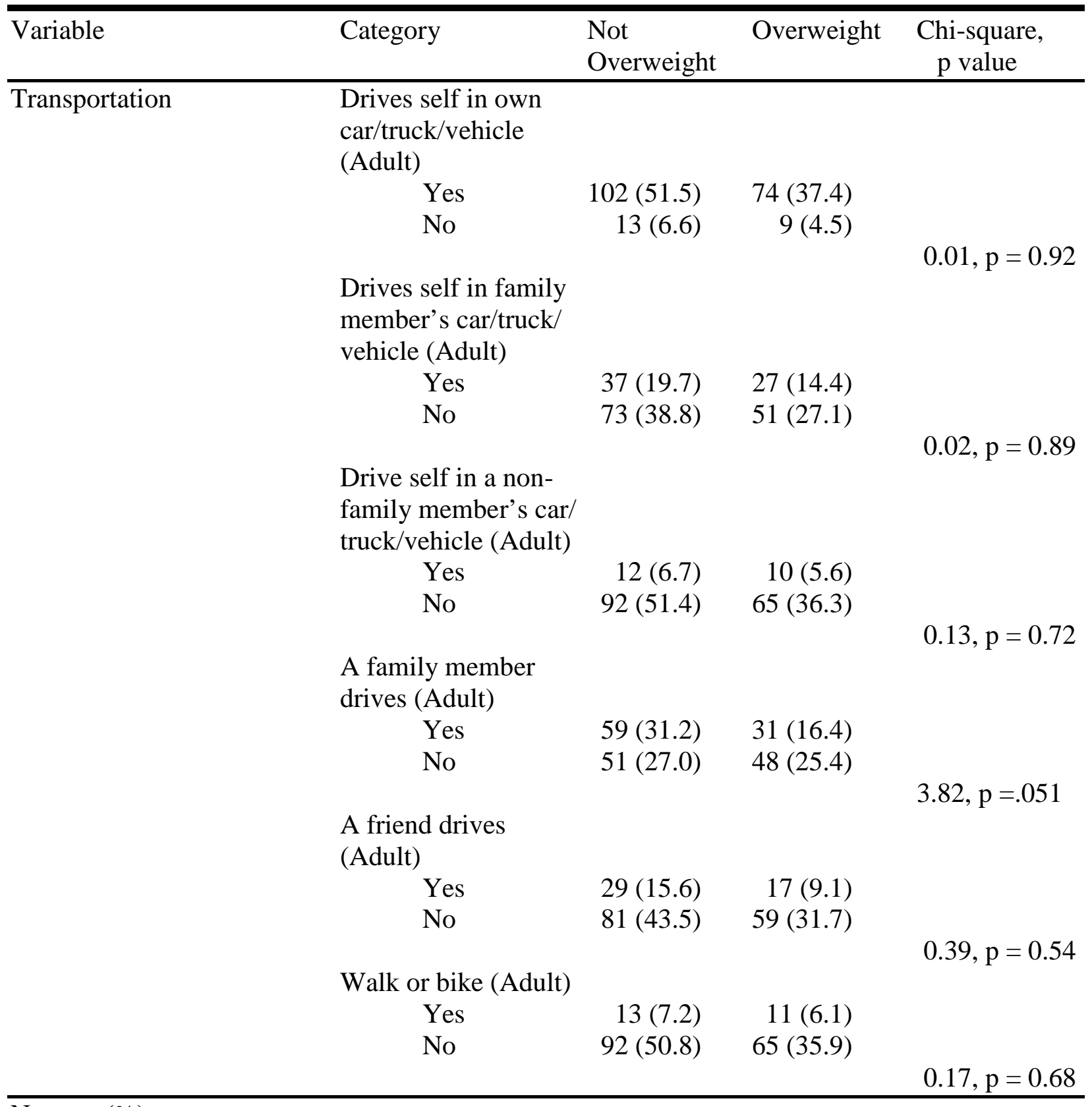

Note. n (\%) 


\section{Appendix C}

Table 15

Chi-square Results for Additional Transportation Variables in the 11 to 13 Year Old Group



Note. n (\%) 


\section{Appendix D}

Table 16

Chi-square Results for Additional Transportation Variables for 14 to 17 Year Old Group

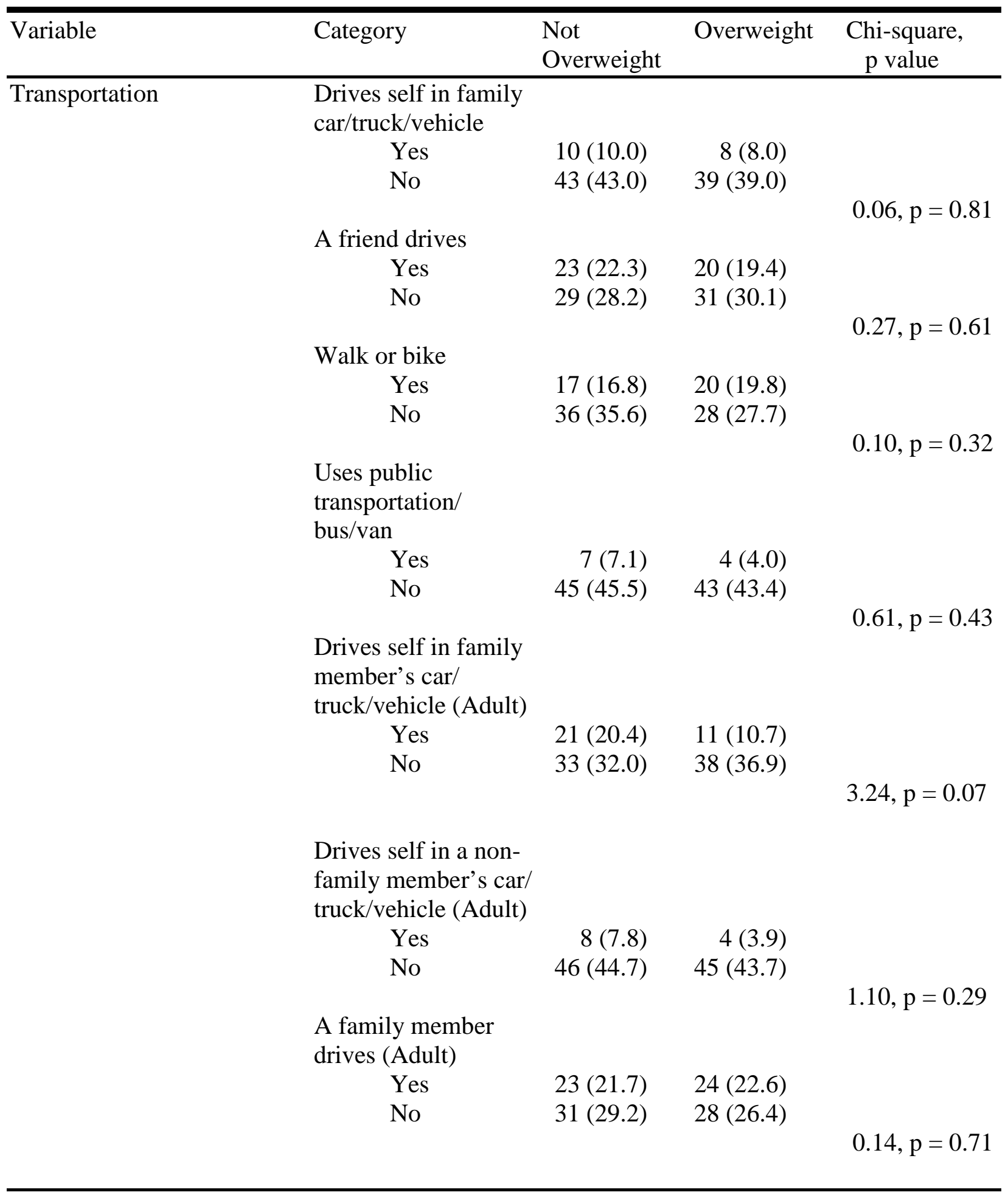




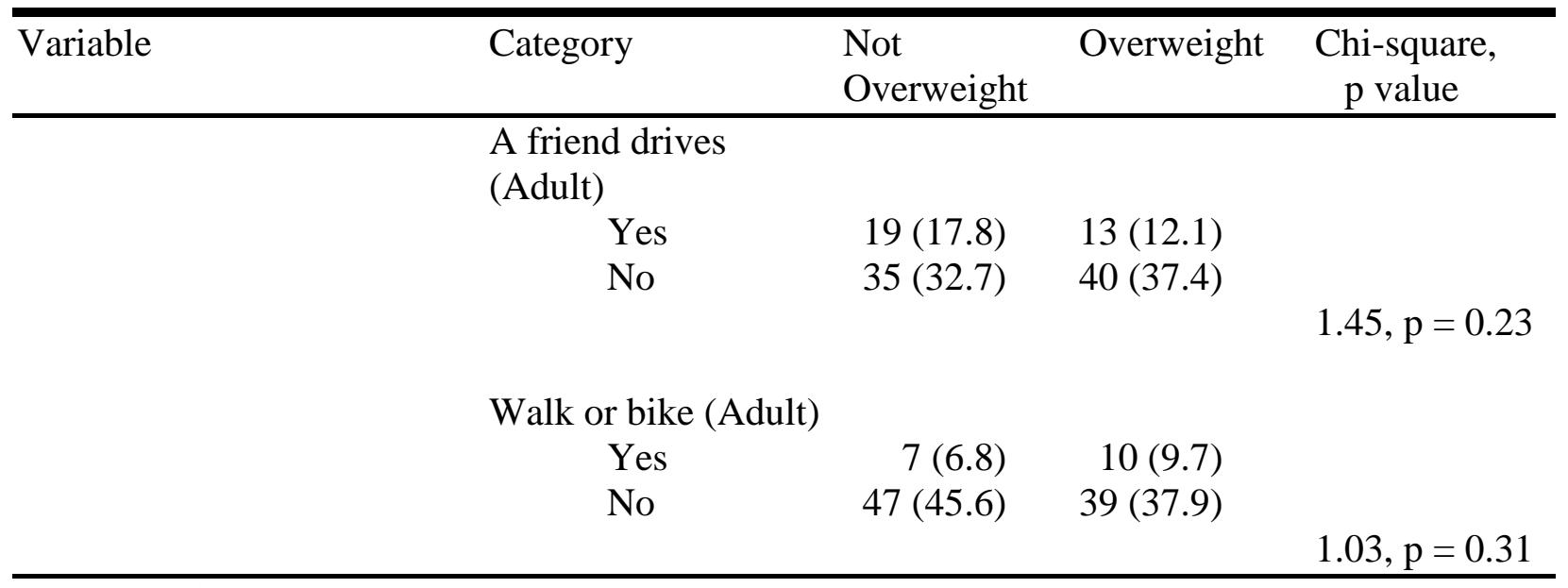

Note. n (\%) 


\section{References}

Aday, L. A. (2001). At risk in America: The health and health care needs of vulnerable populations in the United States. (2nd ed.) San Francisco: Josey-Bass.

Allison, D. B., Downey, M., Atkinson, R. L., Billington, C. J., Bray, G. A., Eckel, R. H. et al. (2008). Obesity as a Disease: A white paper on evidence and arguments commissioned by the Council of The Obesity Society. Obesity, 16, 1161-1177.

American Academy of Pediatrics (2008). Developmental stages. American Academy of Pediatrics [On-line]. Available: http://www.aap.org/healthtopics/stages.cfm\#early

Appalachian Leadership Initiative on Cancer (ALIC) (1994). Sowing seeds in the mountains: Community-based coalitions for cancer prevention and control (Rep. No. 94-3779). Bethesda, MD: National Institutes of Health, National Cancer Institute.

Appalachian Regional Commission (2008). Appalachian region. Appalachian Regional Commission [On-line]. Available: http://www.arc.gov/index.do?nodeId=2

Arcury, T. A., Preisser, J. S., Gesler, W. M., \& Powers, J. M. (2005). Access to transportation and health care utilization in a rural region. The Journal of Rural Health, 21, 31-38.

Atkinson, R. L. (2004). Medical evaluation of the obese patient. In T.A.Wadden \& A.J.Stunkard (Eds.), Handbook of obesity treatment (pp. 173-185). New York: The Guildford Press.

Barlow, S. \& Expert Committee (2007). Expert committee recommendations regarding the prevention, assessment, and treatment of child and adolescent overweight and obesity: Summary report. Pediatrics, 120, S164-S192. 
Bay, E., Kreulen, G. J., Shavers, C. A., \& Currier, C. (2006). A new perspective: A vulnerable population framework to guide research and practice for persons with traumatic brain injury. Research and Theory for Nursing Practice: An International Journal, 20, 141157.

Bolding, J., Wratchford, T., Perkins, K., \& Ogershok, P. (2005). Prevalence of obesity, acanthosis nigricans and hyperinsulinemia in an adolescent clinic. The West Virginia Medical Journal, 101, 112-115.

Bolla, C. D. (2008). Poverty and homelessness. In M.Stanhope \& J.Lancaster (Eds.), Public health nursing: Population-centered health care in the community (7th ed., pp. 734-751). St. Louis, MO: Elsevier.

Bushy, A. (2008). Population-centered nursing in rural and urban environments. In M.Stanhope \& J.Lancaster (Eds.), Public health nursing: Population-centered health care in the community (7th ed., pp. 372-392). St. Louis, MO: Elsevier.

Bushy, A. (2000). Orientation to nursing in the rural community. Thousand Oaks, CA: Sage.

Calderon, K. S., Yucha, C. B., \& Schaffer, S. D. (2005). Obesity-related cardiovascular risk factors: Intervention recommendations to decrease adolescent obesity. Journal of Pediatric Nursing, 20, 3-14.

Centers for Disease Control and Prevention (2007). Morbidity and Mortality Weekly Report: Prevalence of heart disease---United States, 2005 (Rep. No. 56 (06)). Centers for Disease Control and Prevention. 
Centers for Disease Control and Prevention (2008a). Morbidity and Mortality Weekly Report: Youth Risk Behavior Surveillance-United States, 2007 (Rep. No. 57). Atlanta, GA: Centers for Disease Control and Prevention.

Centers for Disease Control and Prevention (2008b). What is a BMI percentile? Centers for Disease Control and Prevention [On-line]. Available: http://www.cdc.gov/nccdphp/dnpa/healthyweight/assessing/bmi/childrens_BMI/about_ch ildrens_BMI.htm\#What\%20is\%20BMI

Chinn, S. (2006). Definitions of childhood obesity: Current practice. European Journal of Clinical Nutrition, 60, 1189-1194.

Cole, T., Bellizzi, M. C., Flegal, K. M., \& Dietz, W. H. (2000). Establishing a standard definition for child overweight and obesity worldwide: International survey. BMJ, 320, 1-6.

Cole, T. J. \& Rolland-Cachera, M. F. (2002). Measurement and definition. In W.Burniat, T.Cole, I.Lissau, \& E.Poskitt (Eds.), Child and adolescent obesity: Causes and consequences, prevention and management (pp. 3-27). Cambridge, UK: University Press.

Copeland, D. A. (2007). Conceptualizing family members of violent mentally ill individuals as a vulnerable population. Issues in Mental Health Nursing, 28, 943-975.

Coyne, C. A., Demian-Popescu, C., \& Friend, D. (2006). Social and cultural factors influencing health in southern West Virginia: A qualitative study. Preventing Chronic Disease, 3, 18. 
Dawber, T. R. \& Kannel, W. B. (1966). The Framingham Study: An epidemiological approach to coronary heart disease. Circulation, 34, 553-555.

Demerath, E. W., Muratova, V. N., Spangler, E., Jianrong, L., Minor, V. E., \& Neal, W. A. (2003). School-based obesity screening in rural Appalachia. Preventive Medicine, 37, 553-560.

DeNavas-Walt, C., Proctor, B. D., \& Smith, J. (2007). Income, poverty, and health insurance coverage in the US, 2006 (Rep. No. P60-233). Washington D.C.: US Government Printing Office.

Deskins, S., Harris, C. V., Bradlyn, A. S., Cottrell, L., Coffman, J. W., Olexa, J. et al. (2006). Preventive care in Appalachia: Use of the theory of planned behavior to identify barriers to participation in cholesterol screenings among West Virginians. The Journal of Rural Health, 22, 367-374.

Dietz, W. H. (2002). Current trends in obesity: Clinical impact and interventions that work. Ethnicity \& Disease, 12, 17-20.

Dietz, W. H. \& Gortmaker, S. L. (2001). Preventing obesity in children and adolescents. Annual Review of Public Health, 22, 337-353.

Elliot, G. R. \& Feldman, S. S. (1990). Capturing the adolescent experience. In G.R.Elliot \& S. S. Feldman (Eds.), At the threshold: The developing adolescent (pp. 1-14). Cambridge, UK: Harvard University Press. 
Eremis, S., Nurcan, C., Tamar, M., Bukusoglu, N., Akdeniz, F., \& Goksen, D. (2004). Is obesity a risk factor for psychopathology among adolescents? Pediatrics International, 46, 296301.

Erickson, S. J., Robinson, T. N., Haydel, F., \& Killen, J. D. (2000). Are overweight children unhappy? Archives of Pediatric and Adolescent Medicine, 154, 931-935.

Estrada, E. (2004). Childhood obesity: Complications (Rep. No. 4). Evansville, Indiana: Mead Johnson \& Company.

Field, A. E., Barnoya, J., \& Colditz, G. A. (2002). Epidemiology and health and consequences of obesity. In T.A.Wadden \& A.J.Stunkard (Eds.), Handbook of obesity treatment (pp. 318). New York: Guilford Press.

Flaskerud, J. H. \& Lee, P. (2001). Vulnerability to health problems in female informal caregivers of persons with HIV/AIDS and age-related dementias. Journal of Advanced Nursing, 33, 60-68.

Flaskerud, J. H. \& Winslow, B. J. (1998). Conceptualizing vulnerable populations health-related research. Nursing Research, 47, 69-78.

Fowler-Brown, A. \& Kahwati, L. C. (2004). Prevention and treatment of overweight in children and adolescents. American Family Physician, 69, 2591-2598.

Freedman, D. S., Dietz, W. H., Srinivasan, S. R., \& Berenson, G. S. (1999). The relation of overweight to cardiovascular risk factors among children and adolescents: The Bogalusa Heart Study. Pediatrics, 103, 1175-1182. 
Gamm, L. D., Hutchinson, L. L., Dabney, B. J., \& Dorsey, A. M. (2003). Rural Healthy People 2010: A companion document to Healthy People 2010 (Rep. No. Volume 1). College Station, TX: The Texas A \& M University System Health Science Center, School of Rural Public Health, Southwest Rural Health Research Center.

Gortmaker, S. L., Must, A., Perrin, J., Sobol, A., \& Dietz, W. H. (1993). Social and economic consequences of overweight in adolescence and young adulthood. The New England Journal of Medicine, 329, 1008-1012.

Hall, D. M. \& Cole, T. (2006). What use is the BMI. Archives of Disease in Children, 91, 283286.

Halverson, J. A., Harner, E. J., \& Ma, L. (2004a). An analysis of disparities in health status and access to health care in the Appalachian region Appalachian Regional Commission.

Halverson, J. A., Ma, L., Harner, E. J., Hanham, R. Q., \& Braham, V. E. (2004b). Adult obesity in Appalachia: An atlas of geographic disparities Morgantown WV: West Virginia University.

Hesketh, K., Crawford, D., Salmon, J., Jackson, M., \& Campbell, K. (2007). Associations between family circumstances and weight status of Australian children. International Journal of Pediatric Obesity, 2, 86-96.

Hsieh, F. Y., Bloch, D. A., \& Larsen, M. D. (1998). A simple method of sample size calculation for linear and logistic regression. Statistics in Medicine, 17, 1623-1634. 
Huttlinger, K. W. \& Purnell, L. D. (2008). People of Appalachian heritage. In L.D.Purnell \& B.J.Paulanka (Eds.), Transcultural health care: A culturally competent approach (3rd ed., pp. 95-112). Philadelphia: F.A. Davis.

Huttlinger, K. W., Schaller-Ayers, J., \& Lawson, T. (2004). Health care in Appalachia: A population-based approach. Public Health Nursing, 21, 103-110.

Jackson, J. E., Doescher, M. P., Jerant, A. F., \& Hart, L. G. (2005). A national study of obesity prevalence and trends by type of rural county. The Journal of Rural Health, 21, 140-148.

Jones, J. (1995). Beyond 'race and culture' American underclass in the late twentieth century. In G.J.Demko \& M.C.Jackson (Eds.), Populations at risk in America ( Boulder, CO: Westview.

Jung, R. T. (1997). Obesity as a disease. British Medical Bulletin, 53, 307-321.

Kannel, W. B., Dawber, T. R., Kagan, A., Revotskie, N., \& Stokes, J. (1961). Factors of risk in the development of coronary heart disease: Six-year follow-up experience. Annuals of Internal Medicine, 55, 33-50.

Kannel, W. B. \& McGee, D. L. (1979). Diabetes and cardiovascular risk factors: The Framingham Study. Circulation, 59, 8-13.

Lasserre, A. M., Chiolero, A., Cachat, F., Paccaoud, F., \& Bovet, P. (2007). Overweight in Swiss children and associations with children's and parent's characteristics. Obesity, 15, 29122919. 
Leight, S. B. (2003). The application of a vulnerable populations conceptual model to rural health. Public Health Nursing, 20, 440-448.

Lutfiyya, M. N., Lipsky, M. S., Wisdom-Behounek, J., \& Inpanbutr-Martinkus, M. (2007). Is rural residency a risk factor for overweight and obesity for U.S. children? Obesity, 15, 2348-2356.

Marazita, M. L., Weyant, R., Resick, J., Crout, R., \& McNeil, D. W. (2006). CORHA research manual.

Martin, C. A., McNeil, D. W., Crout, R. J., Ngan, P. W., Weyant, R. J., Heady, H. R. et al. (2008). Oral health disparities in Appalachia: Orthodontic treatment need and demand. Journal of the American Dental Association, 139, 598-604.

McArt, E. W. \& McDougal, L. W. (1985). Secondary data analysis-A new approach to nursing research. Image: The Journal of Nursing Scholarship, XVII, 54-57.

McCarthy, M., Cole, T. J., Fry, T., Jebb, S., \& Prentice, A. M. (2006). Body fat reference curves for children. International Journal of Obesity, 30, 598-602.

McMurray, R. G., Harrell, J. S., Bangdiwala, S. I., \& Deng, S. (1999). Cardiovascular disease risk factors and obesity of rural and urban elementary school children. The Journal of Rural Health, 15, 365-374.

McMurray, R. G., Harrell, J. S., Deng, S., Bradley, C. B., Cox, L. M., \& Bangdiwala, S. I. (2000). The influence of physical activity, socioeconomic status, and ethnicity on the weight status of adolescents. Obesity Research, 8, 130-139. 
Merril, R. M. \& Timmreck, T. C. (2006). Introduction to epidemiology. (4th ed.) Jones and Bartlett.

Mokdad, A. H., Ford, E. S., Bowman, B. A., Dietz, W. H., Vinicor, F., Bales, V. S. et al. (2003). Prevalence of obesity, diabetes, and obesity-related health risk factors, 2001. Journal of the American Medical Association, 289, 76-79.

Mokdad, A. H., Marks, J. S., Stroup, D. F., \& Gerberding, J. L. (2004). Actual causes of death in the United States, 2000. Journal of the American Medical Association, 291, 1238-1245.

Montgomery-Reagan, K., Bianco, J., Heh, V., Rettos, J., \& Huston, R. (2009). Prevalence and correlates of high body mass index in rural Appalachian children aged 6-11 years. Rural and Remote Health, 9.

Muratova, V. N., Demerath, E. W., Spangler, E., Ogershok, P., Elliott, E., Minor, V. E. et al. (2002). The relation of obesity to cardiovascular risk factors among children: The CARDIAC project. The West Virginia Medical Journal, 98, 267.

Muratova, V. N., Islam, S. S., Demerath, E. W., Minor, V. E., \& Neal, W. A. (2001). Cholesterol screening among children and their parents. Preventive Medicine, 33, 1-6.

Must, A. \& Anderson, S. E. (2006). Body mass index in children and adolescents: Considerations for population-based applications. International Journal of Obesity, 30, $590-594$. 
Neal, W. A., Demerath, E., Gonzales, E., Spangler, E., Minor, V. E., Stollings, R. et al. (2001). Coronary Artery Risk Detection in Appalachian Communities (CARDIAC): Preliminary findings. The West Virginia Medical Journal, 97, 102-105.

Needham, B. L. \& Crosnoe, R. (2005). Overweight status and depressive symptoms during adolescence. Journal of Adolescent Health, 36, 48-55.

Neovius, M., Linne, Y., Barkeling, B., \& Rossner, S. (2004). Discrepancies between classification systems of childhood obesity. Obesity Reviews, 5, 105-114.

Nicoll, L. H. \& Beyea, S. C. (1999). Using secondary data analysis for nursing research. Association of Perioperative Registered Nurses, 69, 428, 430, 433.

Ogden, C. L., Carroll, M. D., \& Flegal, K. M. (2008). High body mass index for age among US children and adolescents, 2003-2006. Journal of the American Medical Association, 299, 2401-2405.

Patterson, P. D., Moore, C. G., Probst, J. C., \& Shingole, J. A. (2004). Obesity and physical inactivity in rural America. The Journal of Rural Health, 20, 151-159.

Polk, D. E., Weyant, R. J., Crout, R. J., McNeil, D. W., Tarter, R. E., Thomas, J. G. et al. (2008). Study protocol of the Center for Oral Health Research in Appalachia (COHRA) etiology study. BMC Oral Health, 8, 1-8.

Pollard, K. M. (2003). Appalachia at the millennium: An overview of results from Census 2000 Appalachian Regional Commission. 
Ramsey, P. W. \& Glenn, L. (2002). Obesity and health status in rural, urban, and suburban southern women. Southern Medical Journal, 95, 666-671.

Ramsey, P. W. \& Glenn, L. L. (1998). Risk factors for heart disease in rural Appalachia. Family and Community Health, 20, 71-82.

Rodehorst, T. K. C., Wilhelm, S. L., \& Stepans, M. B. (2006). Screening for asthma: Results from a rural cohort. Issues in Pediatric Nursing, 29, 205-224.

Rofey, D., Kolko, R., Iosif, A., Silk, J., Bost, J., Feng, W. et al. (2009). A longitudinal study of childhood depression and anxiety in relation to weight gain. Child Psychiatry and Human Development, 40, 517-526.

Rosswurm, M. A., Dent, D. M., Persily, C. A., Woodburn, P., \& Davis, B. (1996). Illness experiences and health recovery behaviors of patients in southern Appalachia. Western Journal of Nursing Research, 18, 441-459.

Sebastian, J. G. (2008). Vulnerability and vulnerable populations: An overview. In M.Stanhope \& J.Lancaster (Eds.), Public health nursing: Population-centered health care in the community (7th ed., pp. 710-733). St. Louis, MO: Elsevier.

Shell, R. \& Tudiver, F. (2004). Barriers to cancer screening by rural Appalachian primary care providers. The Journal of Rural Health, 20, 368-373.

Shrewsbury, V. \& Wardle, J. (2008). Socioeconomic status and adiposity in childhood: A systematic review of cross-sectional studies 1990-2005. Obesity, 16, 275-284. 
Singh, G. K., Kogan, M. D., \& Van Dyck, P. C. (2008). A multilevel analysis of state and regional disparities in childhood and adolescent obesity in the United States. Journal of Community Health, 33, 90-102.

Smith, S. L. \& Tessaro, M. A. (2005). Culture perspectives on diabetes in an Appalachian population. American Journal of Health Behavior, 29, 291-301.

Sobal, J. \& Stunkard, A. J. (1989). Socioeconomic status and obesity: A review of the literature. Psychological Bulletin, 105, 260-275.

Speiser, P. W., Rudolf, M., Anhalt, H., Camacho-Hubner, C., Chiarelli, F., Eliakim, A. et al. (2005). Consensus statement: Childhood obesity. The Journal of Clinical Endocrinology and Metabolism, 90, 1871-1887.

Srinivasan, S. R., Weihang, B., Wattigney, W. A., \& Berenson, G. S. (1996). Adolescent overweight is associated with adult overweight and related multiple cardiovascular risk factors: The Bogalusa Heart Study. Metabolism, 45, 235-240.

The Council of the Obesity Society (2008). Obesity as a disease: The Obesity Society Council resolution. Obesity, 16, 1151.

U.S.Census Bureau (2007). Health insurance: Low income uninsured children by state. U.S.Census Bureau [On-line]. Available: http://www.census.gov/hhes/www/hlthins/liuc06.html 
U.S.Department of Health and Human Services (2001). The Surgeon General's call to action to prevent and decrease overweight and obesity Rockville, MD: U.S. Government Printing Office.

U.S.Department of Health and Human Services (2010). The 2009 poverty guidelines for the 48 contiguous states and the District of Columbia. U.S.Department of Health and Human Services [On-line]. Available: http://aspe.os.dhhs.gov/poverty/09poverty.shtml

Veugelers, P. J. \& Fitzgerald, A. L. (2005). Prevalence of and risk factors for childhood overweight and obesity. Canadian Medical Association Journal, 173, 607-613.

Vieweg, V. R., Johnston, C. H., Lanier, J. O., Fernandez, A., \& Pandurangi, A. K. (2007). Correlation between high risk obesity groups and low socioeconomic status in school children. Southern Medical Journal, 100, 8-13.

WV Children's Health Insurance Program (2009). West Virginia children's health insurance program summary plan description (SPD) and welcome guide. WV Children's Health Insurance Program [On-line]. Available: $\underline{\text { http://www.wvchip.org/materials.shtml }}$

WV Department of Health and Human Services (2009). Your guide to medicaid. WV Department of Health and Human Services [On-line]. Available: http://www.wvdhhr.org/bms/

Young-Hyman, D., Tanofsky-Kraff, M., Yanovski, S. Z., Keil, M., Cohen, M. L., Peyrot, M. et al. (2006). Psychological status and weight-related distress in overweight or at-risk-foroverweight children. Obesity, 14, 2249-2258. 


\section{CURRICULUM VITAE \\ Melanie M. Whelan MSN, FNP-BC \\ Senior Lecturer, WVU Tech Department of Nursing \\ Doctoral Candidate, WVU School of Nursing}

\section{EDUCATION}

Graduate:

West Virginia University School of Nursing

Morgantown, WV

Doctor of Philosophy in Nursing

Doctoral defense March 22, 2010

Expected date of graduation is May 15, 2010

West Virginia University School of Nursing

Charleston, WV

Masters of Science in Nursing/Family Nurse Practitioner Track

2001

\section{Undergraduate:}

West Virginia University Institute of Technology

Montgomery, WV

Bachelor of Science in Nursing/RN-BSN

1998

West Virginia University Institute of Technology

Montgomery, WV

Associate Degree in Nursing

1997

\section{EMPLOYMENT HISTORY}

Academic:

WVU Tech Department of Nursing, Montgomery, WV

Senior Lecturer

Community Health Nursing

2003-present

WVU Tech Department of Nursing, Montgomery, WV

Adjunct Clinical Instructor

Sophomore and senior level clinicals

2002-2003

\section{Non-Academic:}

Montgomery General Hospital, Montgomery, WV

C-FNP, WVU Tech Student Health Services

2003-2004 
New River Family Health Center, Scarbro, WV

C-FNP, Oak Hill High School Wellness Center

$1 / 2002-7 / 2002$

Rainelle Medical Center, Rainelle, WV

C-FNP, Family practice/School health

2001-2002

Raleigh General Hospital, Beckley, WV

Staff RN/Charge Nurse CCU

1999-2000

FMC Dialysis, Oak Hill, WV

Charge RN

1998-1999

Raleigh General Hospital, Beckley, WV

Staff RN

1997-1998

\section{LICENSURE AND CERTIFICATION}

Family Nurse Practitioner

American Nurses Credentialing Center

2001-present

Licensure in WV as a Registered Nurse 1997-present

\section{MEMBERSHIP IN PROFESSIONAL AND SCIENTIFIC SOCIETIES}

American Nurses Association/West Virginia Nurses Association Membership since December 2006-present

Sigma Theta Tau

Membership since 2002-present

West Virginia Nurse Leadership Institute (WVNLI) Alumni Association

Membership since June 2006-present

Member of the WVNLI Alumni Association Nominations Committee, October 2007-January 2008; October 2009-present 
Southern Nurses Research Society

Membership since 2003 to October 2006;

September 2009-present

West Virginia Rural Health Association

Membership since October 2006-October 2007;

October 2008-present

West Virginia Association of School Nurses

Membership since November 2006-November 2008

North American Association for the Study of Obesity (NAASO)

Membership since June 2004-June 2005

\section{SCHOLARLY ACTIVITY}

\section{Research, Publications, \& Posters:}

Poster submitted "Use of the Vulnerable Populations Conceptual Framework to Understand Obesity in Appalachian Children and Adolescents" for 2010 Southern Nursing Research Society $24^{\text {th }}$ Annual Conference in Austin, Texas.

Poster presentation "An Exploration of Recovery in Younger and Older On-Pump and Off-Pump Coronary Artery Bypass Grafting Surgery Patients” presented at SNRS $20^{\text {th }}$ Annual Conference in Memphis, Tennessee. Worked on this research study with Dr. Rose Ann DiMaria, PI.

Paper presented at Third Biennial Research Conference 2005, "Positive Identity: State of the Science" in Morgantown, WV.

Poster submitted for presentation "Positive Identity: State of the Science" for the 2005 Southern Nursing Research Society $19^{\text {th }}$ Annual Conference in Atlanta, Georgia.

Poster presentation "Positive Identity: A Concept Analysis" to be presented at the SNRS $18^{\text {th }}$ Annual Conference in Louisville, Kentucky February 19-21, 2004.

Poster presentation "Positive Identity: A Concept Analysis" at the Sigma Theta Tau Nursing Research Conference in Morgantown, WV. October 2003. 


\section{Other Research Activities:}

During 2005-December 2006 I worked as a Research Assistant on Dr. Rose DiMaria-Ghalili's research study titled, "An Exploration of Recovery in Off-Pump CABG Patients. This was part of my research mentorship in the PhD program at WVU School of Nursing.

Use of Health Therapies in Southern WV, Peggy Burkhardt, principle investigator, A. Nathaniel, and M. Nemeth-Pyles. Worked on this study with faculty during MSN program. Wrote a Master's paper using data from this study.

\section{Professional Presentations:}

PEIA Wellness Program presented at WVU Tech Faculty Development Workshops on August 16th 2005.

Presentation at 2004 WV CFO Conference "Importance of Physical Activity, Nutrition, and Sleep” Embassy Suites, Charleston, WV, November 19, 2004.

\section{SERVICE}

Member of the Central AHEC Performance Committee, since November 2007-present

Member and co-chair of the Central Area Health Education Center (AHEC) Advisory Board, October 2007-present

PEIA Worksite Wellness Coordinator for WVU Tech August 2005-present 